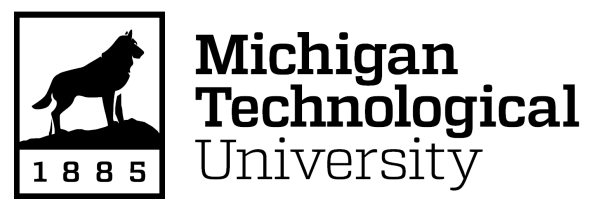

Michigan Technological University Digital Commons @ Michigan Tech

Dissertations, Master's Theses and Master's Reports

2017

\title{
A 3D FEM COMPARATIVE STUDY ON THE IMPACT RESPONSE BETWEEN HUMAN HEAD AND NOCSAE HEAD DUE TO FREE FALL
}

Amey S. Badhe

Michigan Technological University, abadhe@mtu.edu

Copyright 2017 Amey S. Badhe

Recommended Citation

Badhe, Amey S., "A 3D FEM COMPARATIVE STUDY ON THE IMPACT RESPONSE BETWEEN HUMAN HEAD AND NOCSAE HEAD DUE TO FREE FALL", Open Access Master's Report, Michigan Technological University, 2017.

https://doi.org/10.37099/mtu.dc.etdr/316

Follow this and additional works at: https://digitalcommons.mtu.edu/etdr

Part of the Biomechanical Engineering Commons, and the Computer-Aided Engineering and Design Commons 


\title{
A 3D FEM COMPARATIVE STUDY ON THE IMPACT RESPONSE BETWEEN HUMAN HEAD AND NOCSAE HEAD DUE TO FREE FALL
}

By

Amey S. Badhe

\begin{abstract}
A REPORT
Submitted in partial fulfillment of the requirements for the degree of MASTER OF SCIENCE

In Mechanical Engineering
\end{abstract}

MICHIGAN TECHNOLOGICAL UNIVERSITY

2017

(C) 2017 Amey S. Badhe 
This report has been approved in partial fulfillment of the requirements for the Degree of MASTER OF SCIENCE in Mechanical Engineering.

Department of Mechanical Engineering - Engineering Mechanics

Report Advisor: $\quad$ Dr. Gopal Jayaraman

Committee Member: Dr. K.V.C. Rao

Committee Member: Dr. Trisha Sain

Department Chair: $\quad$ Dr. William Predeborn 


\section{Table of Contents}

Acknowledgements ........................................................................................... ii

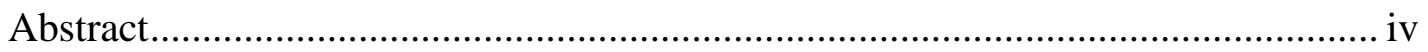

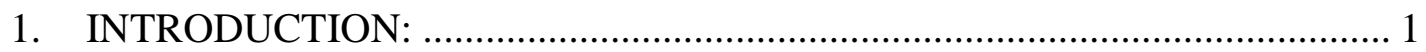

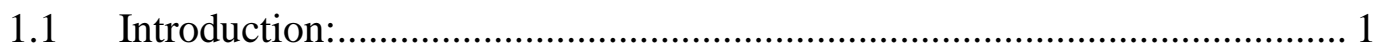

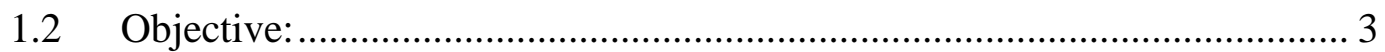

2. FE Modelling of Human Head and NOCSAE headform:...................................... 5

$2.1 \quad$ Finite Element Model: ....................................................................... 5

2.2 Material assignments: ......................................................................

2.3 Boundary Conditions: .......................................................................... 11

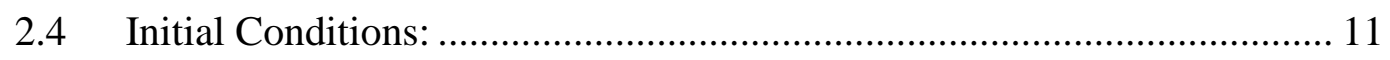

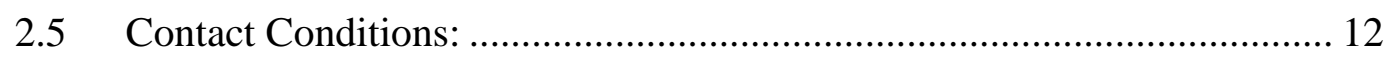

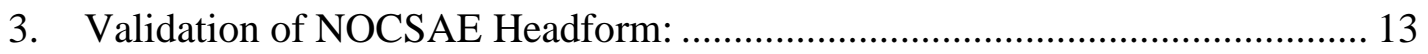

4. Simulation of Impacts on Human Head and NOCSAE Headform:.................... 15

4.1 Frontal Impact:............................................................................... 15

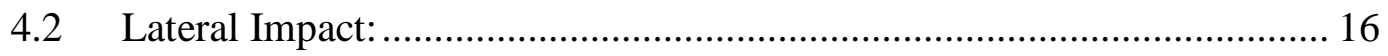

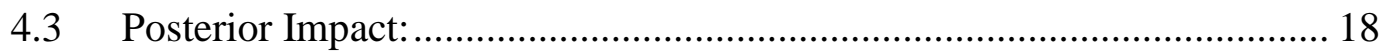

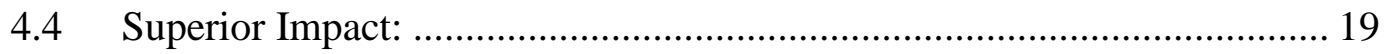

5. Analytical Calculations for Linear and Angular Accelerations: ......................... 20

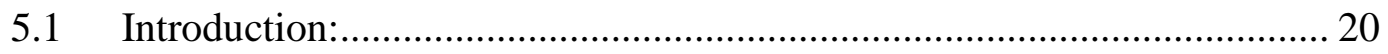

5.2 Linear Acceleration Calculations: ........................................................ 20

5.3 Angular Acceleration Calculations:........................................................... 20

6. Validation of Analytical Method: .................................................................. 24

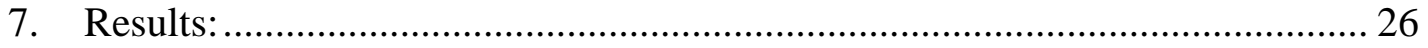

7.1 Linear Acceleration: .......................................................................... 26

7.2 Linear Acceleration - Frontal Impact:.................................................... 26

7.3 Linear Acceleration - Lateral Impact:.......................................................... 27

7.4 Linear Acceleration - Posterior Impact: ................................................... 28

7.5 Linear Acceleration - Superior Impact:……………………………....... 29 


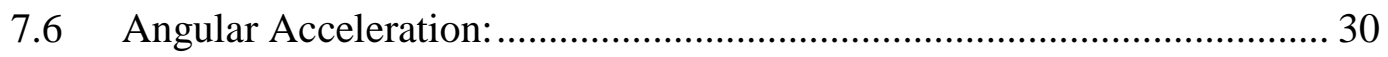

7.7 Angular Acceleration - Frontal Impact: .............................................. 31

7.8 Angular Acceleration - Lateral Impact: .............................................. 32

7.9 Angular Acceleration - Posterior Impact: .............................................. 33

7.10 Angular Acceleration - Superior Impact: ......................................... 34

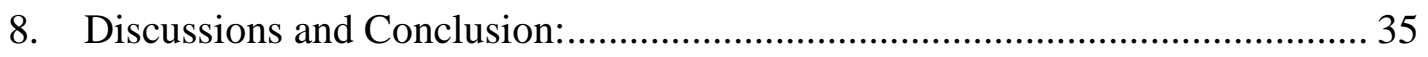

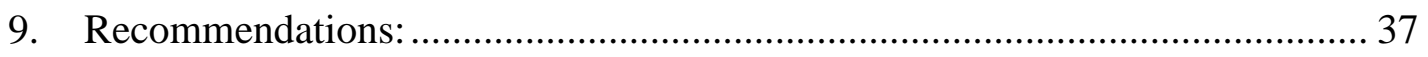

Appendix A Linear Acceleration Time History Curves .......................................... 38

Appendix B Angular Acceleration Time History Plots........................................... 54

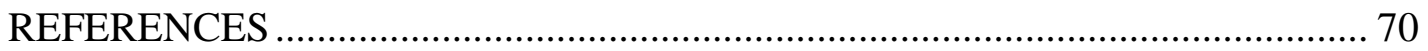




\section{Acknowledgements}

Firstly, I would like to thank my family for all the support they provided during the course of my Masters degree. My parents, Sanjay and Vaishali Badhe for the emotional support when things got tough. My sister, Kimaya for urging me on when I thought I couldn't do it.

Thanks a lot to my academic advisor, Dr. Gopal Jayaraman, without whose guidance this work would not be possible. I would like thank him for believing in me and guiding to complete my Masters. In addition, I would like to thank Mr. David Labyak for the guidance he provided for my research and helped me with all the questions I had. I would like to thank Dr. Chris Passerello for helping out in areas of the research that were difficult to understand. Thank to my Defense committee Dr. KVC Rao and Dr. Trisha Sain for taking time out of their busy schedules to go through my research.

Lastly, I would like to thank my friends, Datta Sandesh, Sandesh Gandhi, Amol Paithankar and Nikhil Khopkar at Michigan Tech for believing in me. You guys helped me when I was down, guiding me when I thought I couldn't do it. You guys made my Masters life, away from family, an easier and fun journey. Thank You for always being there for me.

Finally, Thank You Michigan Tech for molding me into a better person. 


\section{Abstract}

We all enjoy sports be it watching or playing. Concussion is well known topic when it comes sports related injuries. However, concussion and brain injury is not exclusive to sports and outdoor activities. Sometimes, even the impact due to slip and fall at small heights can cause serious damage to the head and brain.

This report studies the response generated in the human head model and the commercially use dummy NOCSAE headform due to drop from height of 2, 3, 4 and 5 feet. Earlier studies have related brain kinetics and head kinematics to concussion and traumatic brain injury ( $\mathrm{TBI})$. There are also studies that relate the linear and angular accelerations between different commercial dummy head models and the human head model, which were done experimentally. The main purpose of his study is to compare these parameters for the both models analytically using simulations.

The linear velocity corresponding to each drop height were calculated and used as input data for the simulations. The impacts were simulated using RADIOSS solver in Hypermesh. Various parameters like contact force, linear acceleration and its components along each of the co-ordinate axes were extracted from the FE analysis. These values were utilized to calculate linear and angular acceleration for the entire models. These values were plotted against tolerance limits for various levels of brain injury. 
It was observed that linear acceleration values for both the Human Head model and the dummy NOCSAE Headform confirm each other. Superior impact of the head was found most susceptible to traumatic brain injury followed by lateral impact when linear acceleration was considered as the criteria. The values of angular acceleration though did not represent glaring similarities between the two models, but there was a general trend of increase in angular acceleration with increase in drop height. 


\section{I NTRODUCTI ON:}

\subsection{Introduction:}

We all enjoy watching sports. How many times in a game of football do we see a player crash down after tackling someone? Even though they have helmets, we observe many head and brain injuries. It is the case with almost all the outdoor activities we perform. We use helmets for protection while biking, sports and working like construction safety equipment. However, we do not even realize that a common fall or slip can also cause serious injury to the brain.

Brain injuries have become a major cause of physical and social illness. Around 1.4 million people [1] in the United States suffer traumatic brain injuries every year. Seventy-five percent [2] of these injuries are mild traumatic brain injuries or concussions [1]. Despite such a high percentage, they are mostly ignored yielding to the common misconception that concussions are not very serious injuries. As opposed to popular belief, recurring concussions or mild traumatic injuries can lead to permanent impairment of cognitive functions or can even be fatal. These injuries are also dangerous because multiple regions of the brain are affected during an impact. Sports injuries, vehicular accidents and injuries to military personnel are the most common scenarios for brain injuries. This study aims to contribute to the field of sports-related head injuries through finite element methods. 
There are two theories to describe the causes of brain injuries, namely, injuries due to linear motion and injuries due to rotational (angular) motion. The Wayne State Tolerance Curve [3] was the first attempt to describe the relation between linear accelerations of human head and the pulse duration required to cause skull fracture and head injury. Since this method uses the skull fracture limit as a basis to determine the tolerance limit for head injury, a more precise relation between the accelerations and the tolerance for head injury is needed.

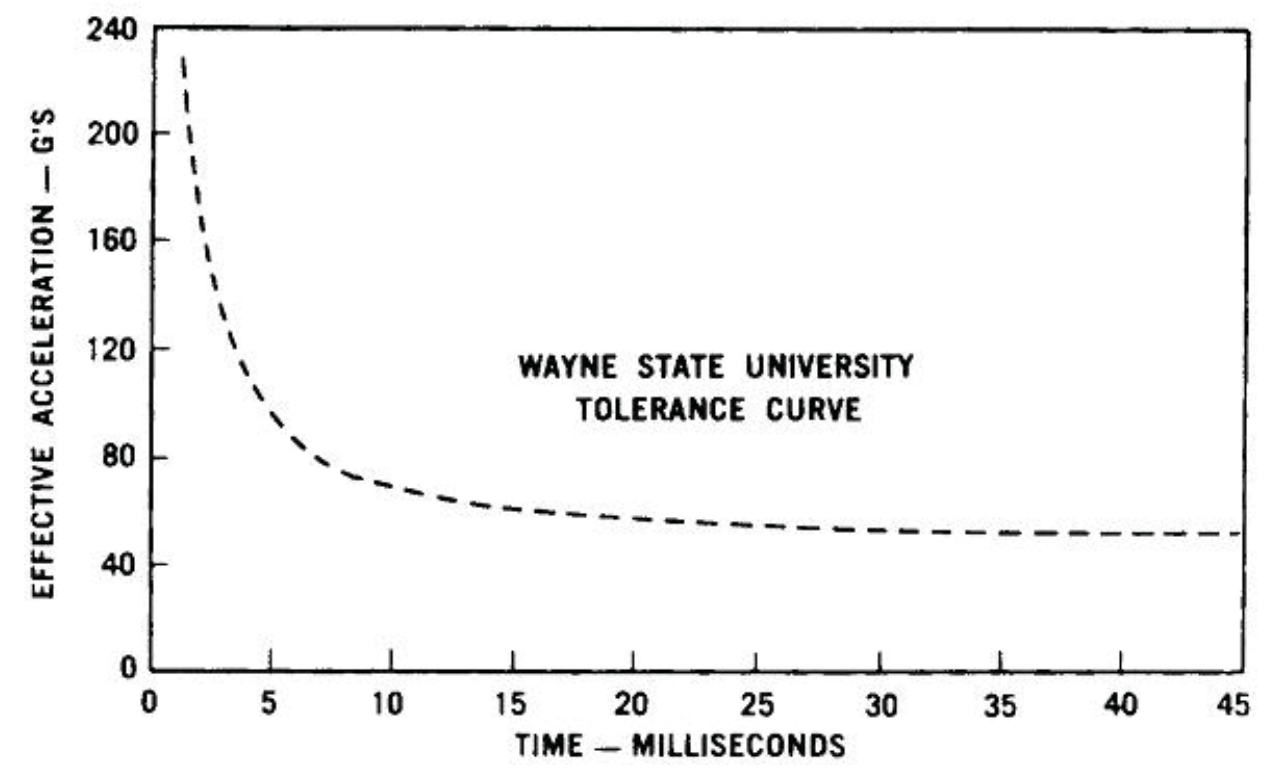

Figure 1.1 Wayne State Tolerance Curve [3]

The headform dynamic response for non-persistent concussions, persistent post-concussive group and traumatic brain injuries was studied by Anna Oeur and her team at University of Ottawa [4]. Because of their examination, they came up with values of linear and angular acceleration given in Table 1.1. These values will be taken as tolerance limits in this study. 


\begin{tabular}{|l|l|l|l|}
\hline & $\begin{array}{l}\text { Non- } \\
\text { Persistent } \\
\text { Concussion }\end{array}$ & $\begin{array}{l}\text { Persistent } \\
\text { Post- } \\
\text { Concussive } \\
\text { Group }\end{array}$ & $\begin{array}{l}\text { Traumatic } \\
\text { Brain Injury }\end{array}$ \\
\hline $\begin{array}{l}\text { Linear } \\
\text { Acceleration } \\
(\text { Gs })\end{array}$ & 146 & 182 & 318 \\
\hline $\begin{array}{l}\text { Angular } \\
\text { Acceleration } \\
\left(\mathrm{krad} / \mathrm{s}^{2}\right)\end{array}$ & 6.2 & 16.4 & 23 \\
\hline
\end{tabular}

Table 1.1 Tolerance limits for Linear and Angular accelerations [4]

\subsection{Objective:}

The main objective of this study is to compare the linear and angular accelerations of the Human Head and NOCSAE head model. This is done to obtain the relation between head kinematics and brain kinetics to explain the dynamics of brain injuries. Specifically, this study will address:

- Which acceleration is the dominant cause of traumatic brain injuries?

- Which region of the head and brain is most vulnerable to these injuries?

- Whether the commonly used NOCSAE head dummy exhibits similar head and brain injury mechanisms as the human head?

To address these questions, following goals were set:

- Mesh the NOCSAE head and validate it using previous experimental results. 
- Subject the validated FE Head model and the NOCSAE model to impacts on frontal, lateral, posterior and superior regions of the head.

- Use analytical procedures to obtain the values of linear and angular accelerations in the various cases using the data obtained from the simulations.

- Correlate these values of accelerations with the tolerance levels and determine the region and type of injury.

- Do a comparative study of the accelerations of both models to observe the injury mechanisms. 


\section{FE Modelling of Human Head and NOCSAE headform:}

\subsection{Finite Element Model:}

The Human head model was taken from the thesis of David Labyak [5]. The model had the impactor and contact surfaces defined for his simulations. The validated model has an orphan mesh in ABAQUS (.inp) format. Hypermesh and RADIOSS were chosen taking into consideration the availability of software licenses in the university and the versatility of the solver. Since RADIOSS was chosen for the simulations, the model was imported in Hypermesh and modifications were done to obtain a RADIOSS (.rad) output file. The mesh was kept consistent with the validated model.

The geometry of NOCSAE headform was meshed using Hypermesh. Firstly, a 2D mesh was generated on the geometry consisting of 6 noded triangular elements and 4 noded quad elements. Then a 3D mesh was generated from this 2D mesh consisting of purely tetrahedral elements.

The details of both the models is given in Table 2.1. 


\begin{tabular}{|l|l|l|l|}
\hline Body Name & Nodes & Elements & $\begin{array}{l}\text { Generic } \\
\text { Element } \\
\text { Type in } \\
\text { Original } \\
\text { Model }\end{array}$ \\
\hline Scalp (yellow) & 3762 & 3665 & Linear Wedge \\
\hline Skull (white) & 6847 & 22930 & $\begin{array}{l}\text { Linear } \\
\text { Tetrahedron }\end{array}$ \\
\hline $\begin{array}{l}\text { Dura matter } \\
\text { (blue) }\end{array}$ & 4158 & 4154 & Linear Wedge \\
\hline $\begin{array}{l}\text { Brain Tissue } \\
\text { (red) }\end{array}$ & 3971 & 17088 & $\begin{array}{l}\text { Linear } \\
\text { Tetrahedron }\end{array}$ \\
\hline $\begin{array}{l}\text { NOCSAE } \\
\text { Headform }\end{array}$ & 4645 & 20542 & $\begin{array}{l}\text { Linear } \\
\text { Tetrahedron }\end{array}$ \\
\hline
\end{tabular}

Table 2.1 FE Model details of Human Head and NOCSAE headform

The different layers of the Human Head model are shown in Figure 2.1. The impact regions for the human head model are shown in Figure 2.2. Figure 2.3 shows the meshed NOCSAE headform. Similar impact cases were applied to both model. 


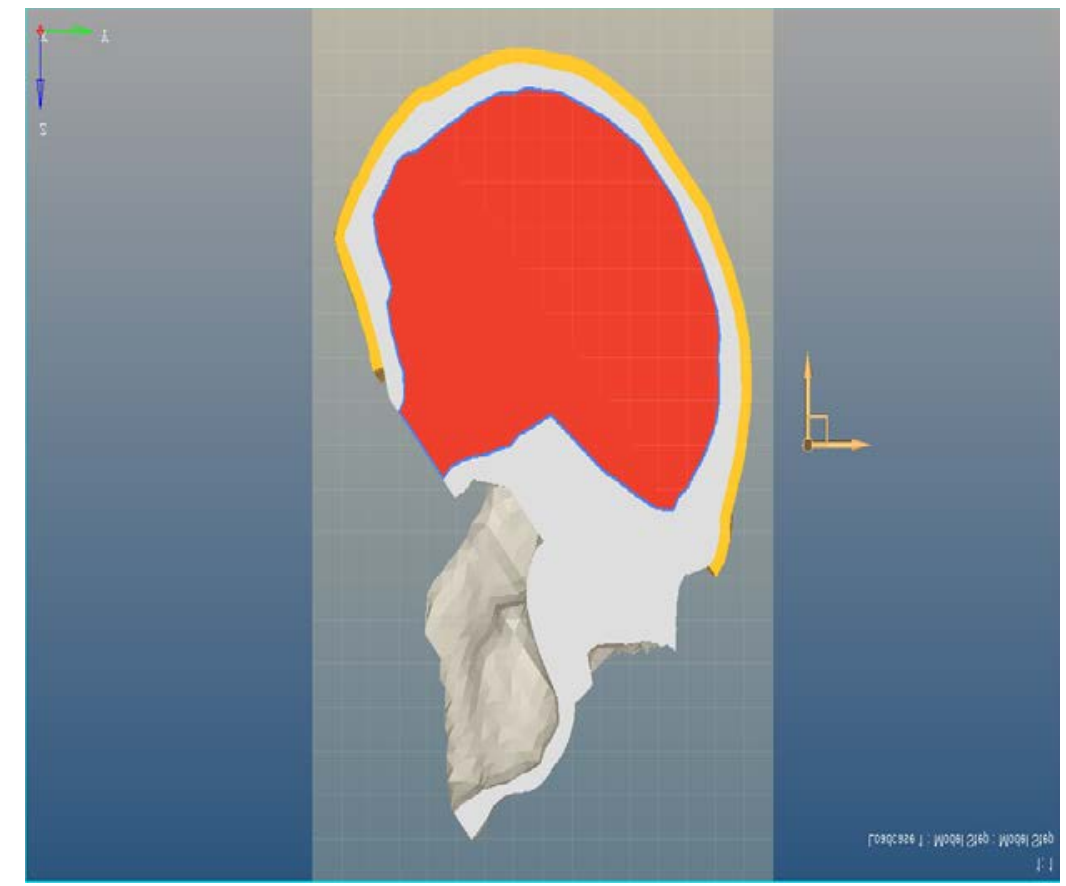

Figure 2.1 FE Model of Human Head showing different layers

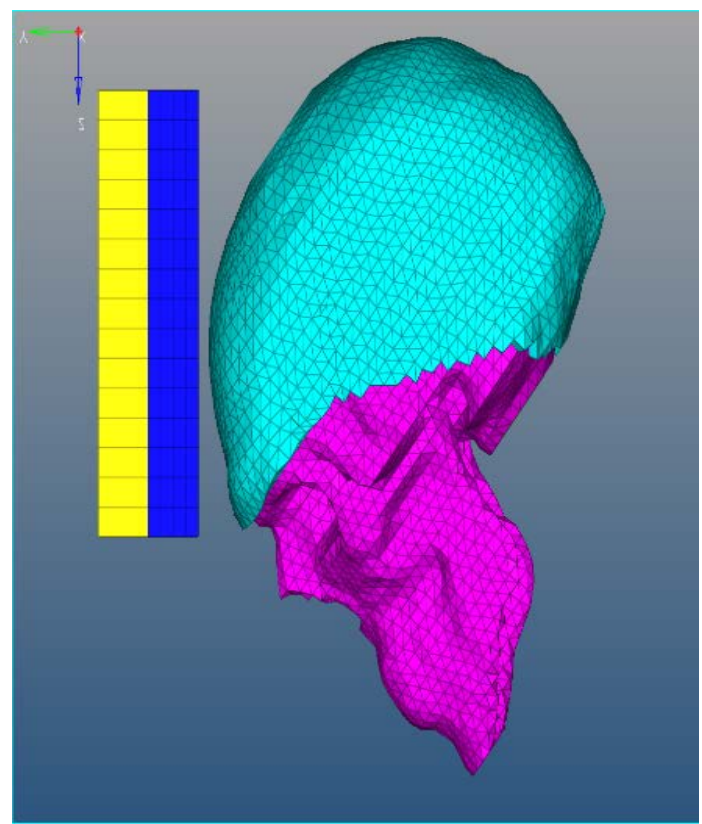

(a) Frontal I m pact

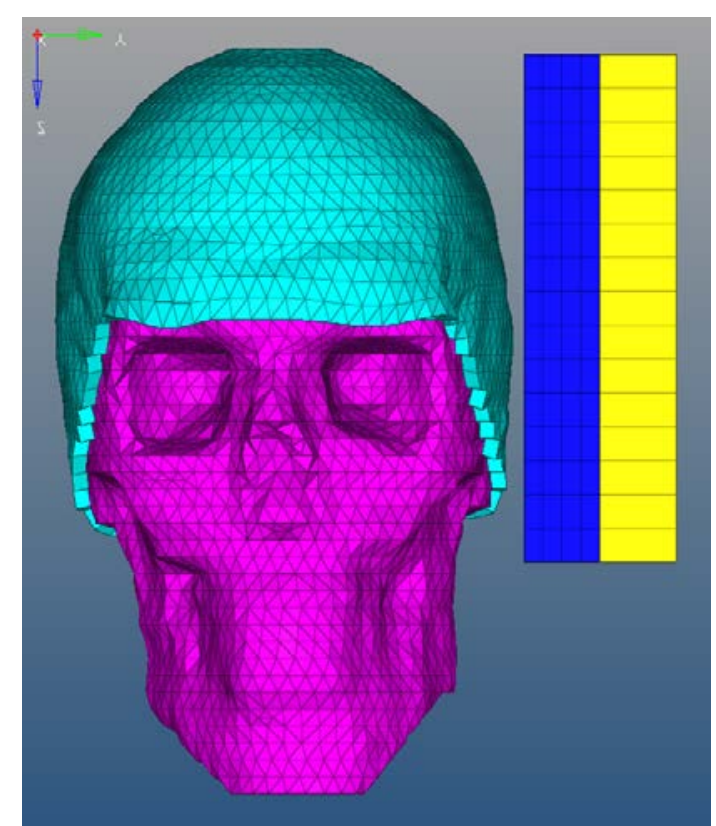

(b) Lateral I mpact

Figure 2.2 I mpact Regions in Human Head Model 


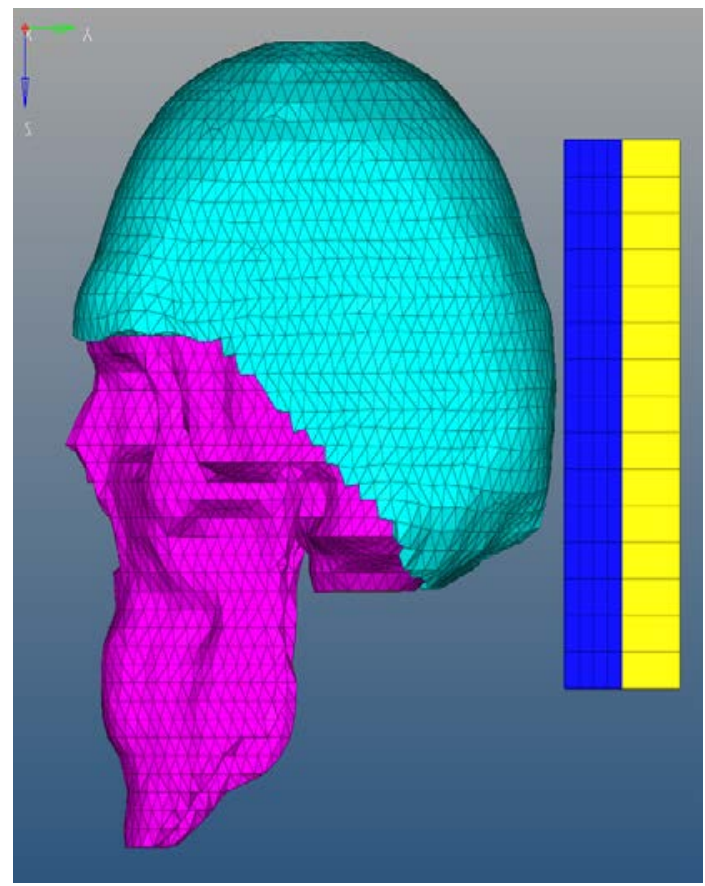

(c) Posterior I mpact

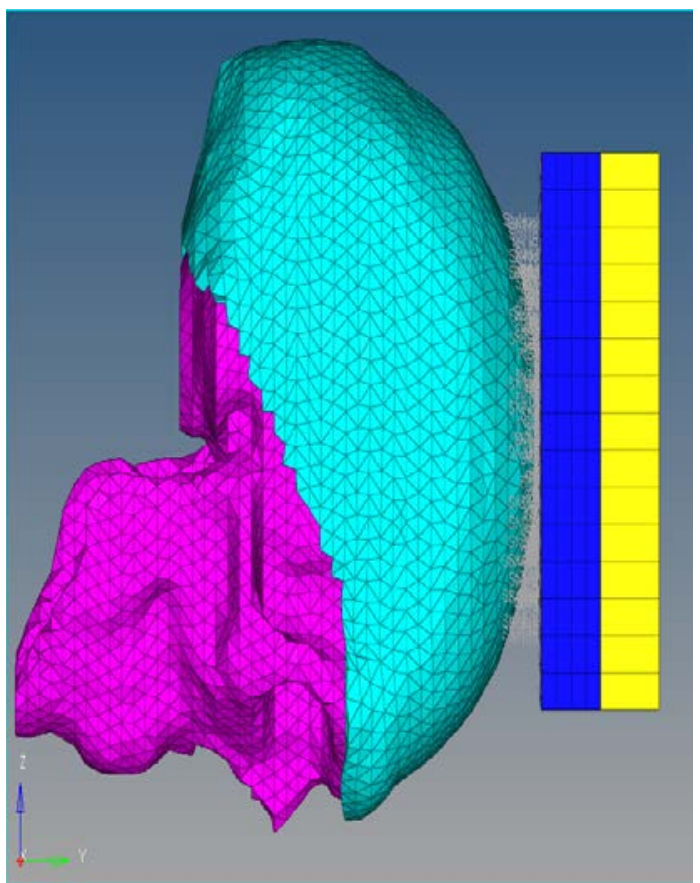

(d) Superior I mpact

Figure 2.2 I mpact Regions in Human Head Model

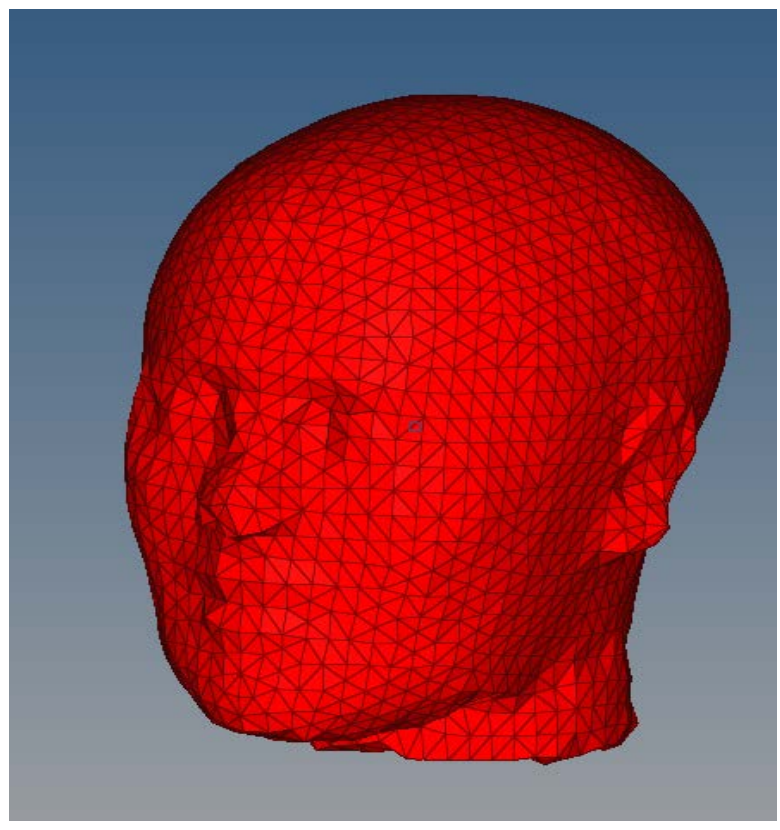

Figure 2.3 Meshed NOCSAE headform 


\subsection{Material assignments:}

The different layers of the human head were grouped and named appropriately. Respective material properties were assigned to these groups. The properties for the NOCSAE headform were taken from the thesis of Timothy Darling [6]. The density of the headform was adjusted to match the mass of the NOCSAE headform as per the NOCSAE $50^{\text {th }}$ percentile Male Crash Test Dummy developed originally by General Motors [7].

\begin{tabular}{|c|c|c|}
\hline Model & $\begin{array}{c}\text { Human Head } \\
\text { Model }\end{array}$ & $\begin{array}{c}\text { NOCSAE } \\
\text { Headform }\end{array}$ \\
\hline Mass ( kg) & 3.79 & 4.54 \\
\hline
\end{tabular}

Table 2.2. Mass of the Head Models used for simulations

All the layers were assumed as general solids (P14_SOLID card in Hypermesh [8]) in the model. In addition, all the materials were assumed perfectly elastic and were assigned M1_ELAST property [8] in the model. The material properties were kept same according to the validated head model shown in Table 2.2. 


\begin{tabular}{|c|c|c|c|}
\hline Layer Name & Density $\left(\mathrm{kg} / \mathrm{m}^{3}\right)$ & $\begin{array}{l}\text { Young's } \\
\text { Modulus } \\
\text { (MPa) }\end{array}$ & $\begin{array}{l}\text { Poisson's } \\
\text { Ratio }\end{array}$ \\
\hline Scalp & 1412 & 8.05 & 0.42 \\
\hline Skull & 2700 & 6500 & 0.22 \\
\hline Dura matter & 1040 & 0.148 & 0.49 \\
\hline Brain Tissue & 1040 & 0.533 & 0.499 \\
\hline $\begin{array}{l}\text { NOCSAE } \\
\text { headform }\end{array}$ & 1003.6 & 45000 & 0.3 \\
\hline
\end{tabular}

Table 2.3 Material Properties of Human Head (validated FE model) [5] and NOCSAE headform [6]

The material properties of the impactor were also kept the same as the validated model as listed in Table 2.4. The same impactor was used in simulations for both models to get an accurate comparison.

\begin{tabular}{|l|l|l|l|}
\hline $\begin{array}{l}\text { Layer } \\
\text { Name }\end{array}$ & Density $\left(\mathbf{k g} / \mathbf{~ m}^{\mathbf{3}} \mathbf{)}\right.$ & $\begin{array}{l}\text { Young's } \\
\text { Modulus } \\
\text { (MPa) }\end{array}$ & $\begin{array}{l}\text { Poisson's } \\
\text { Ratio }\end{array}$ \\
\hline Padding & 1200 & 10 & 0.3 \\
\hline Steel & 7800 & 209000 & 0.28 \\
\hline
\end{tabular}

Table 2.4 Material Properties of I mpactor (validated FE model) [5] 


\subsection{Boundary Conditions:}

To simulate a series of impact experiments, the steel plate connected to the impactor pad was fully constrained. In these experiments, the head was given the initial velocity and the impactor was kept stationary. All nodes on the rear side of the steel plate, opposite the impact site, were constrained both in translation and in rotation.

\subsection{I nitial Conditions:}

In these simulations, both the FE models of Human head and NOCSAE headform were subjected to initial velocities corresponding to various drop heights. The case of $2 \mathrm{ft}, 3 \mathrm{ft}, 4 \mathrm{ft}$ and $5 \mathrm{ft}$ drop heights were taken. The corresponding velocities were calculated using the formula,

$$
v=\sqrt{2 g h}
$$

Where, $v$ - initial velocity in $\mathrm{m} / \mathrm{s}$

$g$ - Acceleration due to gravity in $\mathrm{m} / \mathrm{s}^{2}$

$h$ - Drop height converted to $\mathrm{mm}$

\begin{tabular}{|c|c|}
\hline Drop Height (ft.) (m) & Velocity (m/ s) \\
\hline $2(0.6096)$ & 3.4584 \\
\hline $3(0.9144)$ & 4.2356 \\
\hline $4(1.2192)$ & 4.8908 \\
\hline $5(1.524)$ & 5.4681 \\
\hline
\end{tabular}

Table 2.5 I nitial Velocity from Drop Heights (Values in brackets are in meters) 


\subsection{Contact Conditions:}

The type of contact use was Type 7 in Hypermesh [8]. Type 7 was used because it is the most general type of contact and does not have the limitations that restrict other types of contacts. The impactor surface elements were defined as the master surface and the nodes on the Human head model and the NOCSAE headform were included in the slave surface. 


\section{Validation of NOCSAE Headform:}

The NOCSAE headform was validated using the experimental data and observations from the thesis of Chandrika Abhang [11]. Linear acceleration was taken as the parameter for comparison since that is the parameter, which is significant to this study.

The validation model was simulated for a frontal impact at $2 \mathrm{ft}$. drop height. The linear acceleration calculations of the models are explained in further sections. The linear acceleration for the validation model is calculated using the contact force. All the elements that define the contact between the headform and the pad are used to calculate the contact force.

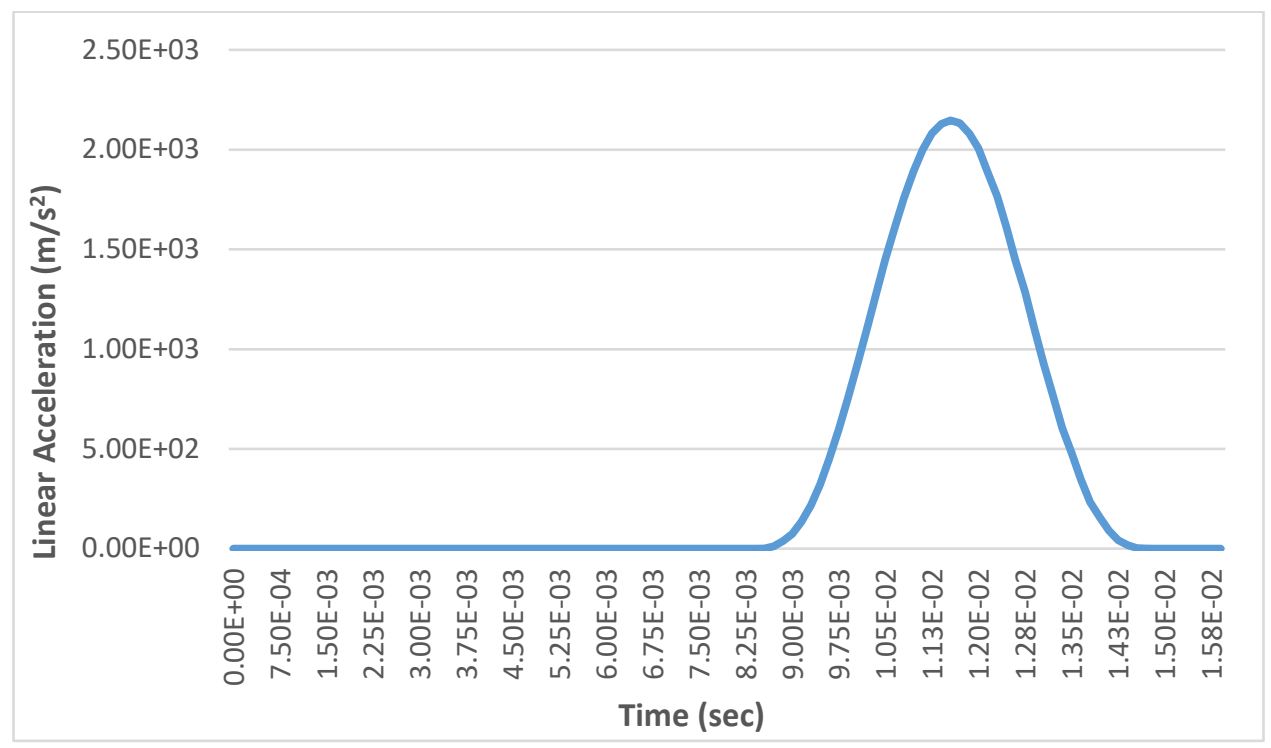

Figure 3.1. Linear acceleration time history of the validation model

The linear acceleration obtained from the NOCSAE drop tests was used by Chandrika Abhang [11] for Impact Pressure calculations. The time history of linear acceleration from experimental data is plotted in figure 3.2. 


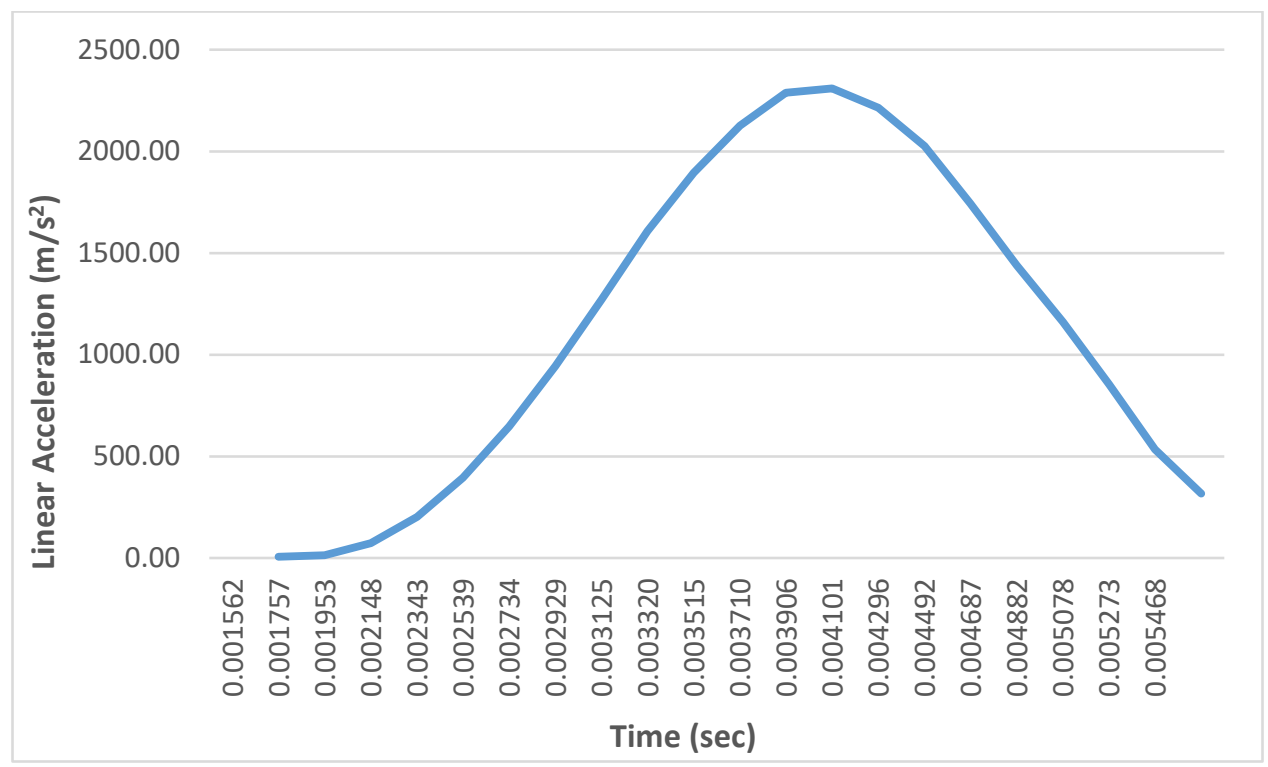

Figure 3.2. Linear acceleration time history from experimental observations

It can be seen the linear acceleration time history curve for the validation model and the experimental data show similar nature. In addition, the peak values lie in same range showing the model reproducing experimental results. 


\section{Simulation of I mpacts on Human Head and NOCSAE Headform:}

It has been proven that in most scenarios of head impact there exists some combination of linear and angular motion of the head. This study aims to find the prominent reason behind head injuries of these two. For this research, the FE model was subjected to impacts on four regions of the head: frontal, lateral, posterior and superior. The output results obtained from the finite element analysis are the impact forces that are displayed in graphical form. The accelerations are calculated analytically using these forces in a later section.

\subsection{Frontal I mpact:}

In case of frontal impact simulation, the impactor is kept stationary and the head is given an initial velocity. This is similar to the research conducted by David Labyak [5]. The FE head models are same as the ones described in Section 2.1. The impactor consists of a steel plate with padding on the surface. The head model aligned such that $\mathrm{Y}$-axis represents the anterior-posterior direction. The initial velocity corresponding to drop height is applied to the model for all impact simulations. The velocity value is assigned as vector quantity in $Y$ direction. The boundary and contact conditions were left the same as in the above-described model. 


\begin{tabular}{|c|c|c|}
\hline Drop Height (ft.) & $\begin{array}{c}\text { Human Head } \\
\text { Model Contact } \\
\text { Force ( N) }\end{array}$ & $\begin{array}{c}\text { NOCSAE } \\
\text { Headform Contact } \\
\text { Force ( N) }\end{array}$ \\
\hline 2 & 7800 & 9750 \\
\hline 3 & 10200 & 12758.75 \\
\hline 4 & 12300 & 15412.50 \\
\hline 5 & 14278.37 & 17868.38 \\
\hline
\end{tabular}

Table 4.1. Maximum Contact Forces for Frontal I mpact of Human Head Model and NOCSAE Headform at different drop heights

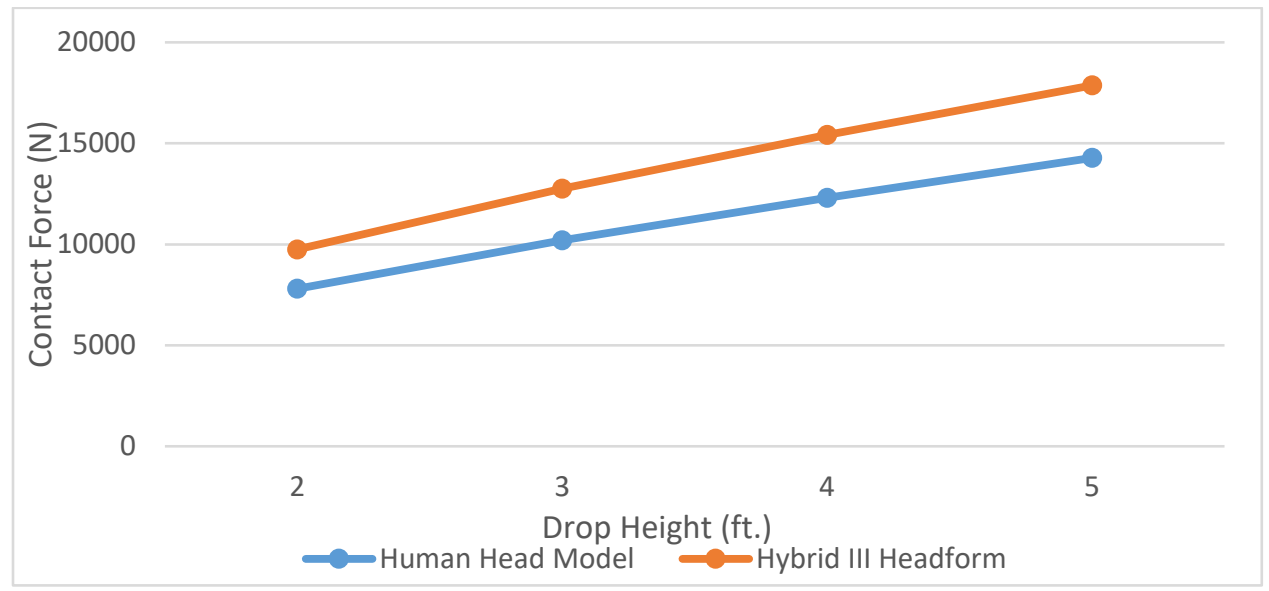

Figure 4.1. Comparison of Maximum Contact Forces for Frontal I mpacts

\subsection{Lateral I mpact:}

The model for lateral impact is similar to the FE model for frontal impact. However, the FE head model is reoriented such that Y-axis is the direction for lateral impact. The anterior-posterior direction of the head is defined by $X$-axis and $X-Y$ plane is the transverse plane. The initial velocity is again applied as a vector quantity in $Y$ direction with a magnitudes corresponding to drop heights $2,3,4$ 
and $5 \mathrm{ft}$. The boundary and contact conditions are kept same as before.

\begin{tabular}{|c|c|c|}
\hline Drop Height (ft.) & $\begin{array}{c}\text { Human Head } \\
\text { Model Contact } \\
\text { Force ( N) }\end{array}$ & $\begin{array}{c}\text { NOCSAE } \\
\text { Headform Contact } \\
\text { Force ( N) }\end{array}$ \\
\hline 2 & 7705.8 & 11553.23 \\
\hline 3 & 10230.51 & 15344.29 \\
\hline 4 & 12300 & 18810.02 \\
\hline 5 & 14278.37 & 22015.54 \\
\hline
\end{tabular}

Table 4.2. Maximum Contact Forces for Lateral Impact of Human Head Model and NOCSAE Headform at different drop heights

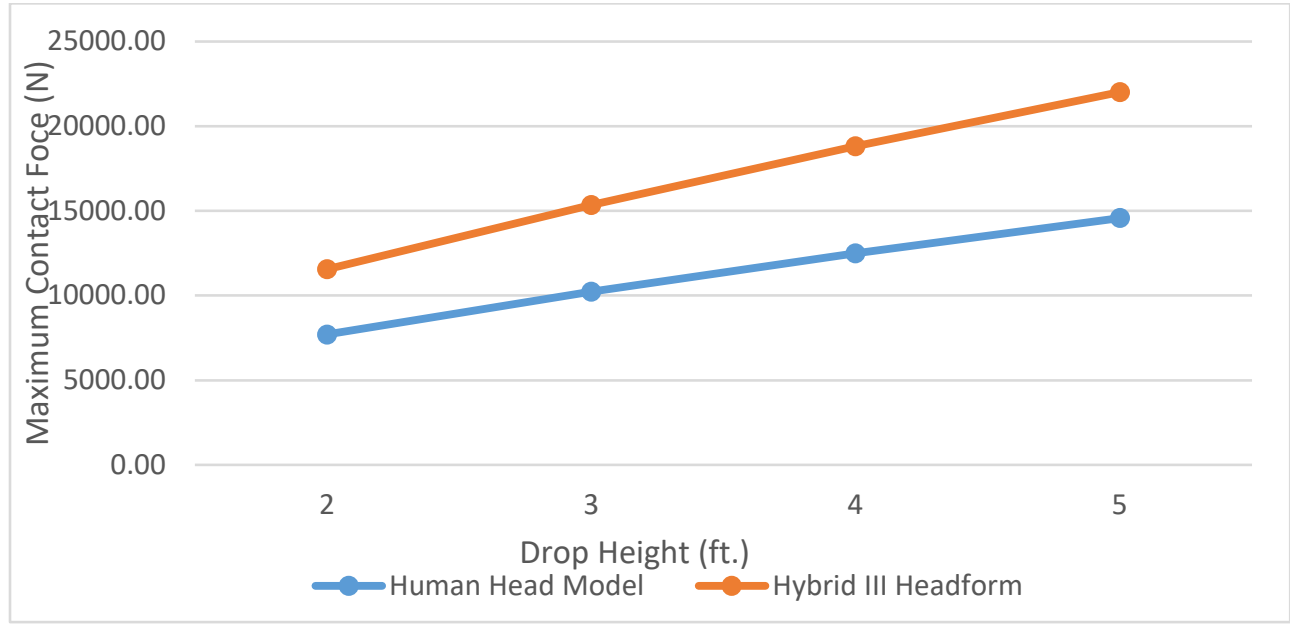

Figure 4.2. Comparison of Maximum Contact Forces for Lateral I mpact 


\subsection{Posterior I mpact:}

For simulations of posterior impact, the impact is in anteriorposterior direction. The FE head model is oriented such that $\mathrm{Y}$-axis defines this direction and the $X-Y$ plane is the transverse plane. The initial velocity applied to the head is consistent with the drop heights as previously stated. The boundary and contact conditions are kept unchanged.

\begin{tabular}{|c|c|c|}
\hline Drop Height (ft.) & $\begin{array}{c}\text { Human Head } \\
\text { Model Contact } \\
\text { Force ( N) }\end{array}$ & $\begin{array}{c}\text { NOCSAE } \\
\text { Headform Contact } \\
\text { Force ( N) }\end{array}$ \\
\hline 2 & 7942.28 & 9457.68 \\
\hline 3 & 10332.04 & 12605.20 \\
\hline 4 & 12388.07 & 15401.95 \\
\hline 5 & 14246.22 & 17970.58 \\
\hline
\end{tabular}

Table 4.3. Maximum Contact Forces for Posterior I mpact of Human Head Model and NOCSAE Headform at different drop heights

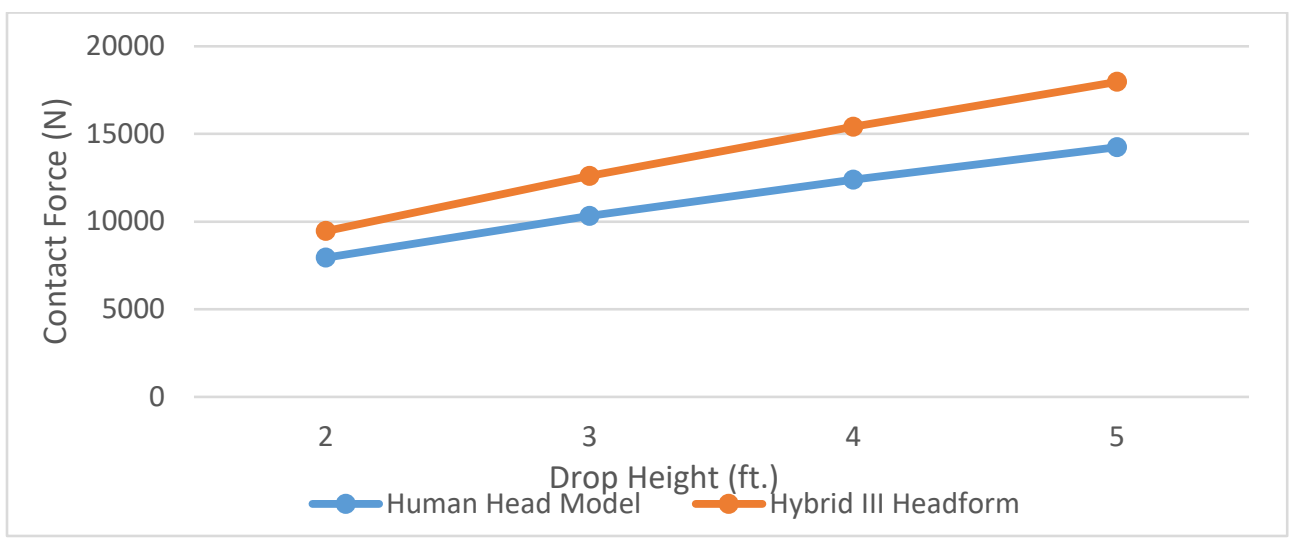

Figure 4.3. Comparison of Maximum Contact Forces for Posterior I mpact 


\subsection{Superior I mpact:}

In case of superior impacts, the impact is directed from the top. The FE head model is oriented such that $Y$-axis is along the direction of impact and $X$ - axis is the anterior-posterior direction. The $X-Y$ plane describes the sagittal plane of the head. The initial velocity was same as in all the previous impacts. The boundary and contact conditions remain unchanged.

\begin{tabular}{|c|c|c|}
\hline Drop Height (ft.) & $\begin{array}{c}\text { Human Head } \\
\text { Model Contact } \\
\text { Force ( N) }\end{array}$ & $\begin{array}{c}\text { NOCSAE } \\
\text { Headform Contact } \\
\text { Force ( N) }\end{array}$ \\
\hline 2 & 8620.78 & 10687.69 \\
\hline 3 & 11362.44 & 14188.64 \\
\hline 4 & 13721.77 & 17364.63 \\
\hline 5 & 15919.96 & 20300 \\
\hline
\end{tabular}

Table 4.4. Maximum Contact Forces for Superior I mpact of Human Head Model and NOCSAE Headform at different drop heights

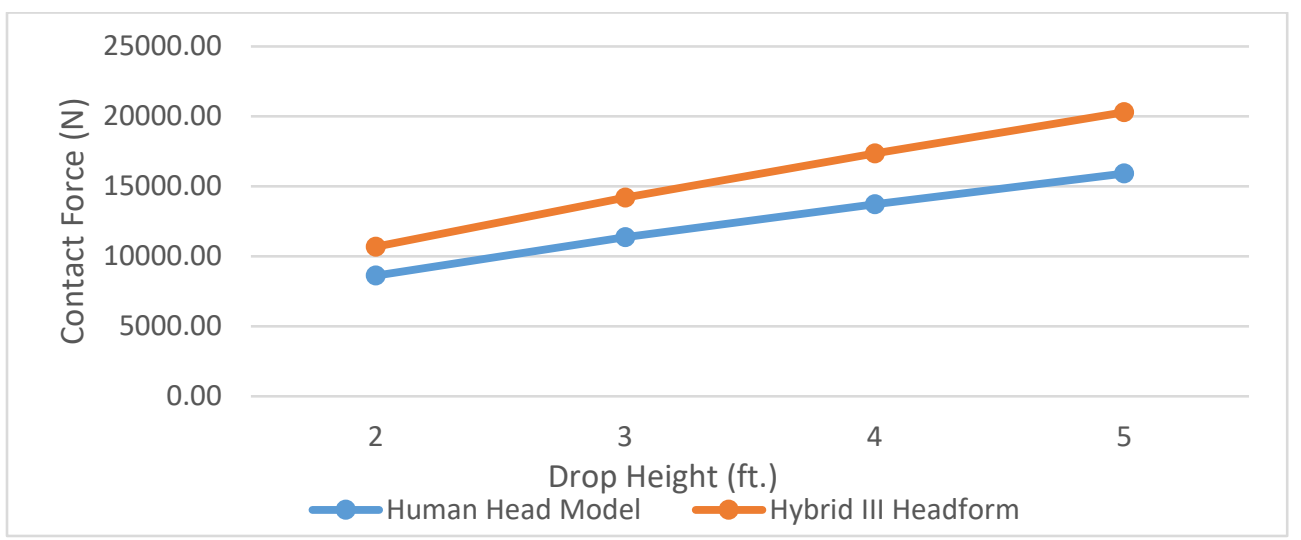

Figure 4.4. Comparison of Maximum Contact Forces for Superior I mpact 


\section{Analytical Calculations for Linear and Angular Accelerations:}

\subsection{Introduction:}

To calculate the linear and angular accelerations analytically, Newton's second law was used. Newton's Second Law states, “The rate of change of momentum of a body is proportional to the impulse impressed on the body, and happens along the straight line on which that impulse is impressed".

\subsection{Linear Acceleration Calculations:}

The mathematical expression for Newton's second law in case of linear motion is:

$$
\vec{F}=\frac{d(m \vec{v})}{d t}=m \frac{d \vec{v}}{d t}=m \vec{a}
$$

Where ' $\vec{F}$ ' is the resultant force applied, ' $\mathrm{m}$ ' is the mass of the body and ' $\vec{a}$ ' is the linear acceleration of the body.

In this case, the resultant force is replaced by the maximum contact force obtained from the simulations. Then the acceleration was calculated using the constant mass of the models as stated in Section 2.2.

\subsection{Angular Acceleration Calculations:}

The calculations of angular acceleration involve a basic understanding of rigid body rotation. Consider a sphere of radius ' $r$ ' with the co-ordinate axes passing through the center as shown in Figure 5.1. 


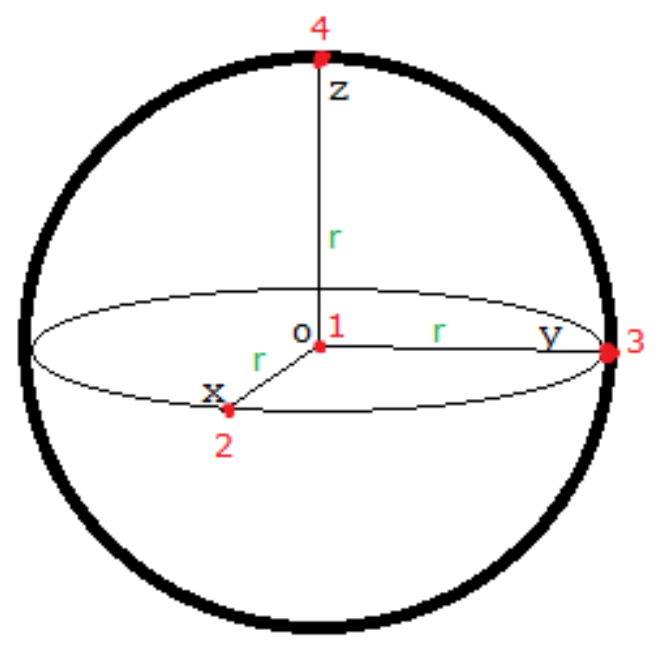

Figure 5.1. Sphere with radius ' $r$ ' and co-ordinate axes passing through the center

We place 4 nodes at origin and at equal distance ' $r$ ' from origin along each axes numbered as shown in Figure 5.1. Now, we know that the angular velocity is a vector that can be resolved into its components along $\mathrm{x}, \mathrm{y}$ and $\mathrm{z}$ directions.

$$
\vec{\alpha}=\overrightarrow{\alpha_{x}}+\overrightarrow{\alpha_{y}}+\overrightarrow{\alpha_{z}}
$$

Now, let us consider the angular acceleration about $x$-axis. The rotation of any plane within the rigid body parallel to $y-z$ plane will have same angular acceleration irrespective of the location along $x$-axis. In general, we know for rotational motion, the relation between linear and angular acceleration is given by,

$$
\alpha=\frac{a}{r}
$$

The acceleration at each of the nodes can be resolved into components along each of the axes. To calculate the angular acceleration about $x$-axis, we use the components of tangential acceleration at each of the nodes that contribute to the rotation 
about $x$-axis. Since nodes 1 and 2 lie on the $x$-axis, they do not provide any rotation about $x$-axis. At node 3 , the $z$-component of linear acceleration contributes to rotation about $x$-axis. Similarly, at node 4 , the $y$ component of linear acceleration contributes to rotation about $x$-axis. So finally, to get the angular acceleration about $x$-axis for the rigid body, we use the formula,

$$
\alpha_{x}=\frac{a_{y}^{4}-a_{z}^{3}}{r}
$$

Where $\alpha_{x}$ - Angular acceleration about $\mathrm{x}$-axis

$a_{y}^{4}$ - Y-component of linear acceleration at node 4

$a_{z}^{3}$ - Z-component of linear acceleration at node 3

$r$ - Distance of node from origin, $O$

Since the components contributing to rotation about $x$-axis at node 3 and 4 are in opposite direction, we subtract the two values. In addition, we have assumed anti-clockwise rotation as positive by convention.

Equations similar to equation (4) can be obtained for rotation about $y$ and $z$-axes.

$$
\begin{aligned}
& \alpha_{y}=\frac{a_{x}^{4}-a_{z}^{2}}{r} \\
& \alpha_{z}=\frac{a_{y}^{2}-a_{x}^{3}}{r}
\end{aligned}
$$

We can use these simplified formulae for pure rotational motion of a rigid body. However, when there is simultaneous translational and rotational motion, we need to take in account the change in coordinates of the center of gravity. In the above description, we assumed that the center of gravity (node 1 ) coincided with the origin, $\mathrm{O}$. 
In the case of head impacts, we have translational motion, which gives rise to linear and angular accelerations. Therefore, we need to ensure that we account for new location of the center of gravity. This is achieved by subtracting the linear acceleration at the center of gravity (node 1 ) from the linear accelerations at each of remaining nodes.

$$
\begin{aligned}
& a_{\text {new }}^{2}=a^{2}-a^{1} \\
& a_{\text {new }}^{3}=a^{3}-a^{1} \\
& a_{\text {new }}^{4}=a^{4}-a^{1}
\end{aligned}
$$

The above set of equations (Equation. (7)) make sure we have a relative frame of pure rotational motion. The new values of acceleration can be used along with equations (4), (5) and (6) to obtain the components of angular acceleration for a rigid body, in this case, the head models.

The above logic was used to develop a MATLAB code. The code was then used to calculate angular acceleration values for all the previously described cases of impacts of Human head model and NOCSAE Headform. 


\section{Validation of Analytical Method:}

The analytical methods proposed above were validated using a test simulation for $37.6 \mathrm{~cm}$ drop height for the Hybrid III Headform. This height was selected since the experimental results for this are available in literature. In addition, this is the drop height used by the current manufacturers (Humanetics ATD) for validating their Hybrid III Headform.

\begin{tabular}{|c|c|c|}
\hline & Frontal & Lateral \\
\hline Max Linear $\left(\mathrm{m} / \mathrm{s}^{2}\right)$ & 1559.826 & 1822.689 \\
\hline Max Linear (g) & 159.0 & 185.8 \\
\hline $\begin{array}{l}\text { Reference (g) Hybrid } \\
\text { III Head }\end{array}$ & $\sim 250$ & $\sim 200$ \\
\hline $\begin{array}{l}\text { Reference }(\mathrm{g}) \\
\text { Hodgson-WSU Head }\end{array}$ & $\sim 250$ & $\sim 250$ \\
\hline Max Angular $\left(\mathrm{rad} / \mathrm{s}^{2}\right)$ & 13930.155 & 11662.243 \\
\hline $\begin{array}{l}\text { Reference Angular } \\
\left(\mathrm{rad} / \mathrm{s}^{2}\right) \text { Hybrid III } \\
\text { Head }\end{array}$ & $\sim 12000$ & $\sim 20000$ \\
\hline $\begin{array}{l}\text { Reference Angular } \\
\left(\mathrm{rad} / \mathrm{s}^{2}\right) \text { Hodgson- } \\
\text { WSU Head }\end{array}$ & $\sim 15000$ & $\sim 25000$ \\
\hline
\end{tabular}

Table 6.1. Linear and Angular acceleration comparison for Hybrid III Head 
All the reference values were taken from the results of Kendall et al. [9]. The simulation results are within acceptable range from the experimental values. The difference in values is mainly due to material differences. The impactor used in the simulations differs from the steel anvil used in the drop tests by Kendall et al. 


\section{Results:}

\subsection{Linear Acceleration:}

The maximum linear acceleration was calculated using the method explained in section 5.2. The maximum contact force for each of cases and models was noted in section 4 . The mass for each of the models is provided in Table 2.2. The comparison between Human Head model and NOCSAE headform for linear acceleration for frontal, lateral, posterior and superior impacts is given in next sections. The linear acceleration values are also being compared with the tolerance limits for different cases of brain injury.

7.2 Linear Acceleration - Frontal I mpact:

\begin{tabular}{|c|c|c|c|c|}
\hline $\begin{array}{c}\text { Drop } \\
\text { Height } \\
\text { (ft.) }\end{array}$ & \multicolumn{2}{|c|}{$\begin{array}{c}\text { Human Head } \\
\text { Model }\end{array}$} & \multicolumn{2}{c|}{ NOCSAE Headform } \\
\hline & $\mathbf{m} / \mathbf{s}^{\mathbf{2}}$ & Gs & $\mathbf{m} / \mathbf{s}^{\mathbf{2}}$ & Gs \\
\hline 2 & 2058.05 & 209.79 & 2147.58 & 218.92 \\
\hline 3 & 2691.29 & 274.34 & 2810.30 & 286.47 \\
\hline 4 & 3245.38 & 330.82 & 3394.82 & 346.06 \\
\hline 5 & 3767.38 & 384.03 & 3935.77 & 401.20 \\
\hline
\end{tabular}

Table 7.1. Maximum Linear Acceleration for Frontal Impact of Human Head Model and NOCSAE Headform at different drop heights 


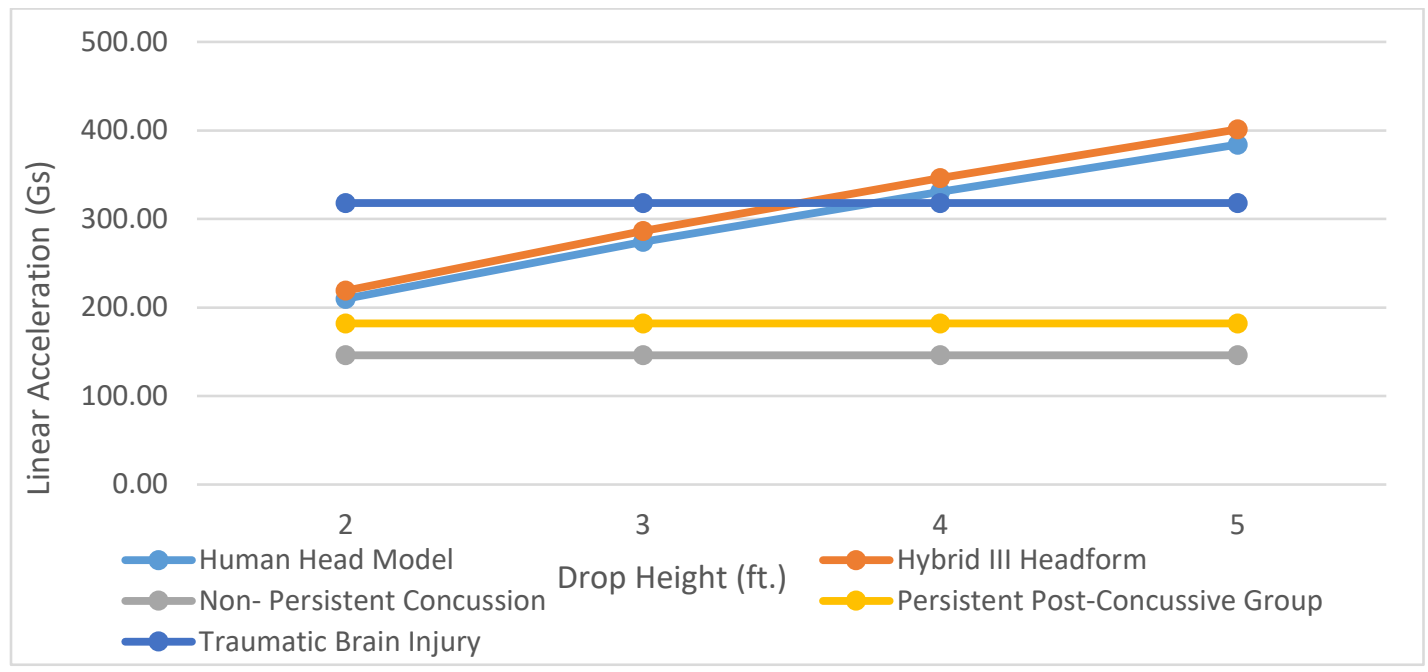

Figure 7.1. Comparison of Maximum Linear acceleration of both models and the tolerance limits for Frontal I mpact

\subsection{Linear Acceleration - Lateral I mpact:}

\begin{tabular}{|c|c|c|c|c|}
\hline $\begin{array}{c}\text { Drop } \\
\text { Height } \\
\text { (ft.) }\end{array}$ & \multicolumn{2}{|l|}{ Human Head Model } & \multicolumn{2}{|c|}{ NOCSAE Headform } \\
\hline & $\mathbf{m} / \mathbf{s}^{\mathbf{2}}$ & Gs & $\mathbf{m} / \mathbf{s}^{\mathbf{2}}$ & Gs \\
\hline 2 & 2033.19 & 207.26 & 2544.76 & 259.41 \\
\hline 3 & 2699.34 & 275.16 & 3379.80 & 344.53 \\
\hline 4 & 3296.70 & 336.05 & 4143.18 & 422.34 \\
\hline 5 & 3845.07 & 391.95 & 4849.24 & 494.32 \\
\hline
\end{tabular}

Human Head Model and NOCSAE Headform at different drop heights 


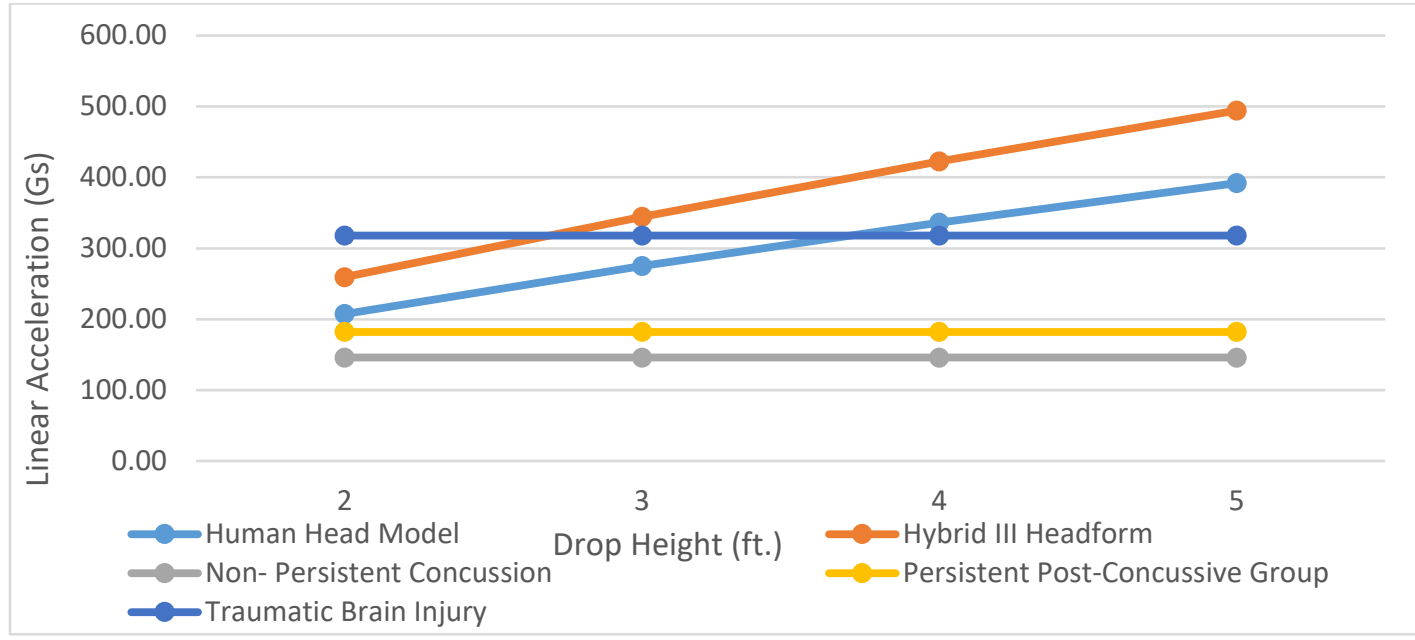

Figure 7.2. Comparison of Maximum Linear acceleration of both models and the tolerance limits for Lateral I mpact

7.4 Linear Acceleration - Posterior I mpact:

\begin{tabular}{|c|c|c|c|c|}
\hline $\begin{array}{c}\text { Drop } \\
\text { Height } \\
\text { (ft.) }\end{array}$ & \multicolumn{2}{|l|}{ Human Head Model } & \multicolumn{2}{|c|}{ NOCSAE Headform } \\
\hline & $\mathbf{m} / \mathbf{s}^{\mathbf{2}}$ & Gs & $\mathbf{m} / \mathbf{s}^{\mathbf{2}}$ & Gs \\
\hline 2 & 2095.59 & 213.62 & 2083.19 & 212.35 \\
\hline 3 & 2726.13 & 277.89 & 2776.47 & 283.02 \\
\hline 4 & 3268.62 & 333.19 & 3392.50 & 345.82 \\
\hline 5 & 3758.90 & 383.17 & 3958.28 & 403.49 \\
\hline
\end{tabular}

Table 7.3. Maximum Linear Acceleration for Posterior I mpact of Human Head Model and NOCSAE Headform at different drop heights 


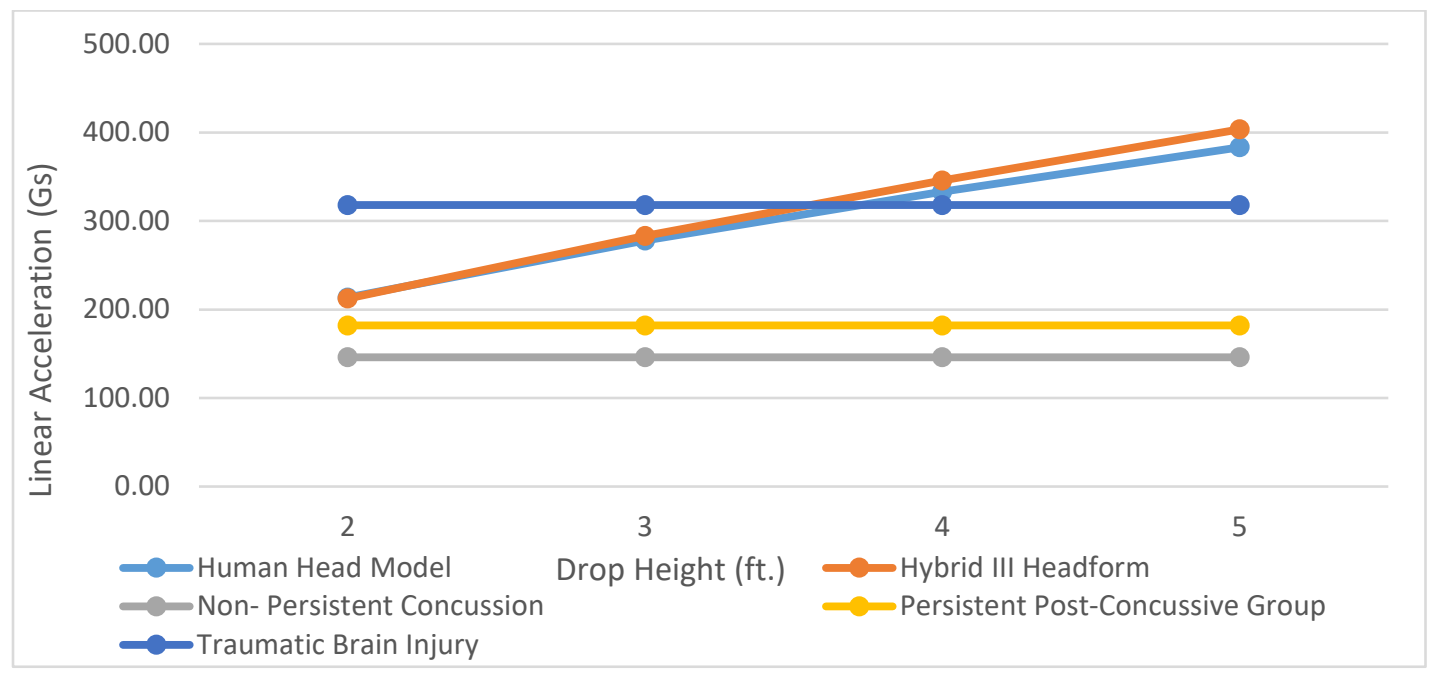

Figure 7.3. Comparison of Maximum Linear acceleration of both models and the tolerance limits for Posterior I mpact

\subsection{Linear Acceleration - Superior I mpact:}

\begin{tabular}{|c|c|c|c|c|}
\hline $\begin{array}{c}\text { Drop } \\
\text { Height } \\
\text { (ft.) }\end{array}$ & \multicolumn{2}{|l|}{ Human Head Model } & \multicolumn{2}{|c|}{ NOCSAE Headform } \\
\hline & $\mathbf{m} / \mathbf{s}^{\mathbf{2}}$ & Gs & $\mathbf{m} / \mathbf{s}^{\mathbf{2}}$ & Gs \\
\hline 2 & 2274.61 & 231.87 & 2354.12 & 239.97 \\
\hline 3 & 3998.01 & 305.61 & 3125.25 & 318.58 \\
\hline 4 & 3620.52 & 369.06 & 3824.81 & 389.89 \\
\hline 5 & 4200.52 & 428.19 & 4471.37 & 455.80 \\
\hline
\end{tabular}

Table 7.4. Maximum Linear Acceleration for Superior I mpact of Human Head Model and NOCSAE Headform at different drop heights 


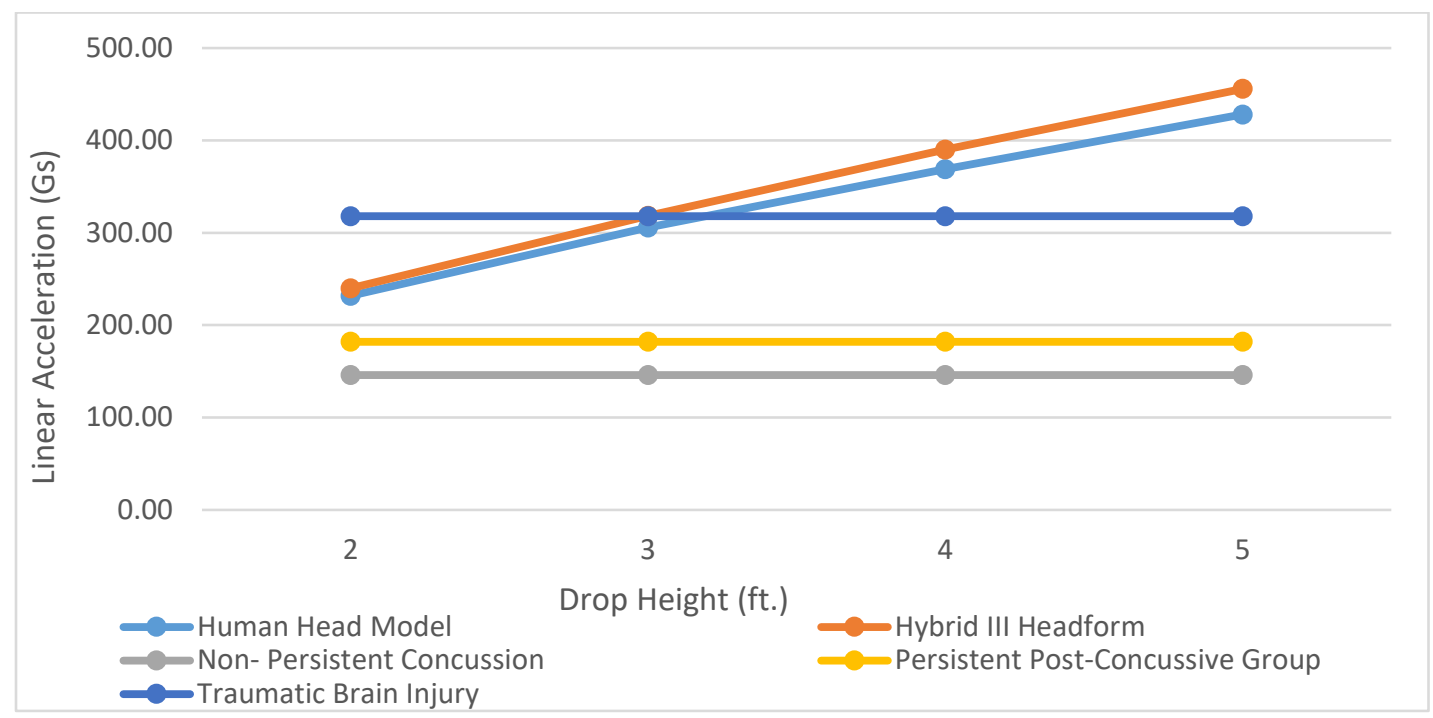

Figure 7.4. Comparison of Maximum Linear acceleration of both models and the tolerance limits for Superior I mpact

\subsection{Angular Acceleration:}

For calculations of Angular Acceleration, the method described in Section 5.3 was used. For using this method, we first need linear acceleration of node at center of gravity and on $X, Y$ and $Z$-axes at equal distance from the center of gravity. These were created in Hypermesh and the linear acceleration time history of each of these nodes was plotted. The data was fed to the code and angular acceleration time history was obtained given in Appendix C. 
7.7 Angular Acceleration - Frontal I mpact:

\begin{tabular}{|c|c|c|}
\hline $\begin{array}{c}\text { Drop Height } \\
\text { (ft.) }\end{array}$ & $\begin{array}{c}\text { Human Head } \\
\text { Model } \\
\text { (krad/ s } \mathbf{~}^{\mathbf{}}\end{array}$ & $\begin{array}{c}\text { NOCSAE } \\
\text { Headform } \\
\text { (krad/ } \mathbf{~}^{\mathbf{}} \text { ) }\end{array}$ \\
\hline 2 & 13.29 & 29.21 \\
\hline 3 & 18.43 & 59.00 \\
\hline 4 & 20.98 & 114.45 \\
\hline 5 & 34.93 & 63.23 \\
\hline
\end{tabular}

Table 7.5. Maximum Angular Acceleration for Frontal I mpact of Human Head Model and NOCSAE Headform at different drop heights

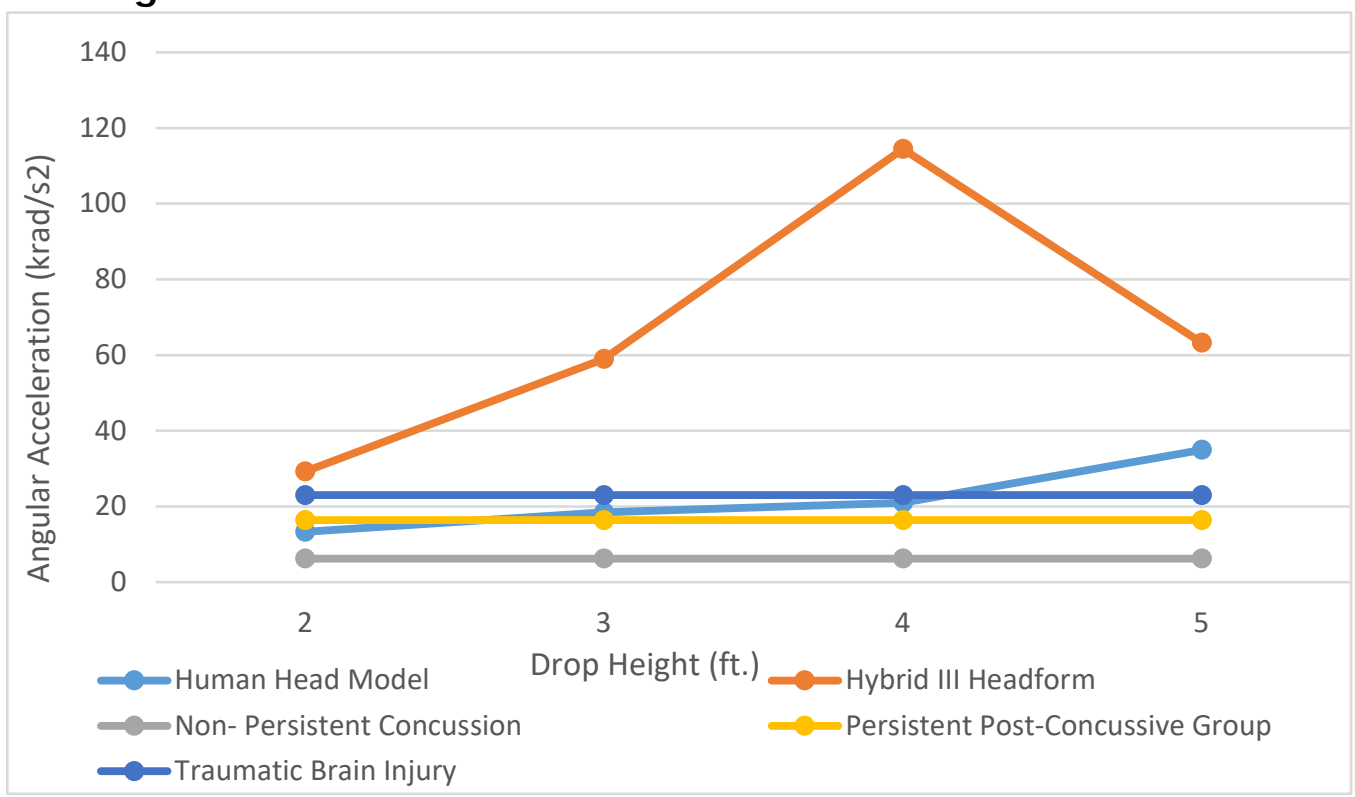

Figure 7.5. Comparison of Maximum Angular Acceleration of both models and the tolerance limits for Frontal I mpact 
7.8 Angular Acceleration - Lateral I mpact:

\begin{tabular}{|c|c|c|}
\hline $\begin{array}{c}\text { Drop Height } \\
\text { (ft.) }\end{array}$ & $\begin{array}{c}\text { Human Head } \\
\text { Model } \\
\left.\text { ( krad/ s } \mathbf{~}^{\mathbf{}}\right)\end{array}$ & $\begin{array}{c}\text { NOCSAE } \\
\text { Headform } \\
\text { ( krad/ } \mathbf{s}^{\mathbf{}} \text { ) }\end{array}$ \\
\hline 2 & 41.37 & 15.80 \\
\hline 3 & 51.39 & 18.69 \\
\hline 4 & 66.39 & 23.65 \\
\hline 5 & 72.14 & 31.48 \\
\hline
\end{tabular}

Table 7.6. Maximum Angular Acceleration for Lateral I mpact of Human Head Model and NOCSAE Headform at different drop heights

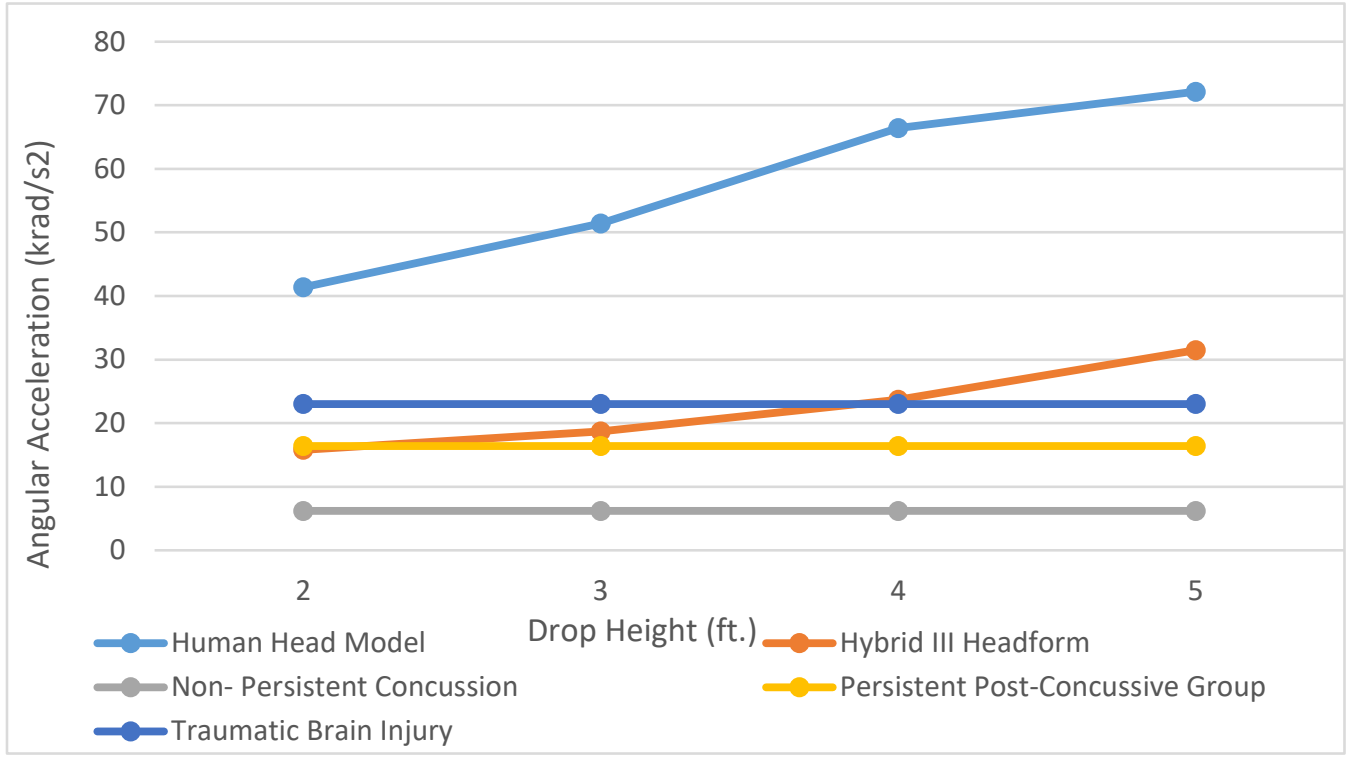

Figure 7.6. Comparison of Maximum Angular Acceleration of both models and the tolerance limits for Lateral I mpact 
7.9 Angular Acceleration - Posterior I mpact:

\begin{tabular}{|c|c|c|}
\hline $\begin{array}{c}\text { Drop Height } \\
\text { (ft.) }\end{array}$ & $\begin{array}{c}\text { Human Head } \\
\text { Model } \\
\left.\text { ( krad/ s } \mathbf{~}^{\mathbf{}}\right)\end{array}$ & $\begin{array}{c}\text { NOCSAE } \\
\text { Headform } \\
\text { (krad/ } \mathbf{~}^{\mathbf{}} \text { ) }\end{array}$ \\
\hline 2 & 9.19 & 11.74 \\
\hline 3 & 18.49 & 18.82 \\
\hline 4 & 21.37 & 37.21 \\
\hline 5 & 26.37 & 73.79 \\
\hline
\end{tabular}

Table 7.7. Maximum Angular Acceleration for Posterior I mpact of Human Head Model and NOCSAE Headform at different drop heights

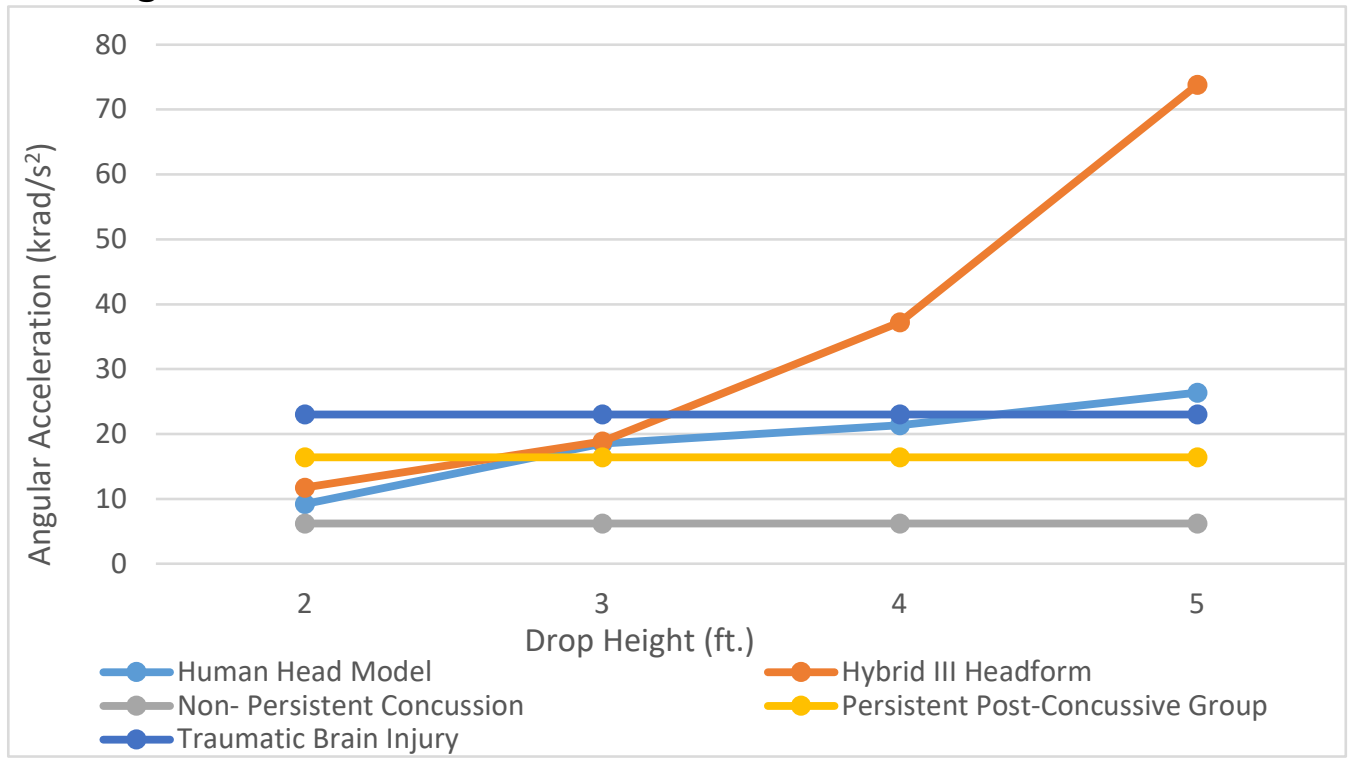

Figure 7.7. Comparison of Maximum Angular Acceleration of both models and the tolerance limits for Posterior I mpact 
7.10 Angular Acceleration - Superior I mpact:

\begin{tabular}{|c|c|c|}
\hline $\begin{array}{c}\text { Drop Height } \\
\text { (ft.) }\end{array}$ & $\begin{array}{c}\text { Human Head } \\
\text { Model } \\
\left(\mathrm{krad} / \mathbf{s}^{2}\right)\end{array}$ & $\begin{array}{l}\text { NOCSAE } \\
\text { Headform } \\
\left(\text { krad } / \mathrm{s}^{2}\right)\end{array}$ \\
\hline 2 & 35.08 & 2.89 \\
\hline 3 & 35.71 & 5.49 \\
\hline 4 & 47.07 & 5.94 \\
\hline 5 & 48.39 & 6.87 \\
\hline
\end{tabular}

Table 7.8. Maximum Angular Acceleration for Superior I mpact of Human Head Model and NOCSAE Headform at different drop heights

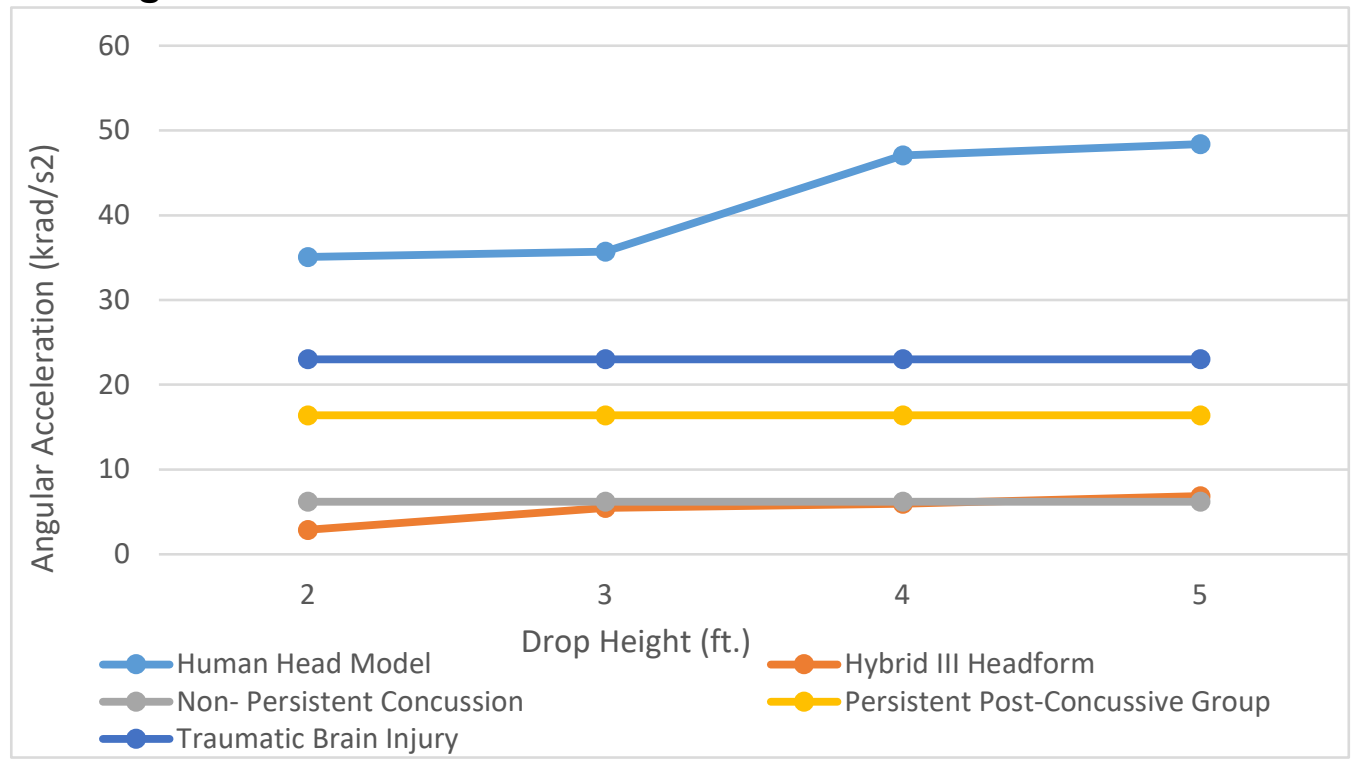

Figure 7.8. Comparison of Maximum Angular Acceleration of both models and the tolerance limits for Posterior I mpact 


\section{Discussions and Conclusion:}

The results of this comparative study show high correlation between maximum linear acceleration for Human Head Model and the $50^{\text {th }}$ percentile male NOCSAE Headform. There appears to be significant difference in the values of maximum angular accelerations for both the models.

The linear accelerations for both headforms demonstrate a linear relationship with increase in drop heights for all regions of impact. For all impact cases, the linear acceleration increases with increase in drop height. For frontal impact, a drop height of $4 \mathrm{ft}$ or higher will cause traumatic brain injury (TBI) for both headforms. For lateral impact, the NOCSAE headform shows TBI for drop height of $3 \mathrm{ft}$ or higher while the Human Head models shows it for $4 \mathrm{ft}$ or higher. The linear acceleration for posterior and superior impacts of both models almost overlaps for different drop heights with possibility of TBI at a drop height of $4 \mathrm{ft}$.

The angular acceleration do not show a clear linear trend but it can be observed from the graphs that angular acceleration for both the models increases with increase in drop height. The exception to this can be observed in case of frontal impact for $4 \mathrm{ft}$ drop height. Unlike linear acceleration, the angular acceleration values do not correlate closely for both the models. For Frontal and Posterior impacts, the Human head model shows lower values of angular acceleration, while opposite is the case with Lateral and Superior impacts. For frontal impact, the human head model shows TBI at a drop height of $5 \mathrm{ft}$ or higher but the NOCSAE headform shows TBI for all drop 
heights. Lateral impact shows opposite nature compared to frontal impact with the Human Head model causing TBI at all drop Heights while the NOCSAE headform shows TBI at a drop height of $5 \mathrm{ft}$ or higher. There is correlation between linear and angular acceleration for posterior impact up to $3 \mathrm{ft}$ drop height. However, the human head model shows TBI above 4ft drop height while NOCSAE headform shows TBI above $3 \mathrm{ft}$ drop height. For superior impact, the NOCSAE headform is safe from TBI at all drop heights while the Human Head models shows TBI at all Drop Heights.

The differences in angular acceleration can be attributed to the biofidelic characteristics and material properties of both the models. The Human Head model consists of layers of materials similar to the actual human head. The material properties of the NOCSAE headform used in this study consists of a uniform rigid body of a single material. The densities and Young's Moduli of each layer in the Human Head model vary while the density and Young's Modulus of the NOCSAE Headform is uniform. In addition, the difference in mass of both the models can also contribute significantly towards the results.

After comparing the linear and angular acceleration for the Human Head model and the NOCSAE headform, it is clear that different physical properties, like mass, density, Young's modulus, will have significant impact on the results. 


\section{Recommendations:}

- Improving and Validating the NOCSAE headform model with more experimental data

- Comparing the two headforms using different impactor materials

- Further research into the physical properties of the NOCSAE headform like moment of inertia

- Comparative study of the two models for Oblique impacts

- Compare the two models after attaching the helmets 


\section{Appendix A Linear Acceleration Time History Curves}

\section{A.1. Frontal I mpact - 2ft. Drop Height:}

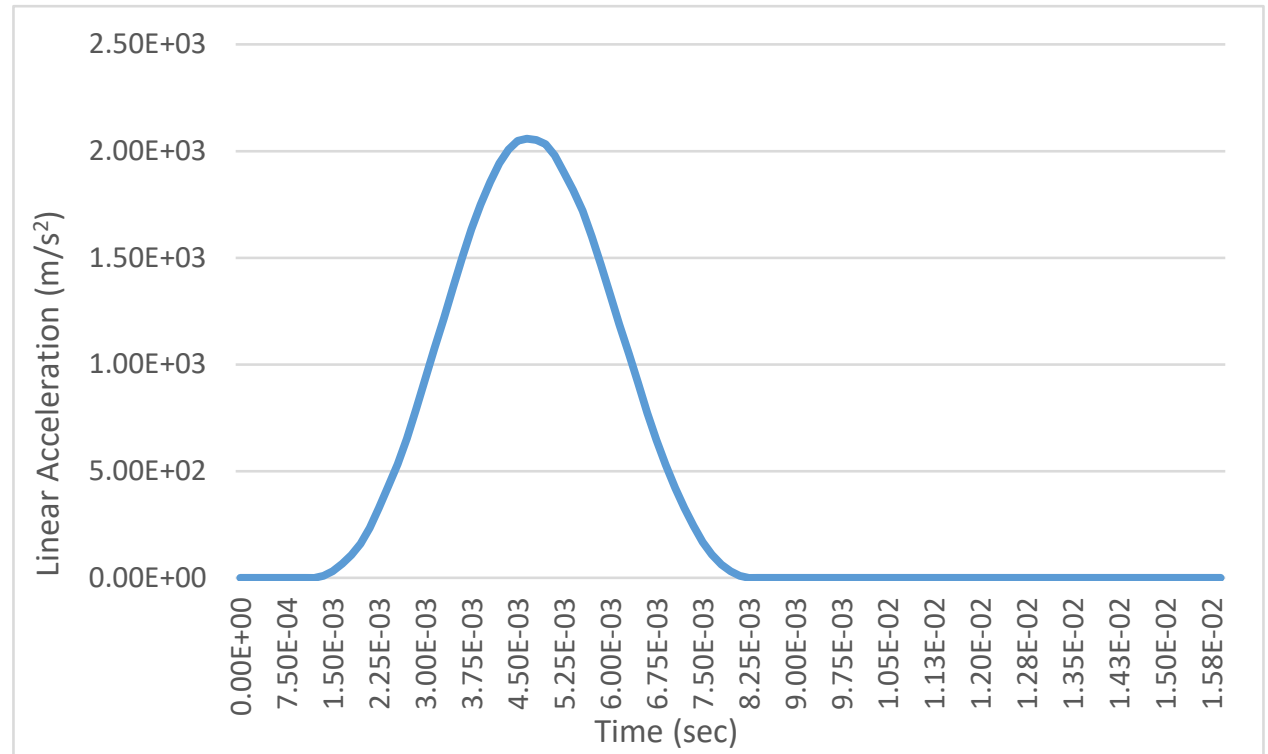

Figure A.1. Linear Acceleration time history of Human Head model for 2ft. Drop Height

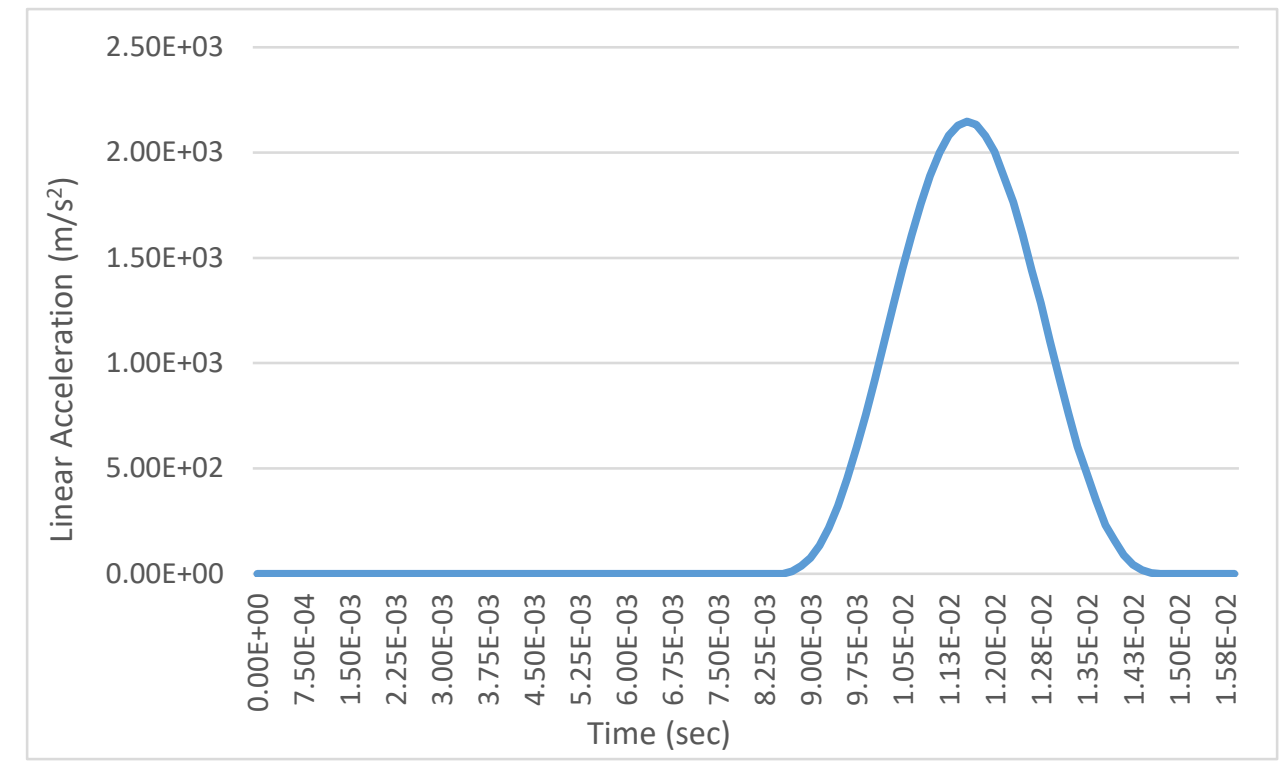

Figure A.2. Linear Acceleration time history of NOCSAE Headform for 2ft. Drop Height 


\section{A.2. Frontal I mpact - 3ft. Drop Height:}

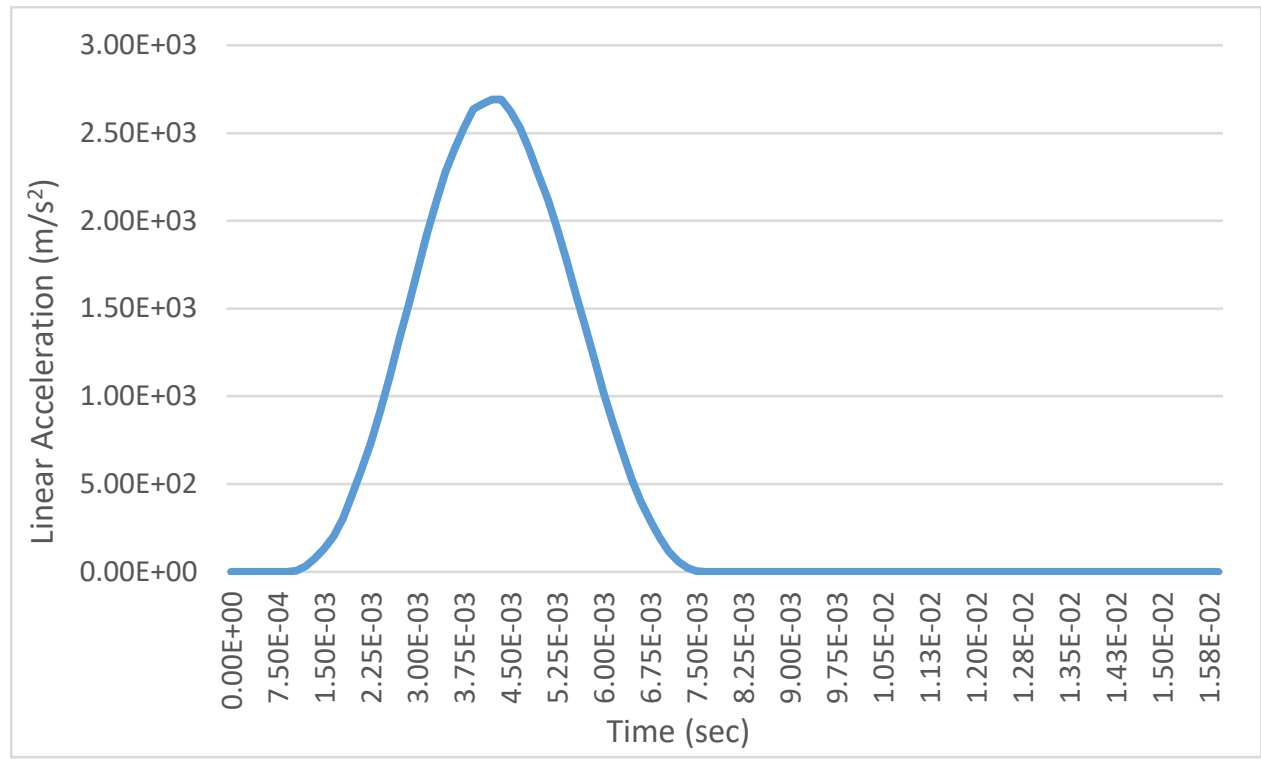

Figure A.3. Linear Acceleration time history of Human Head model for 3ft. Drop Height

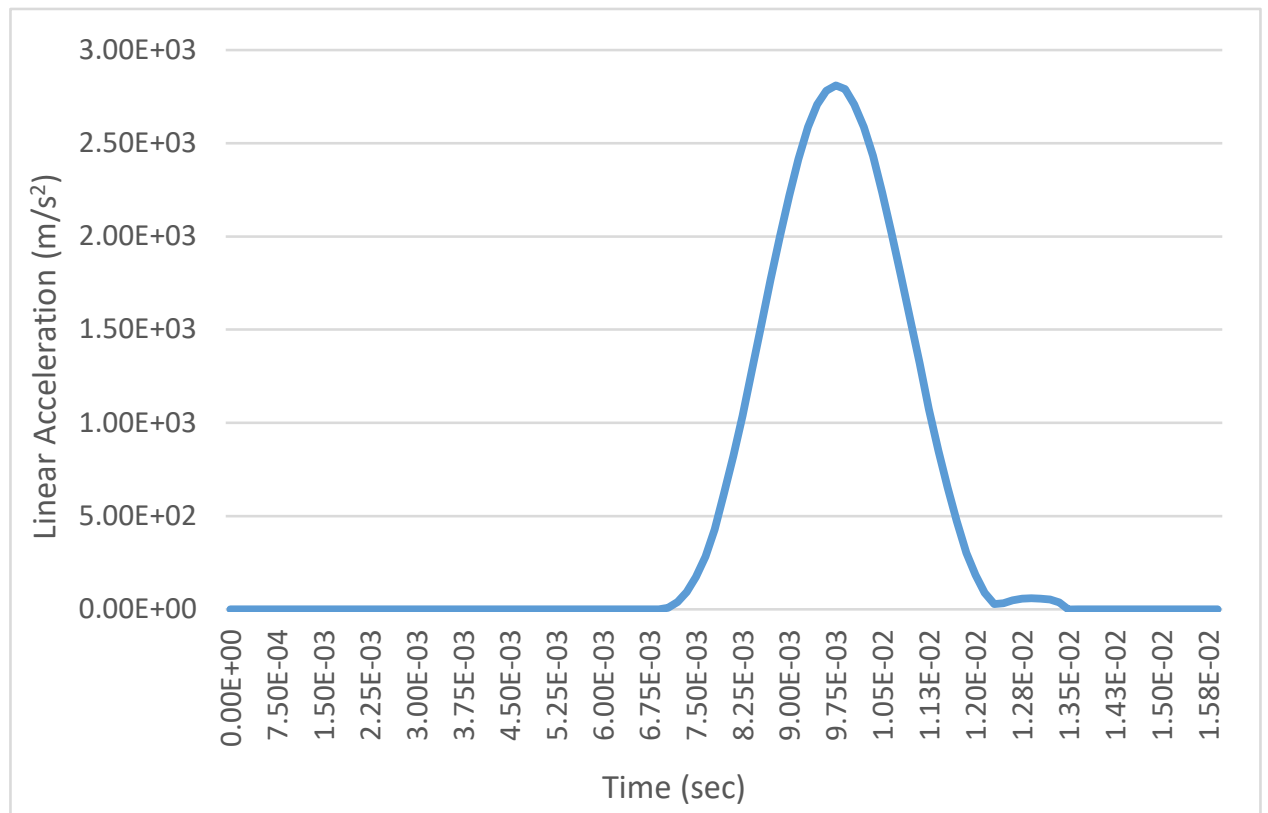

Figure A.4. Linear Acceleration time history of NOCSAE Headform for 3 ft. Drop Height 


\section{A.3. Frontal I mpact - 4ft. Drop Height:}

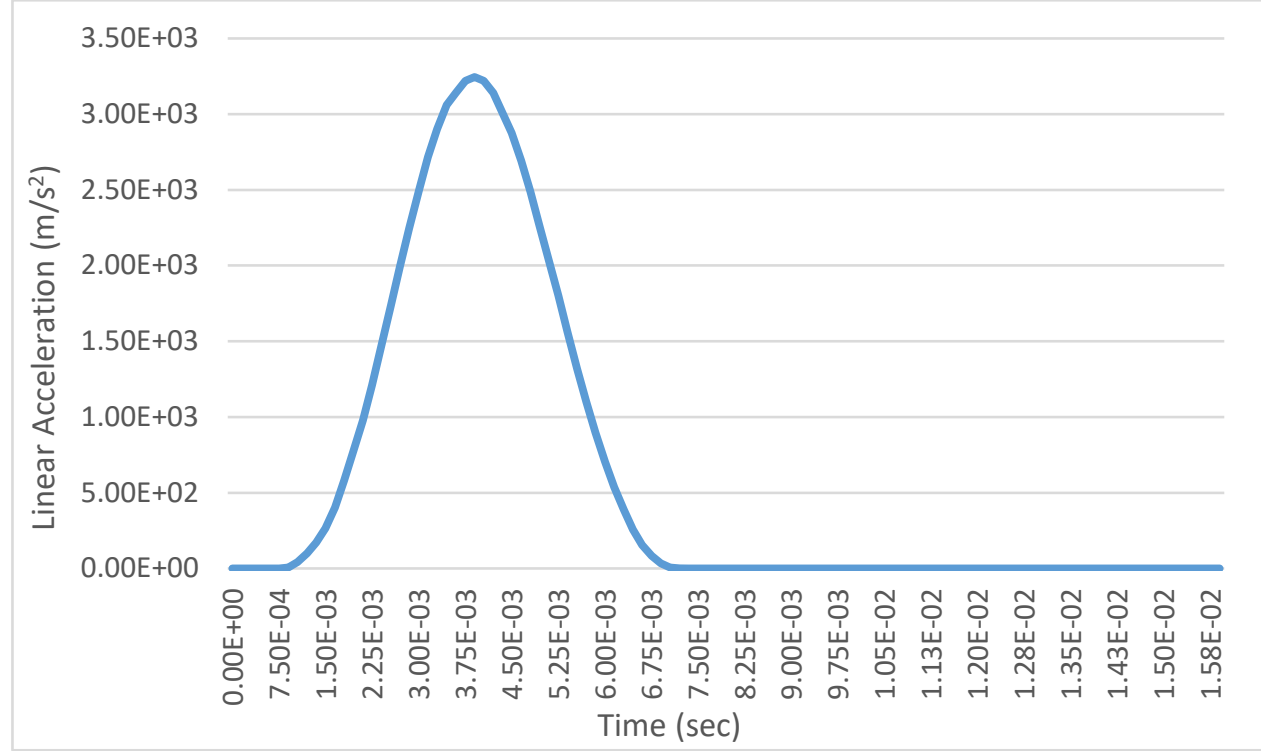

Figure A.5. Linear Acceleration time history of Human Head model for 4ft. Drop Height

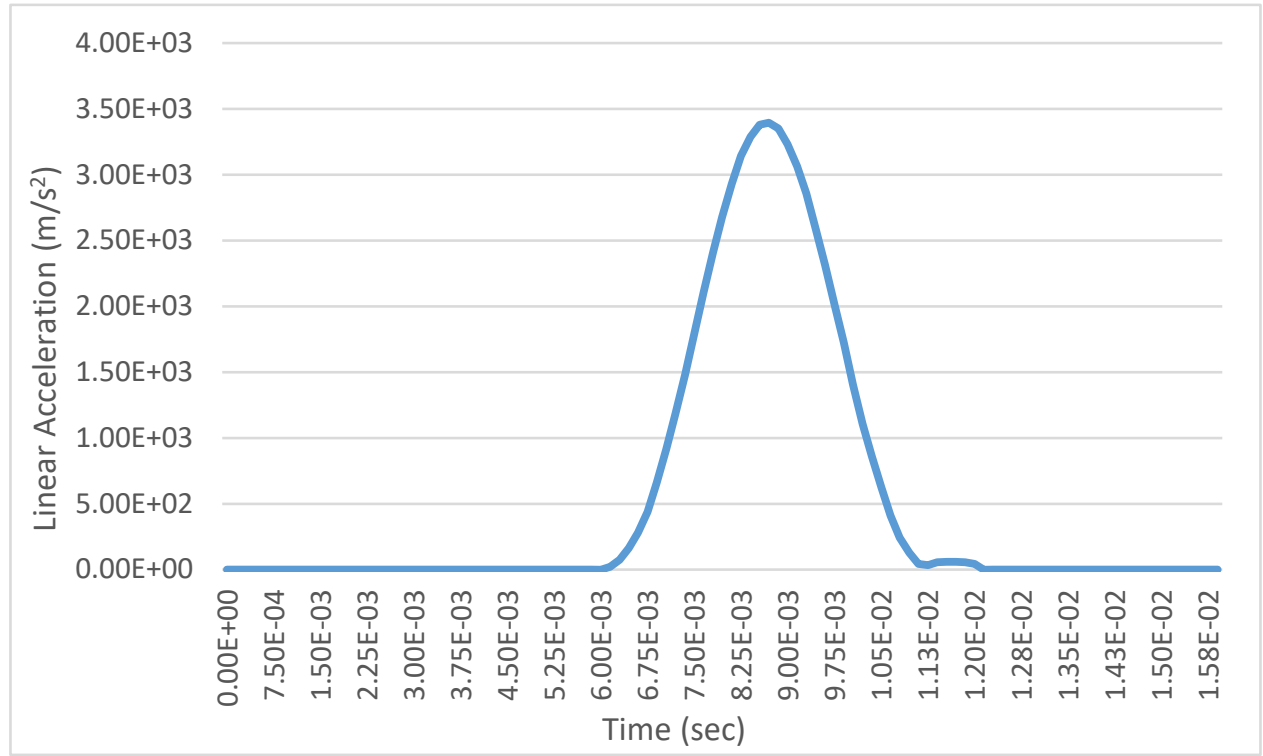

Figure A.6. Linear Acceleration time history of NOCSAE Headform for 4ft. Drop Height 


\section{A.4. Frontal I mpact - 5ft. Drop Height:}

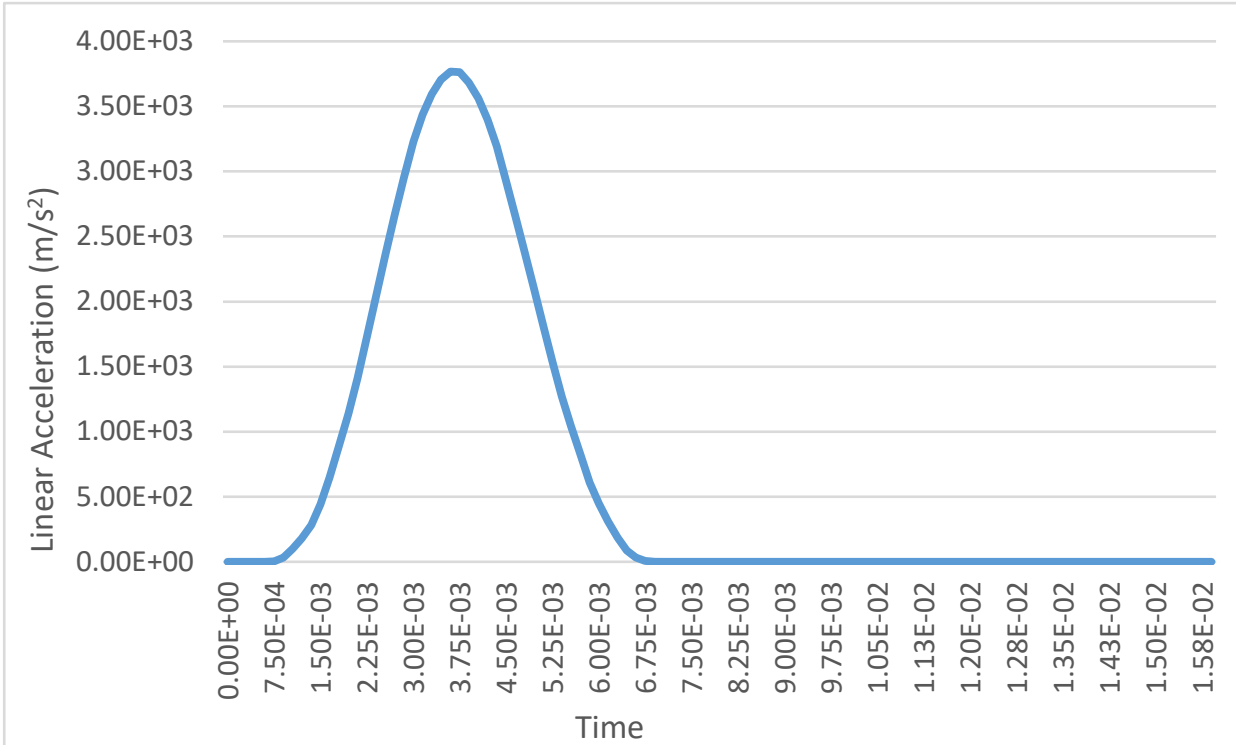

Figure A.7. Linear Acceleration time history of Human Head model for 5ft. Drop Height

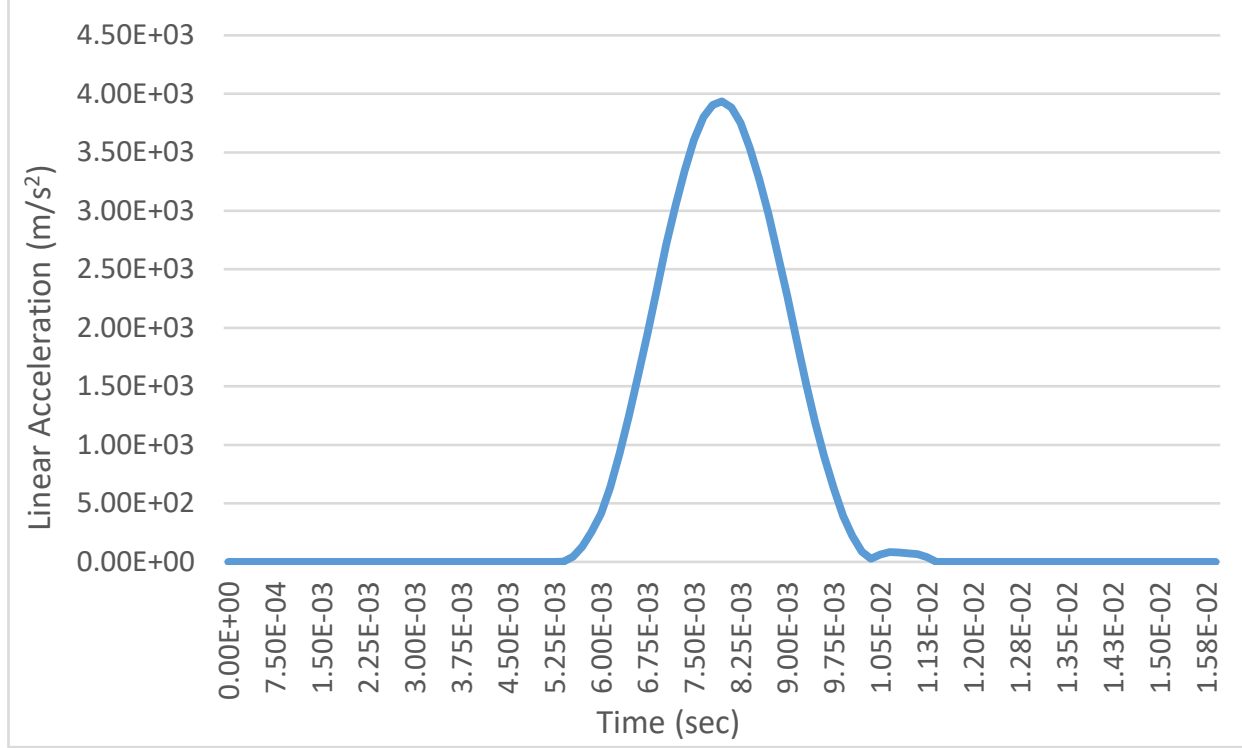

Figure A.8. Linear Acceleration time history of NOCSAE Headform for 5ft. Drop Height 


\section{A.5. Lateral I mpact - 2ft. Drop Height:}

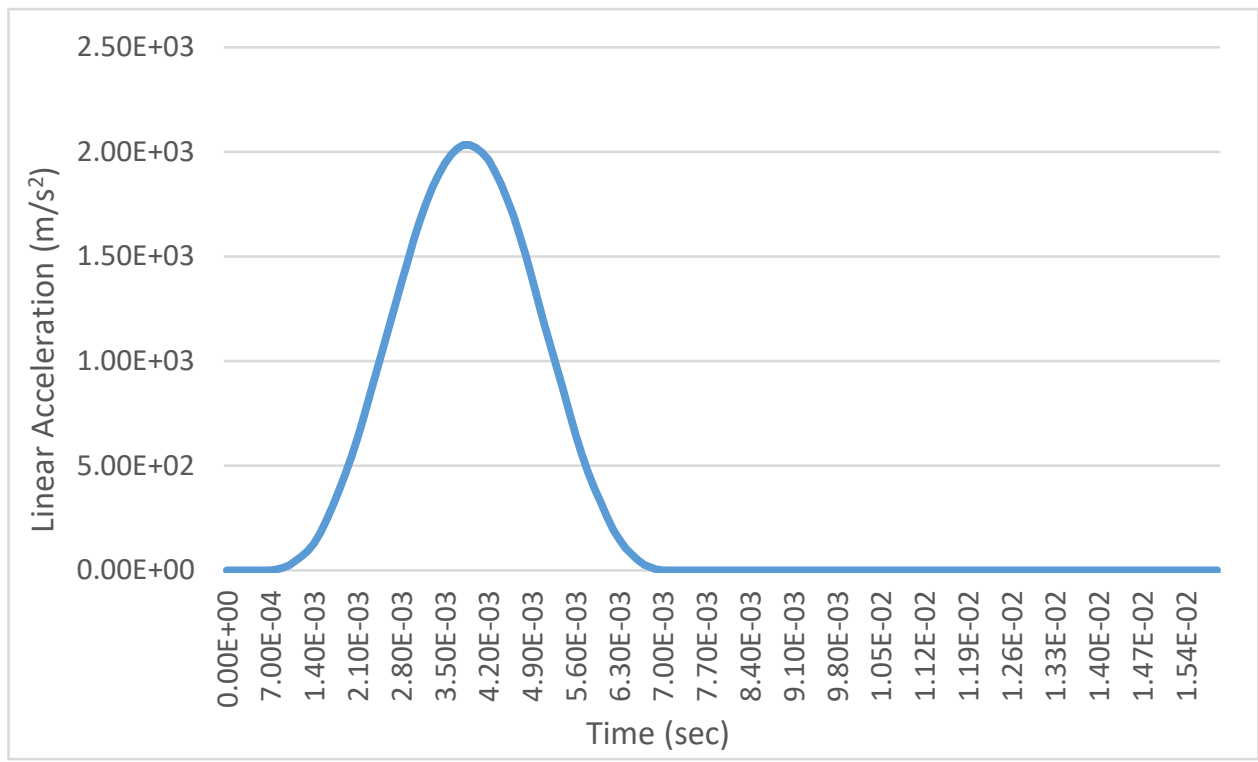

Figure A.9. Linear Acceleration time history of Human Head model for 2ft. Drop Height

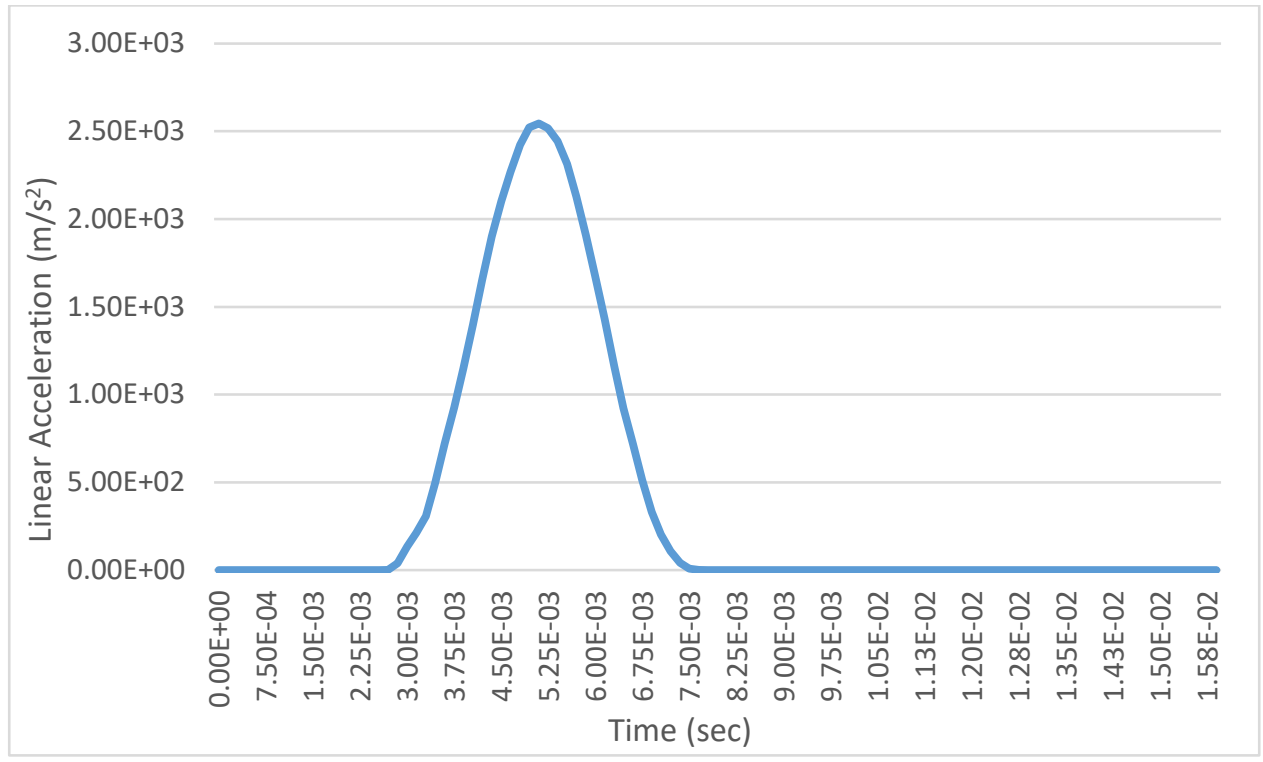

Figure A.10. Linear Acceleration time history of NOCSAE Headform for 2ft. Drop Height 


\section{A.6. Lateral I mpact - 3ft. Drop Height:}

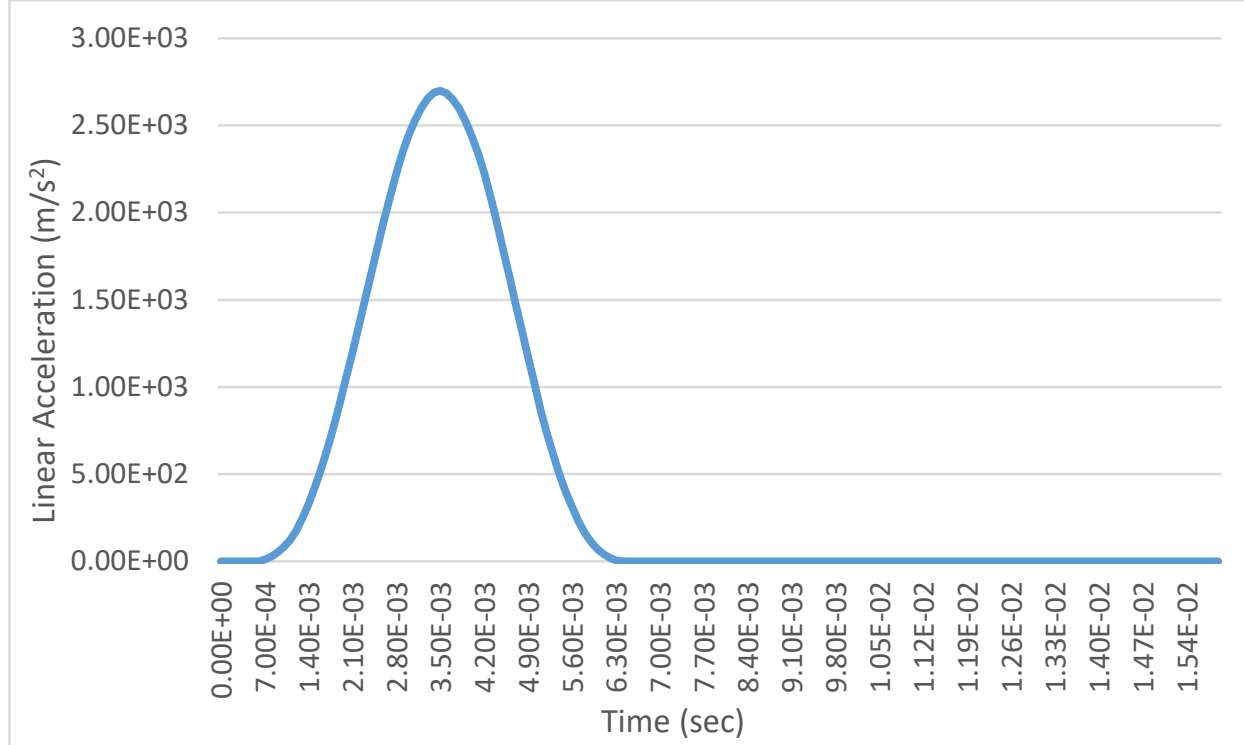

Figure A.11. Linear Acceleration time history of Human Head model for 3ft. Drop Height

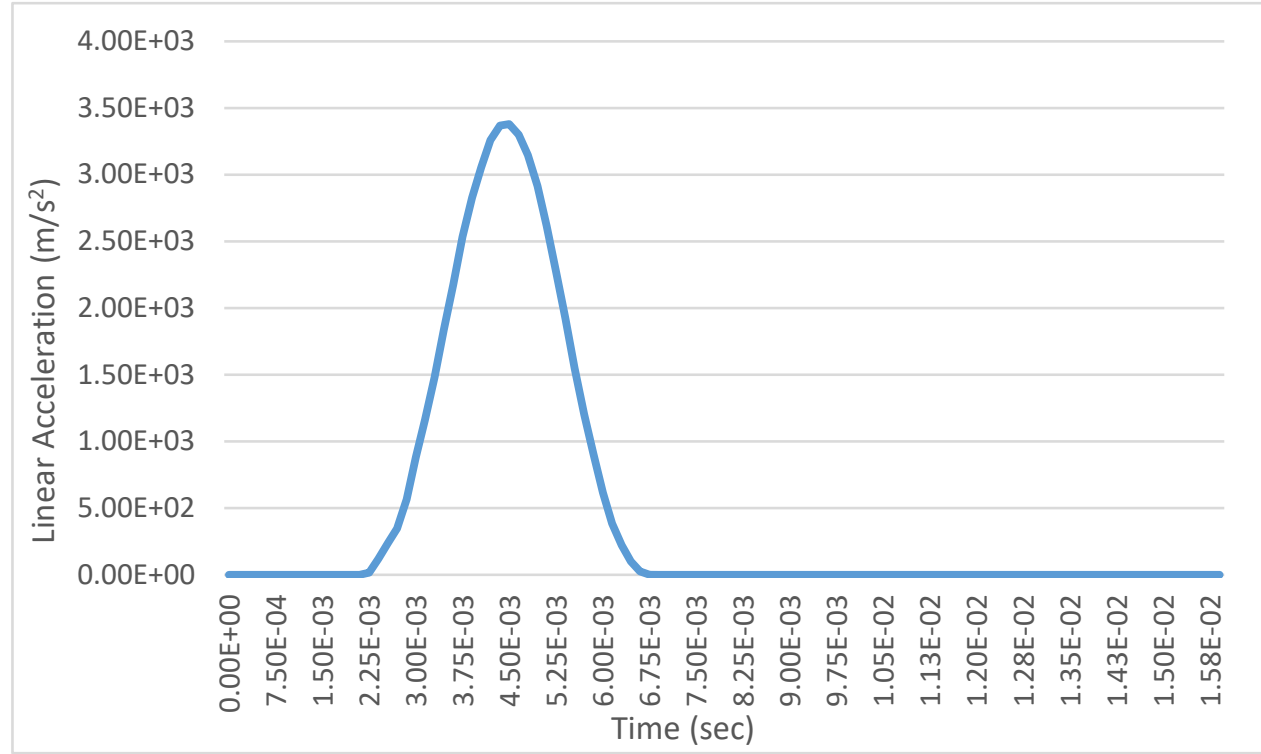

Figure A.12. Linear Acceleration time history of NOCSAE Headform for 3ft. Drop Height 


\section{A.7. Lateral I mpact - 4ft. Drop Height:}

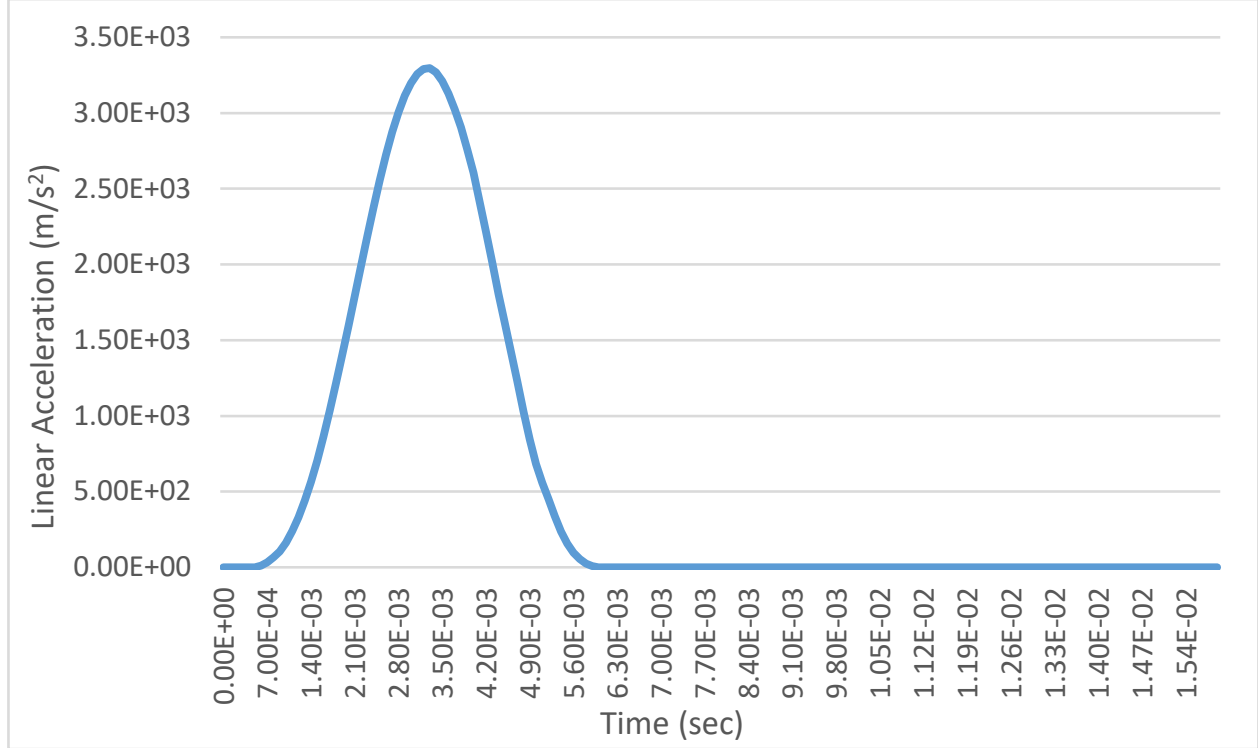

Figure A.13. Linear Acceleration time history of Human Head model for 4ft. Drop Height

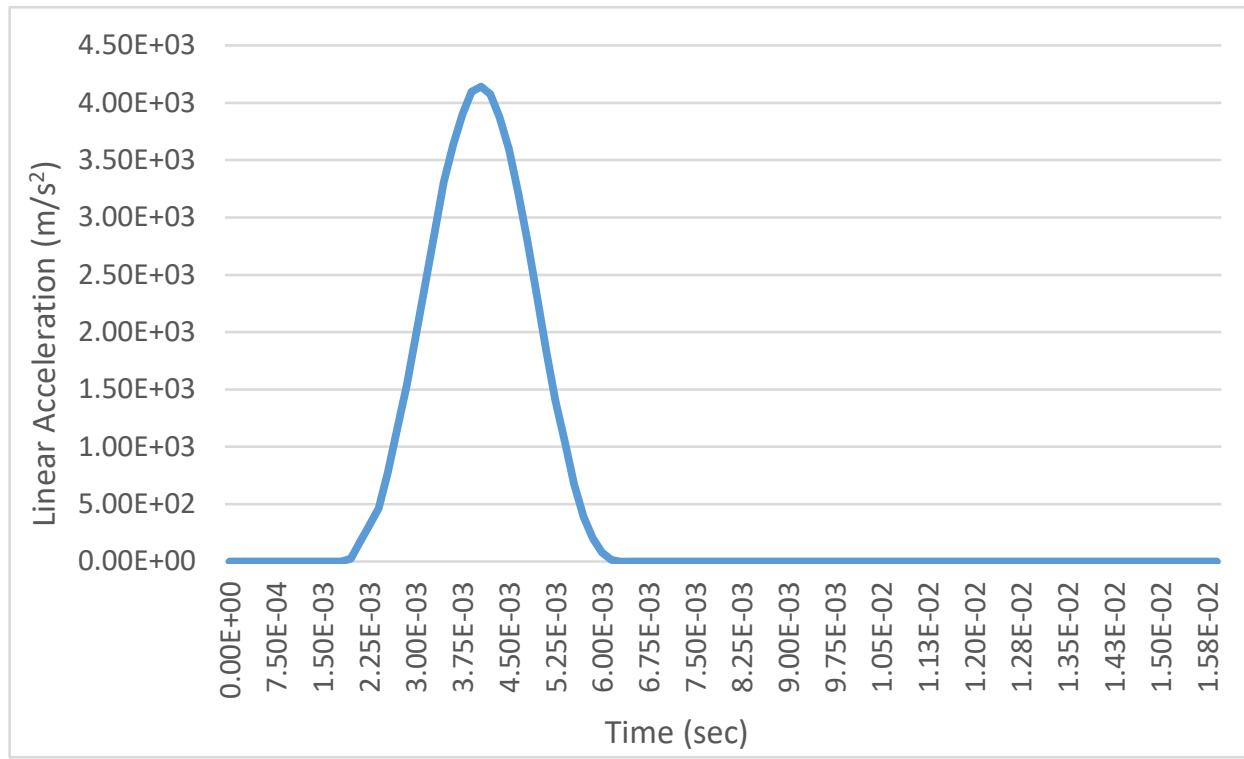

Figure A.14. Linear Acceleration time history of NOCSAE Headform for 4ft. Drop Height 


\section{A.8. Lateral I mpact - 5ft. Drop Height:}

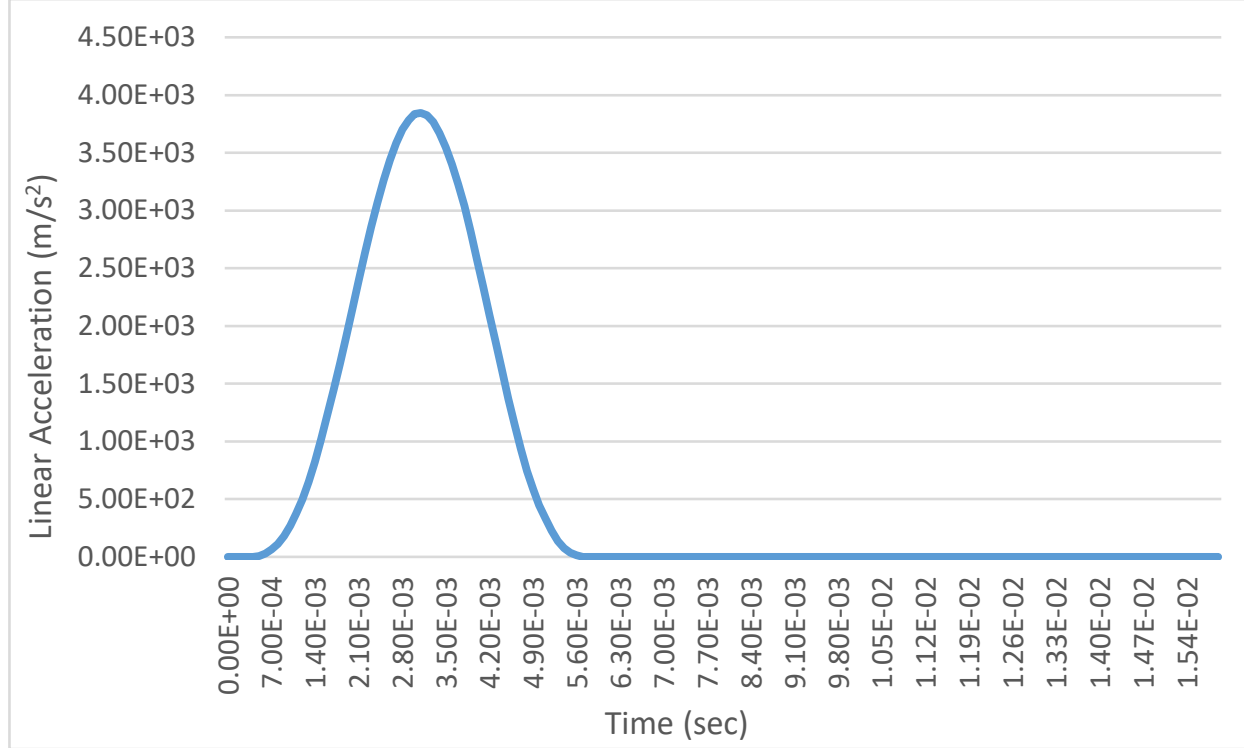

Figure A.15. Linear Acceleration time history of Human Head model for 5ft. Drop Height

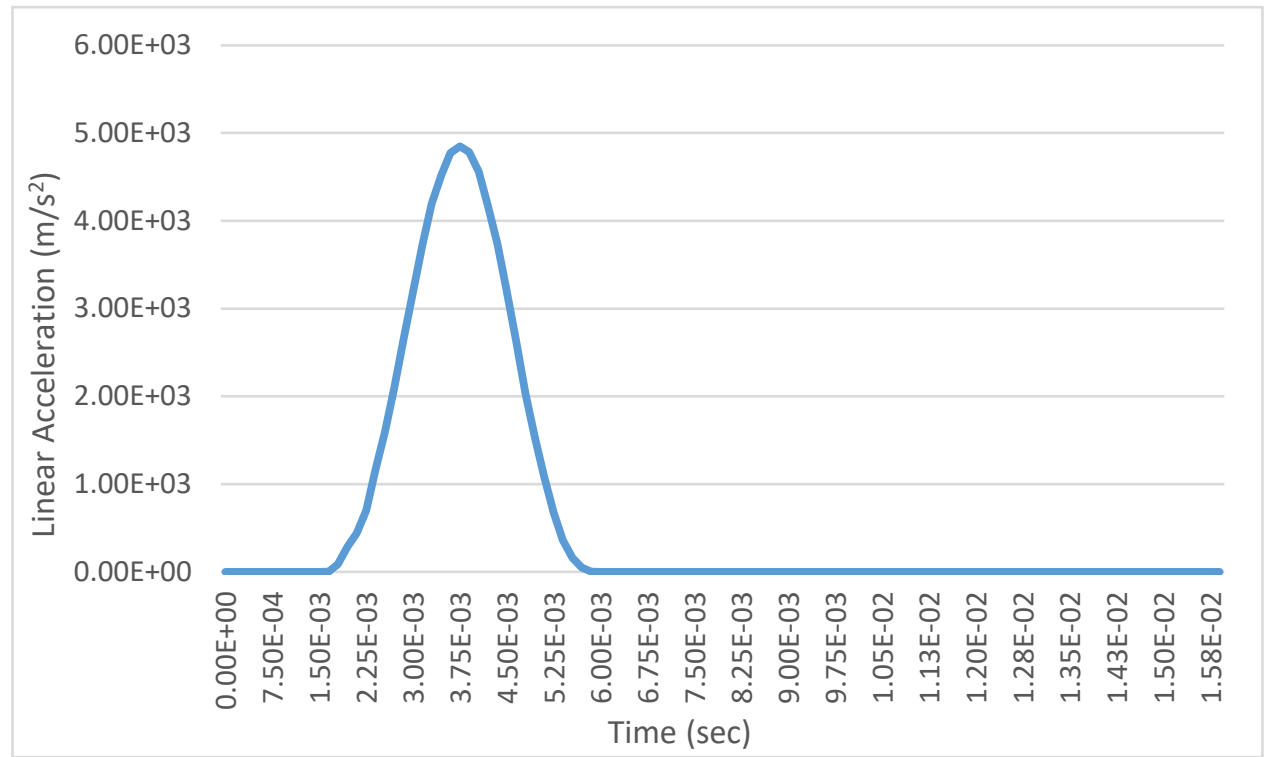

Figure A.16. Linear Acceleration time history of NOCSAE Headform for 5ft. Drop Height 


\section{A.9. Posterior I mpact - 2ft. Drop Height:}

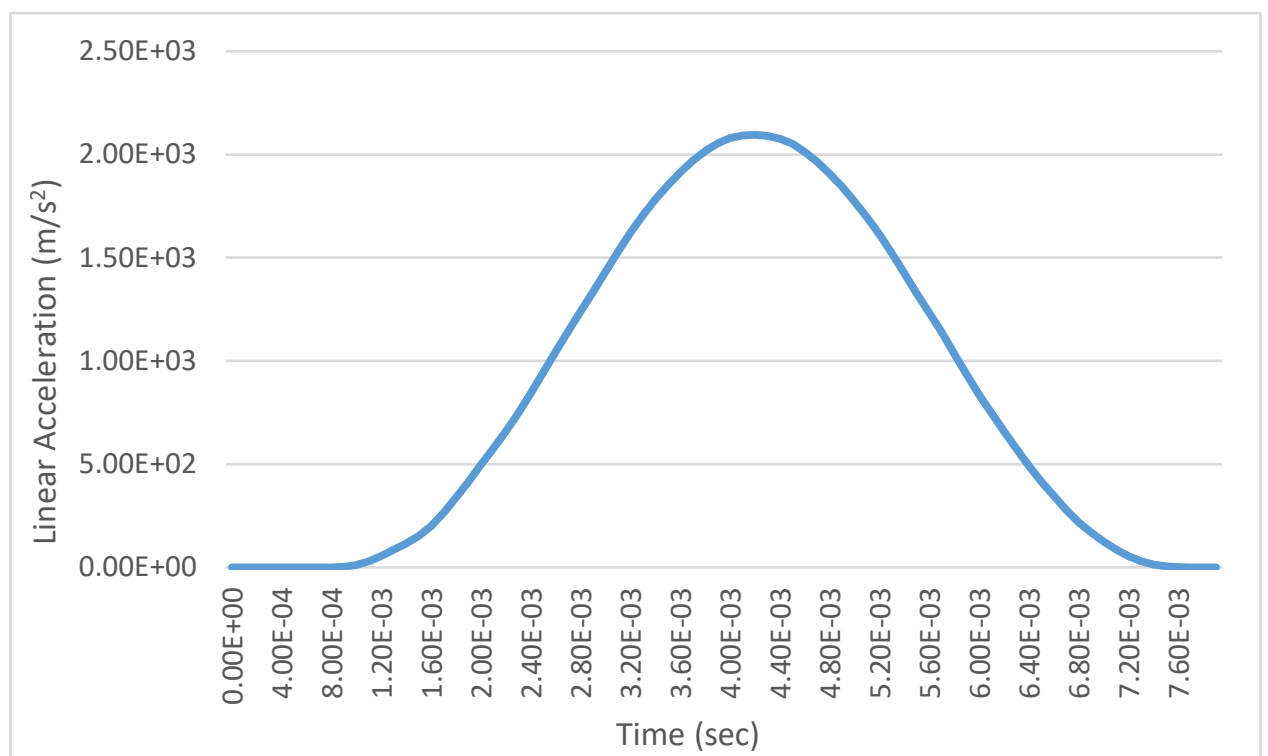

Figure A.17. Linear Acceleration time history of Human Head model for 2ft. Drop Height

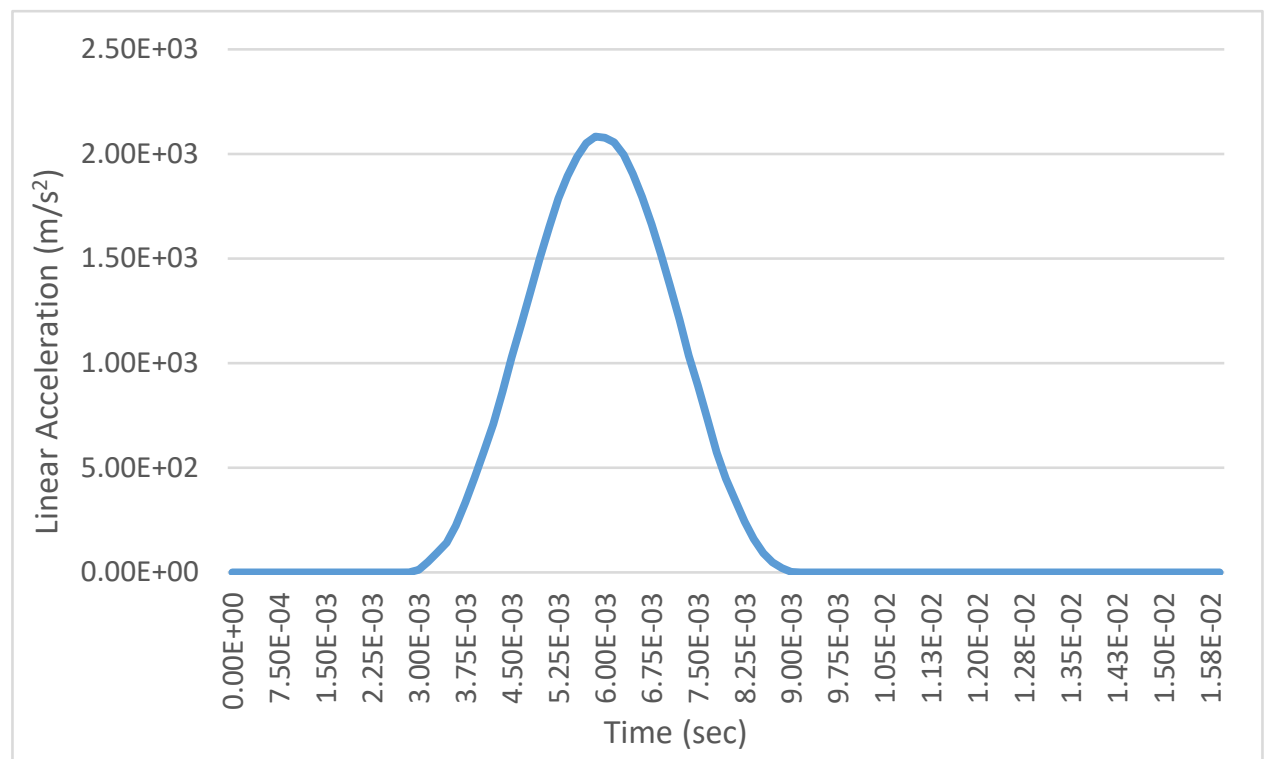

Figure A.18. Linear Acceleration time history of NOCSAE Headform for 2ft. Drop Height 


\section{A.10. Posterior I mpact - 3ft. Drop Height:}

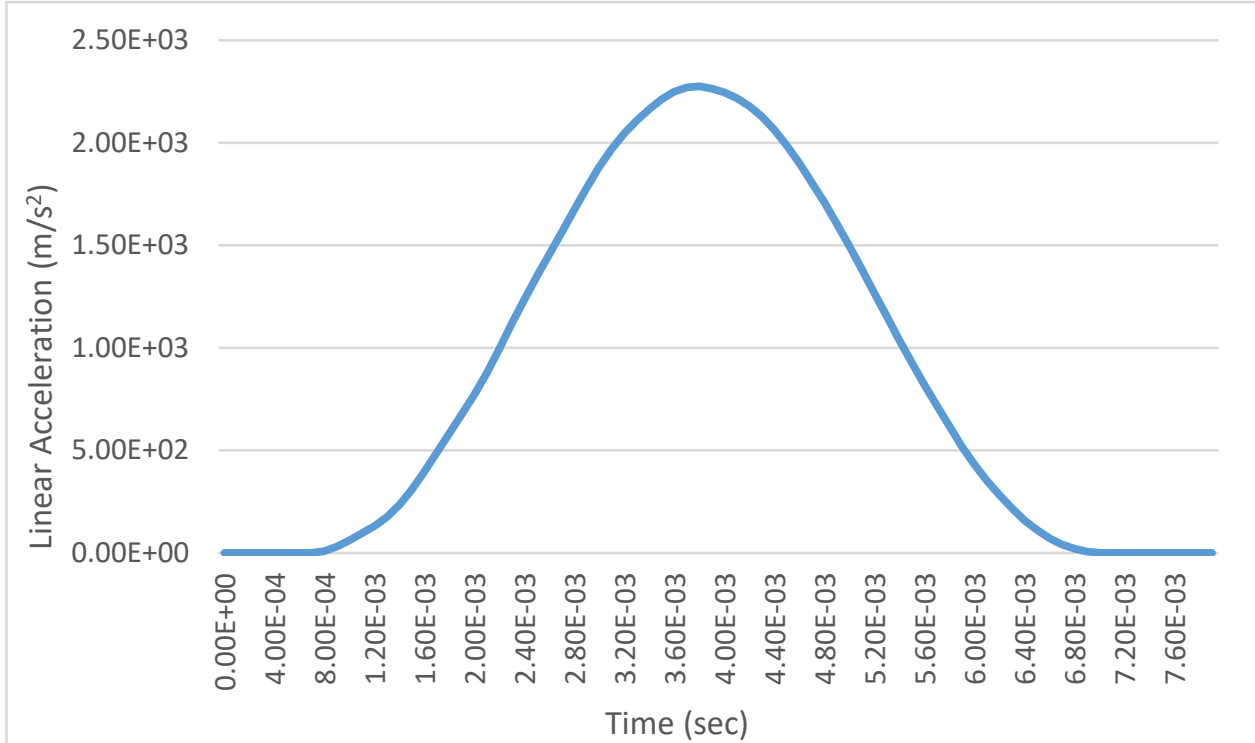

Figure A.19. Linear Acceleration time history of Human Head model for 3ft. Drop Height

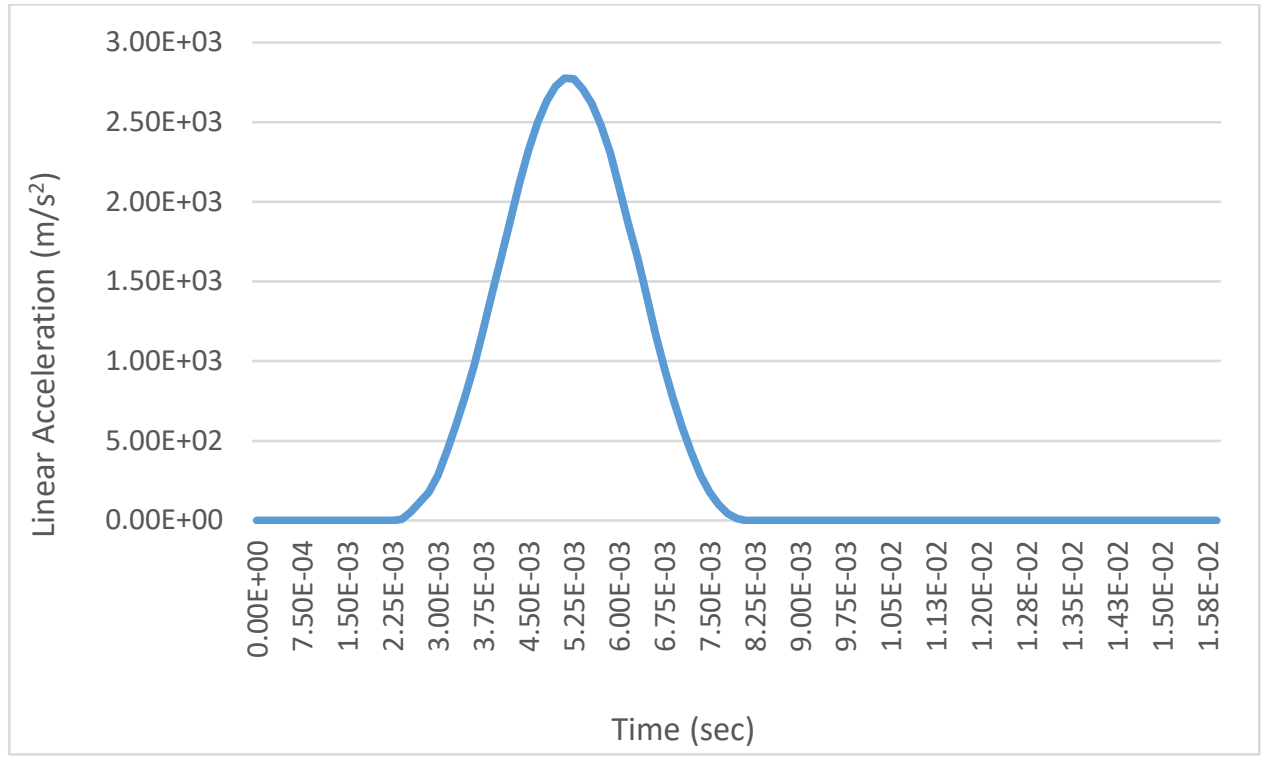

Figure A.20. Linear Acceleration time history of NOCSAE Headform for 3ft. Drop Height 


\section{A.11. Posterior I mpact - 4ft. Drop Height:}

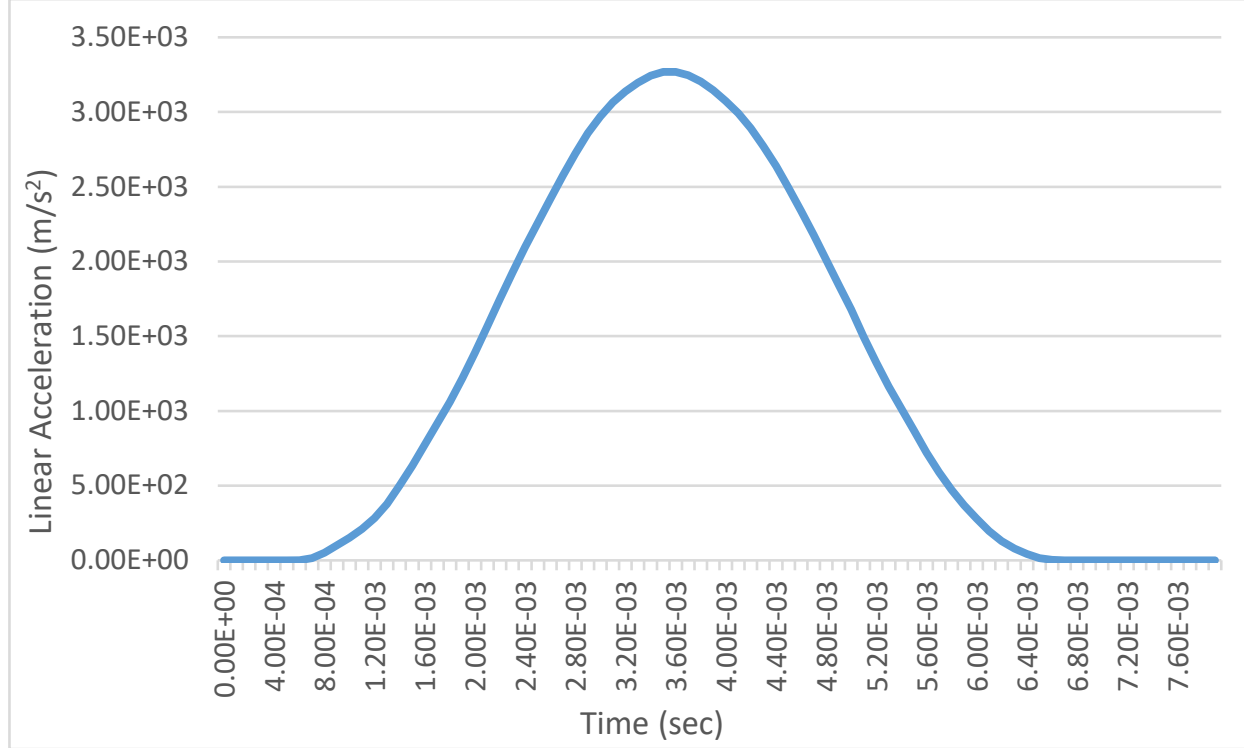

Figure A.21. Linear Acceleration time history of Human Head model for 4ft. Drop Height

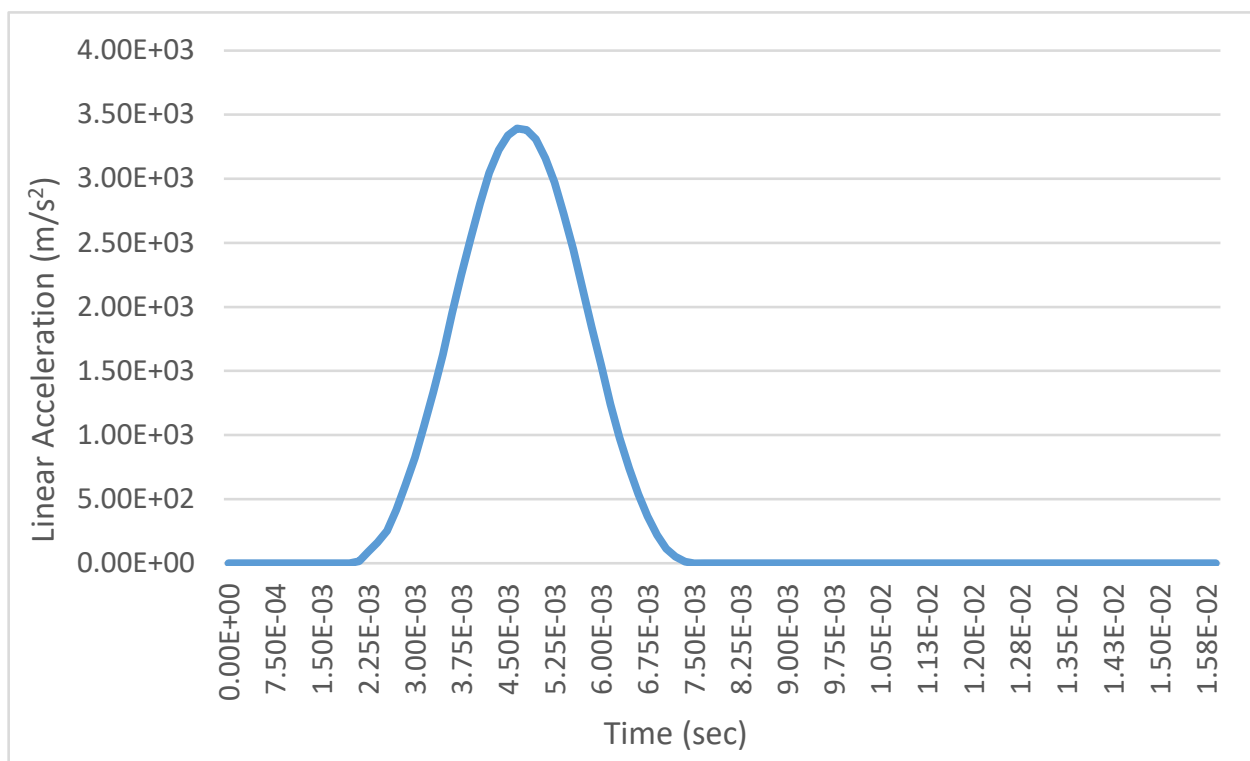

Figure A.22. Linear Acceleration time history of NOCSAE Headform for 4ft. Drop Height 


\section{A.12. Posterior I mpact - 5ft. Drop Height:}

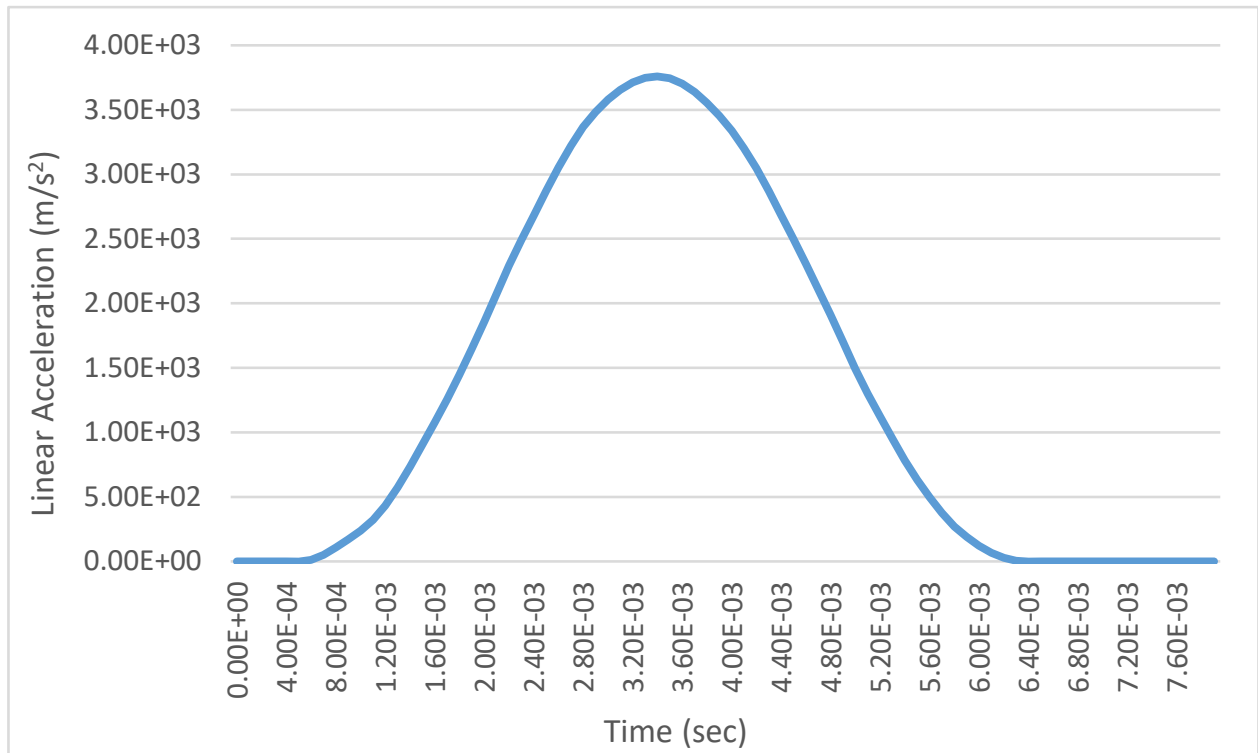

Figure A.23. Linear Acceleration time history of Human Head model for 5ft. Drop Height

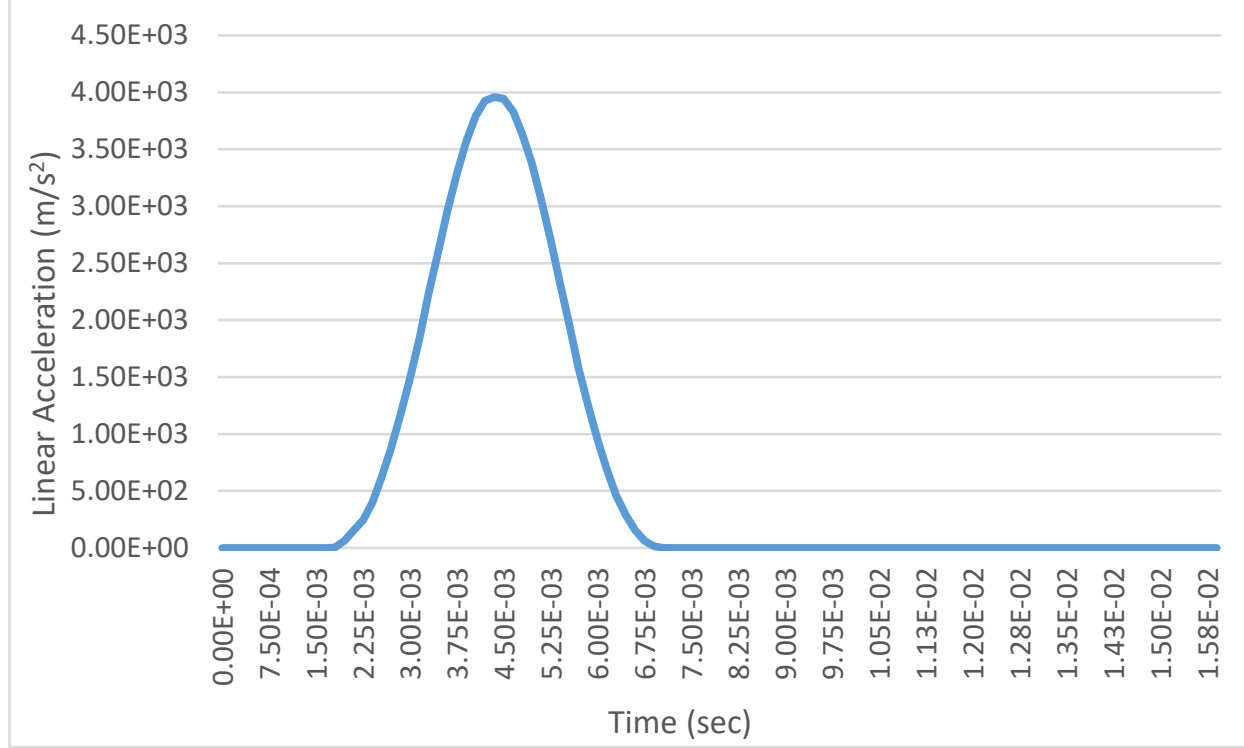

Figure A.24. Linear Acceleration time history of NOCSAE Headform for 5ft. Drop Height 


\section{A.13. Superior I mpact - 2ft. Drop Height:}

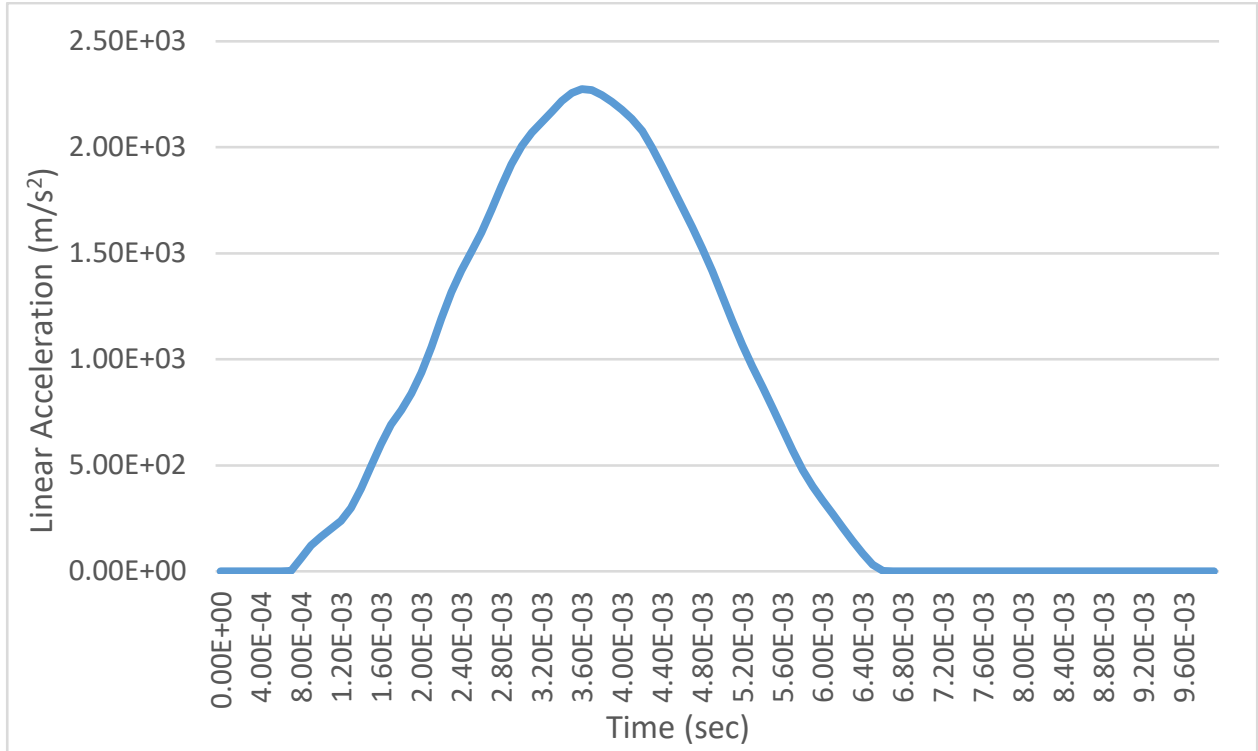

Figure A.25. Linear Acceleration time history of Human Head model for 2ft. Drop Height

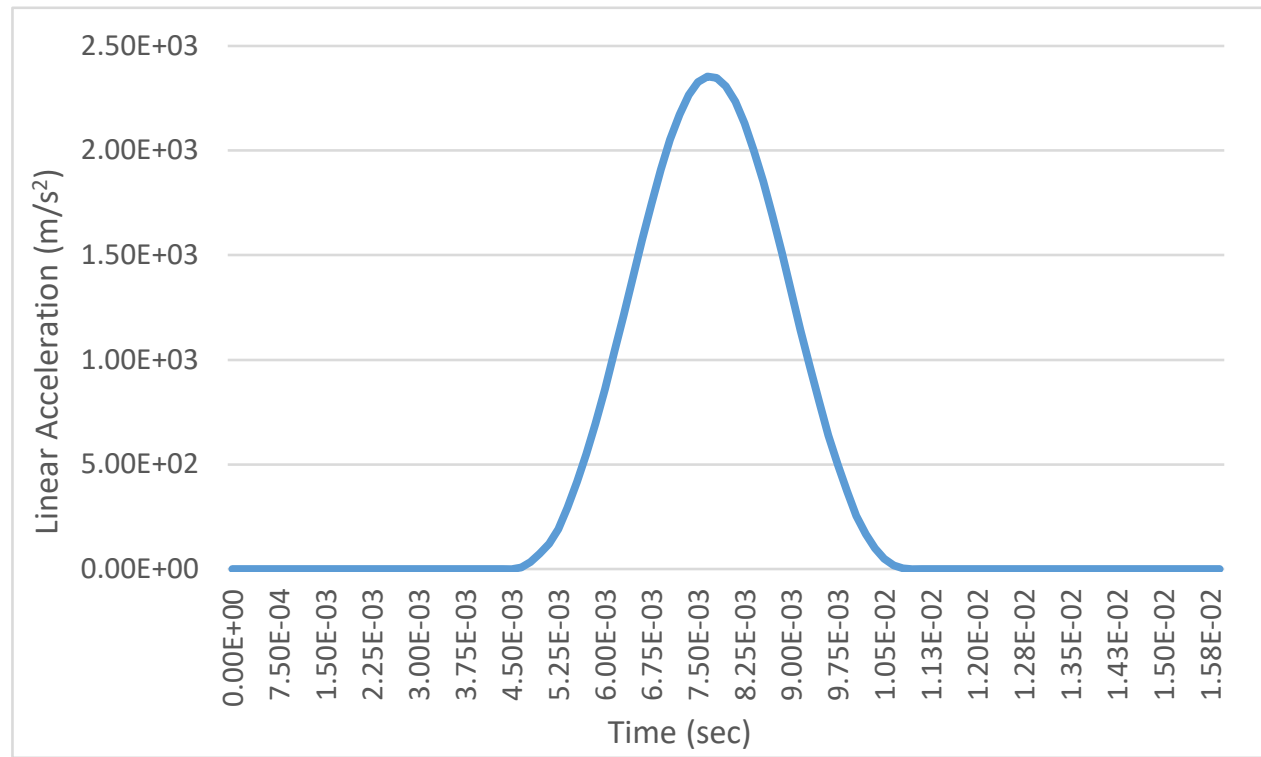

Figure A.26. Linear Acceleration time history of NOCSAE Headform for 2ft. Drop Height 


\section{A.14. Superior I mpact - 3ft. Drop Height:}

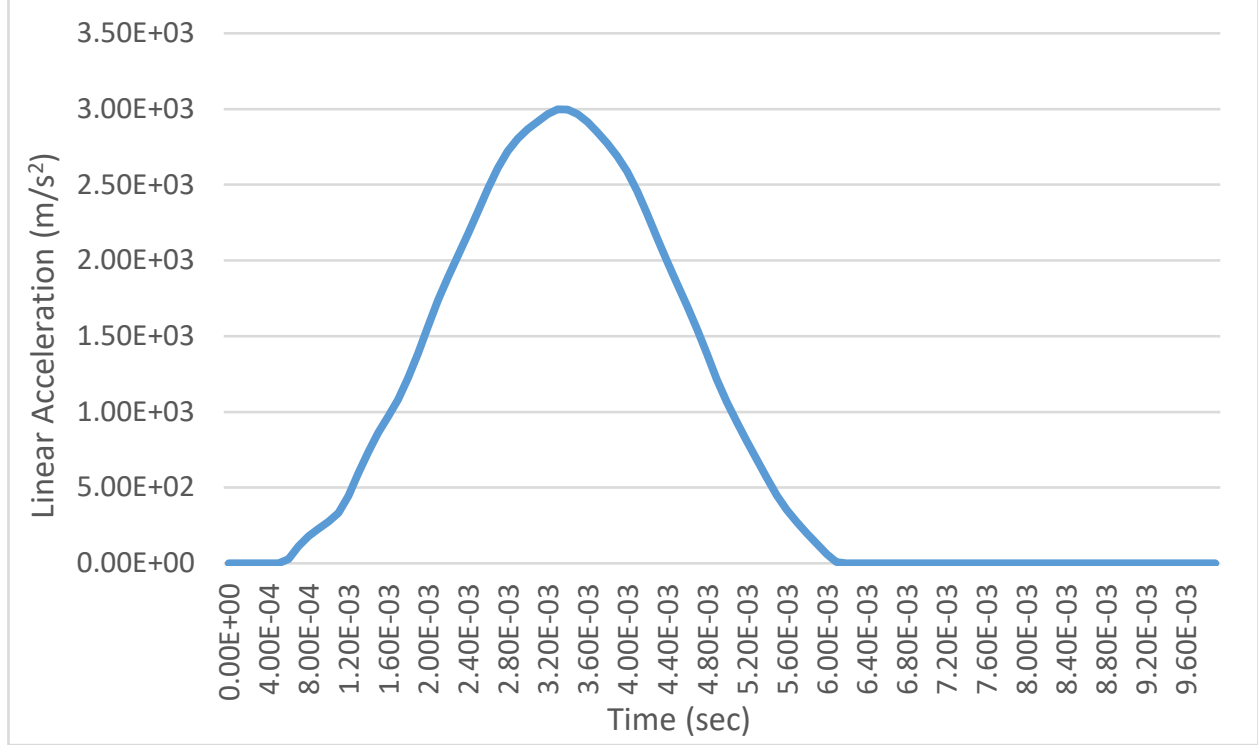

Figure A.27. Linear Acceleration time history of Human Head model for 3ft. Drop Height

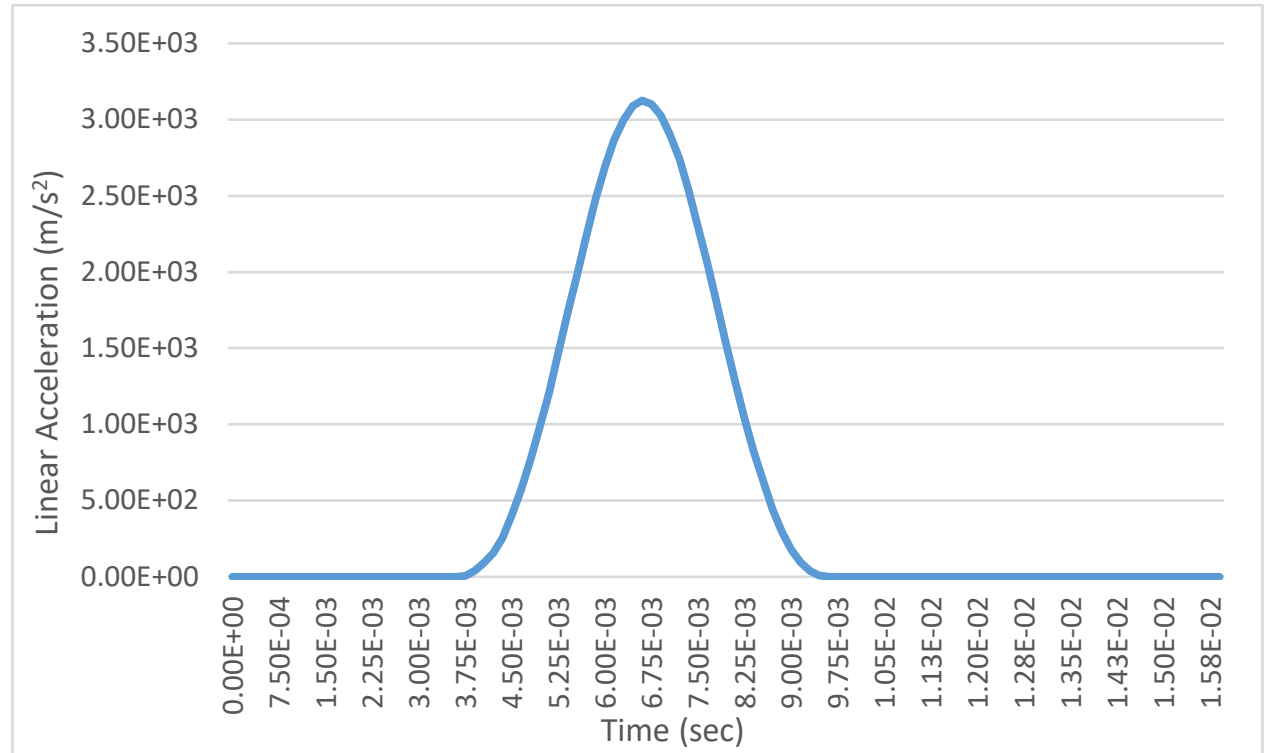

Figure A.28. Linear Acceleration time history of NOCSAE Headform for 3ft. Drop Height 


\section{A.15. Superior I mpact - 4ft. Drop Height:}

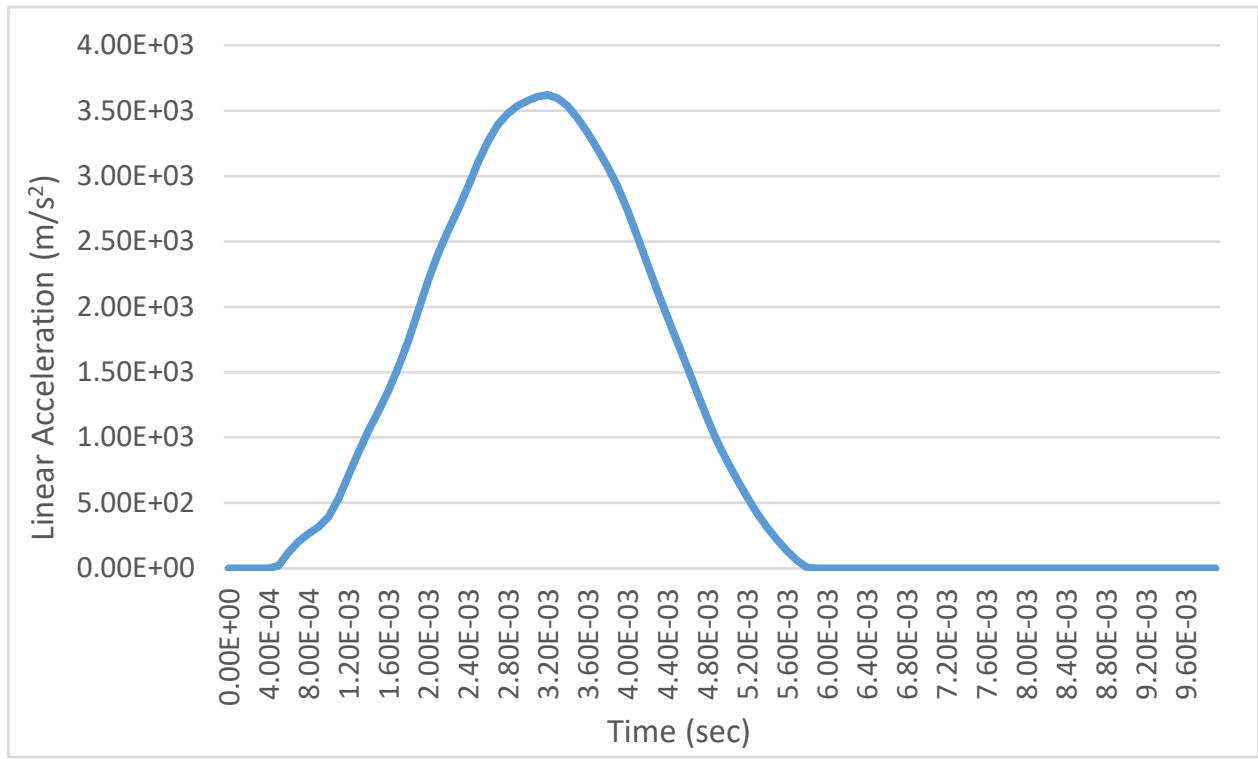

Figure A.29. Linear Acceleration time history of Human Head model for 4ft. Drop Height

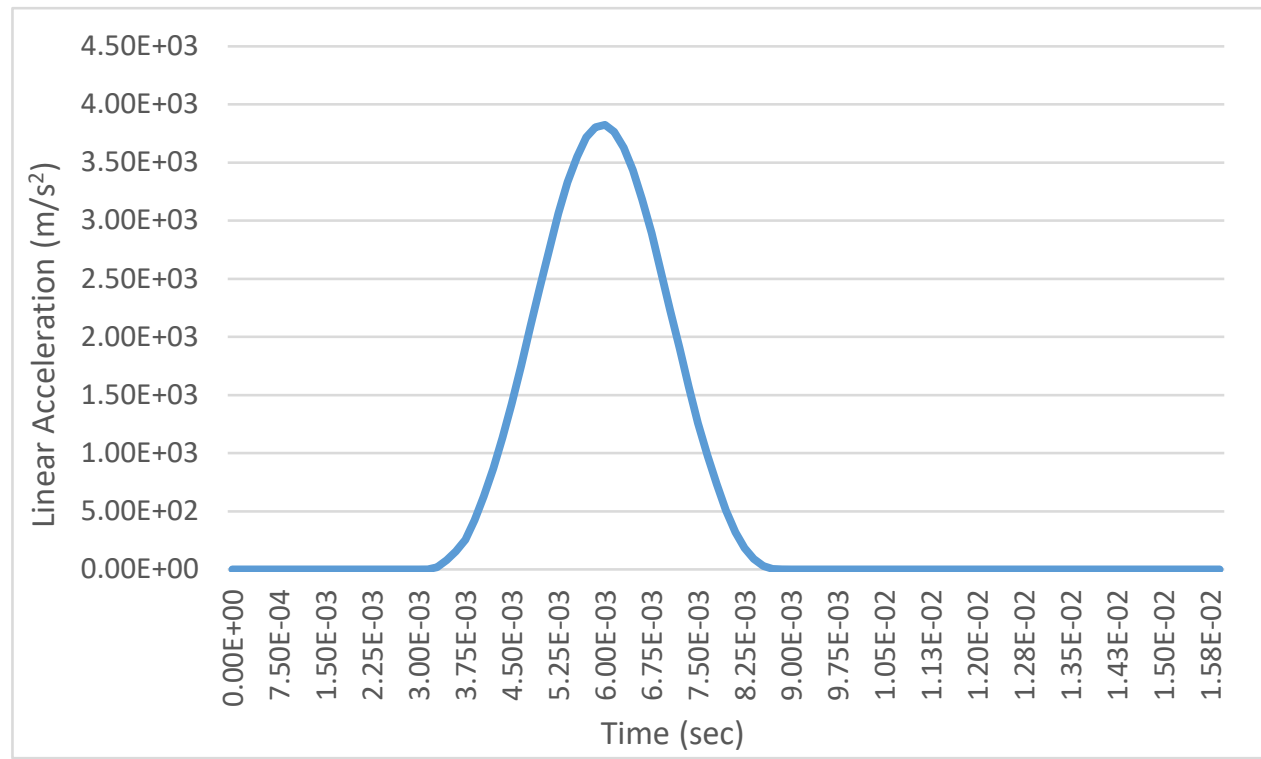

Figure A.30. Linear Acceleration time history of NOCSAE Headform for 4ft. Drop Height 


\section{A.16. Superior I mpact - 5ft. Drop Height:}

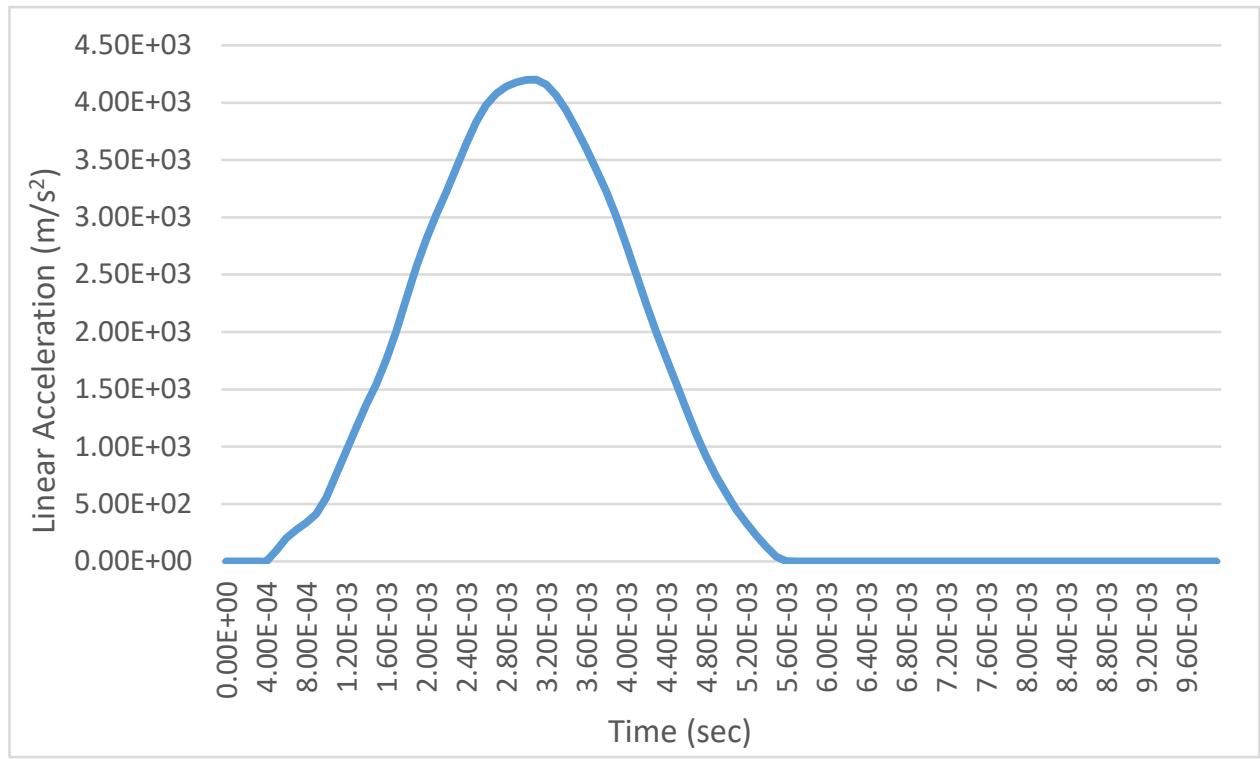

Figure A.31. Linear Acceleration time history of Human Head model for 5ft. Drop Height

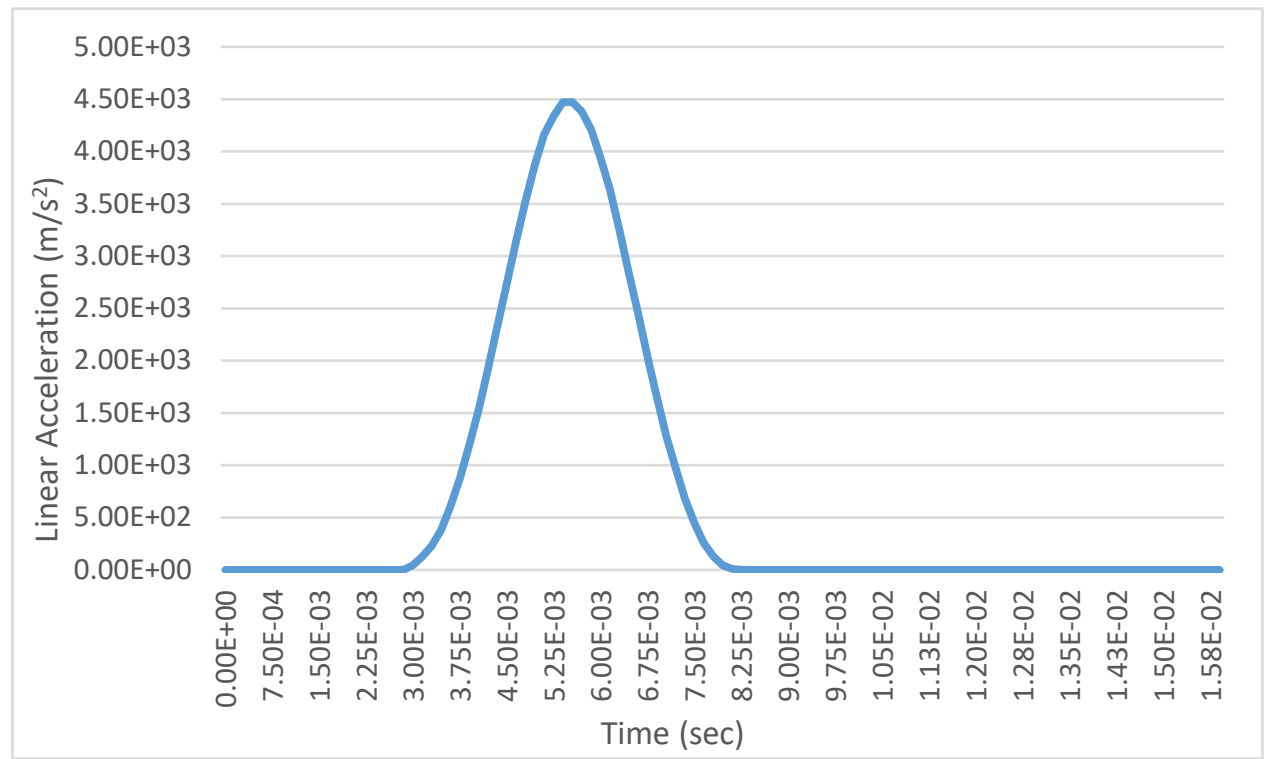

Figure A.32. Linear Acceleration time history of NOCSAE Headform for 5ft. Drop Height 


\section{Appendix B Angular Acceleration Time History Plots}

\section{B.1. Frontal I mpact- 2ft. Drop Height:}

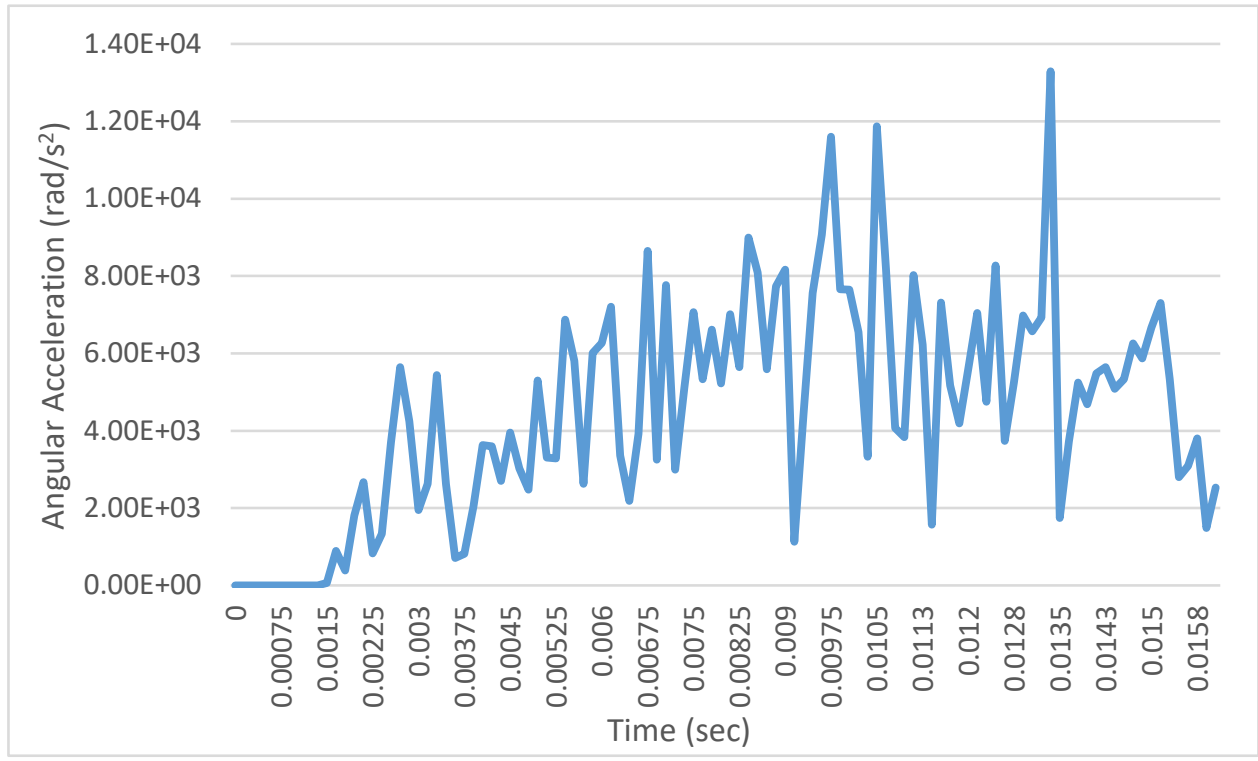

Figure B.1. Angular Acceleration time history of Human Head model for 2ft. Drop Height

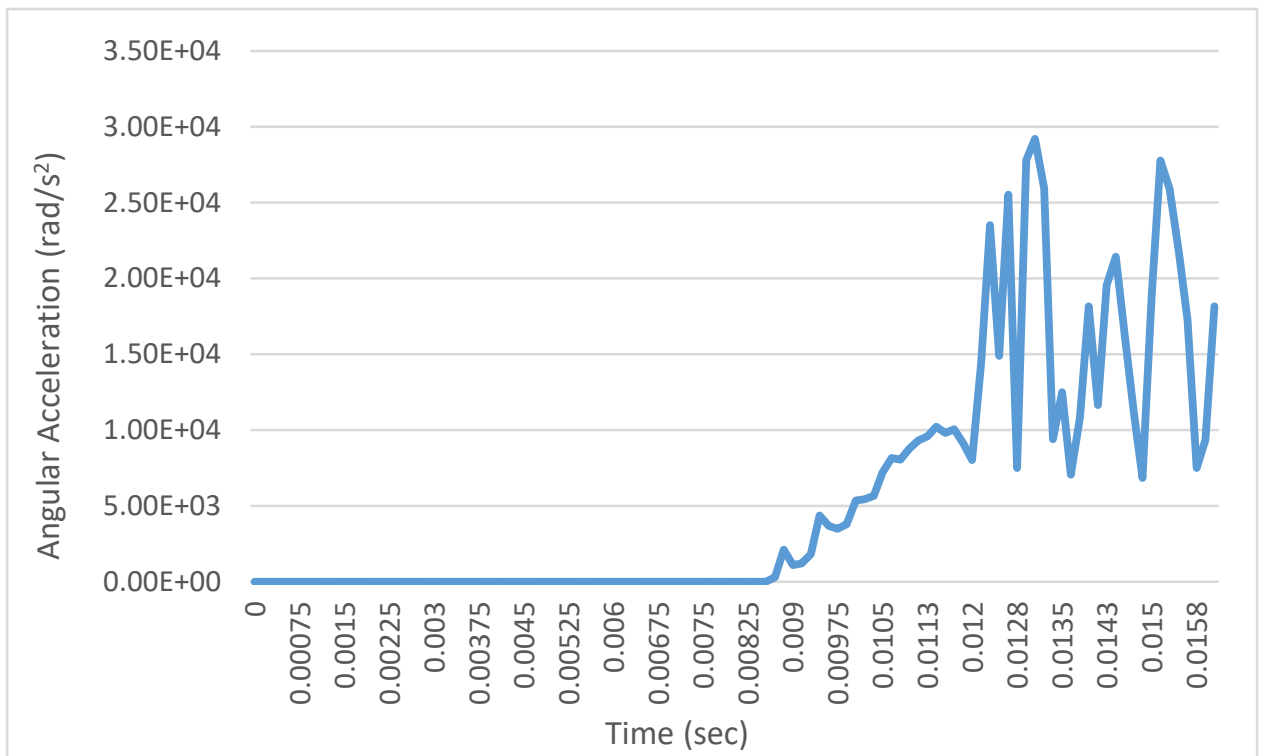

Figure B.2. Angular Acceleration time history of NOCSAE Headform for 2ft. Drop Height 


\section{B.2. Frontal I mpact - 3ft. Drop Height:}

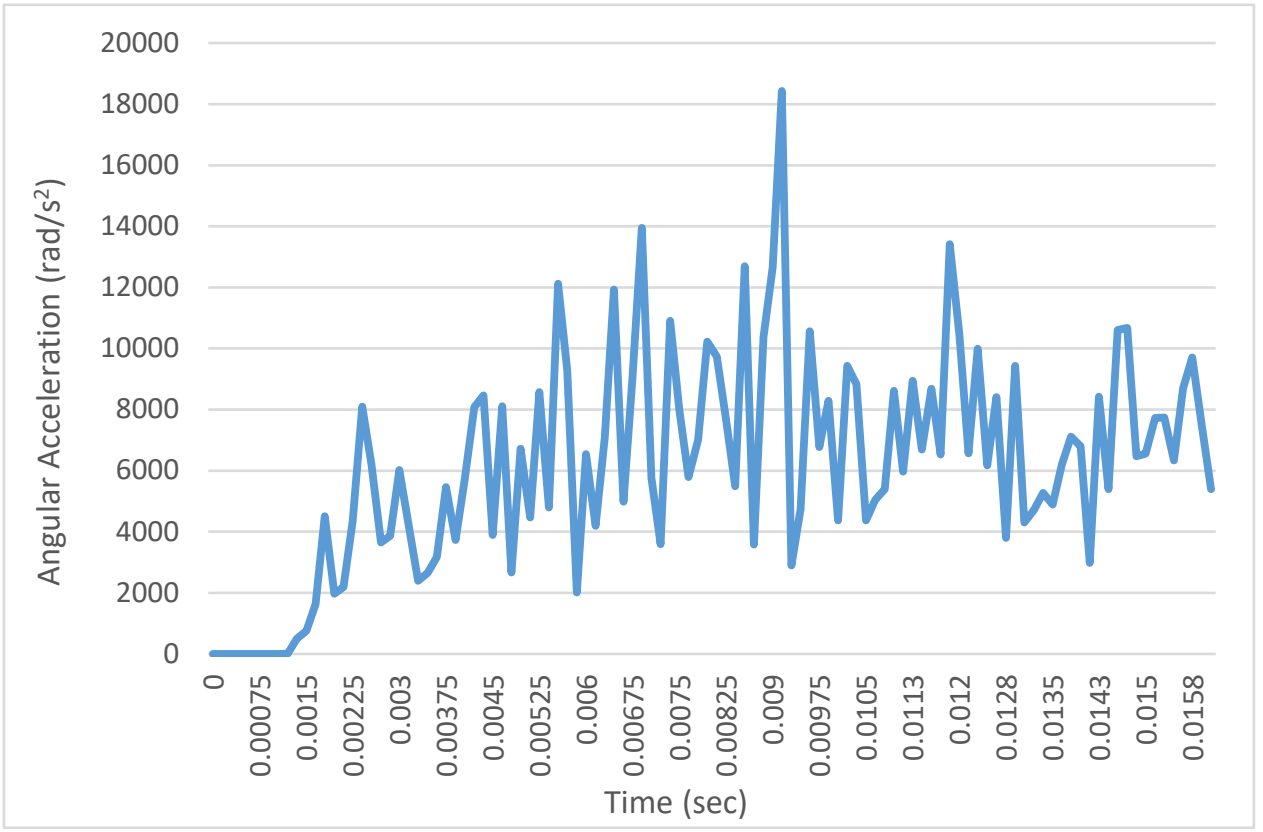

Figure B.3. Angular Acceleration time history of Human Head model for 3ft. Drop Height

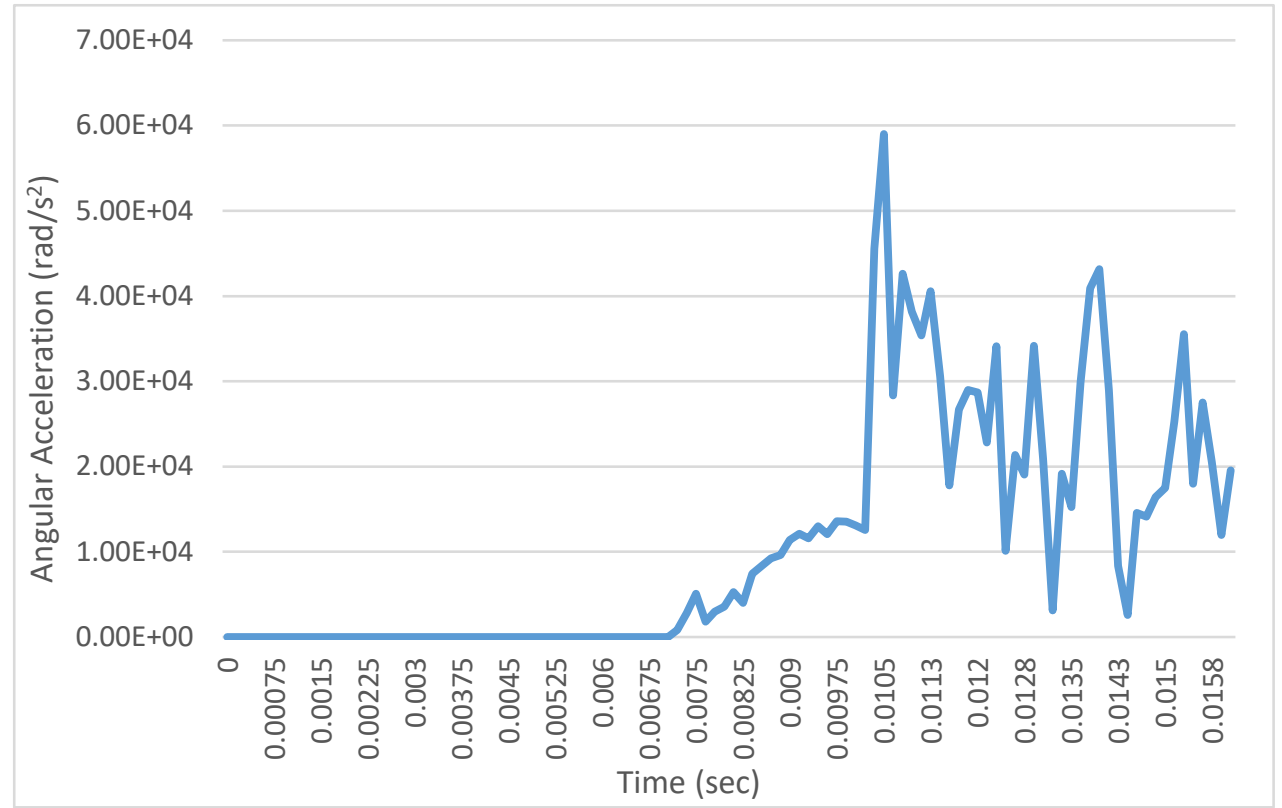

Figure B.4. Angular Acceleration time history of NOCSAE Headform for 3ft. Drop Height 


\section{B.3. Frontal I mpact - 4ft. Drop Height:}

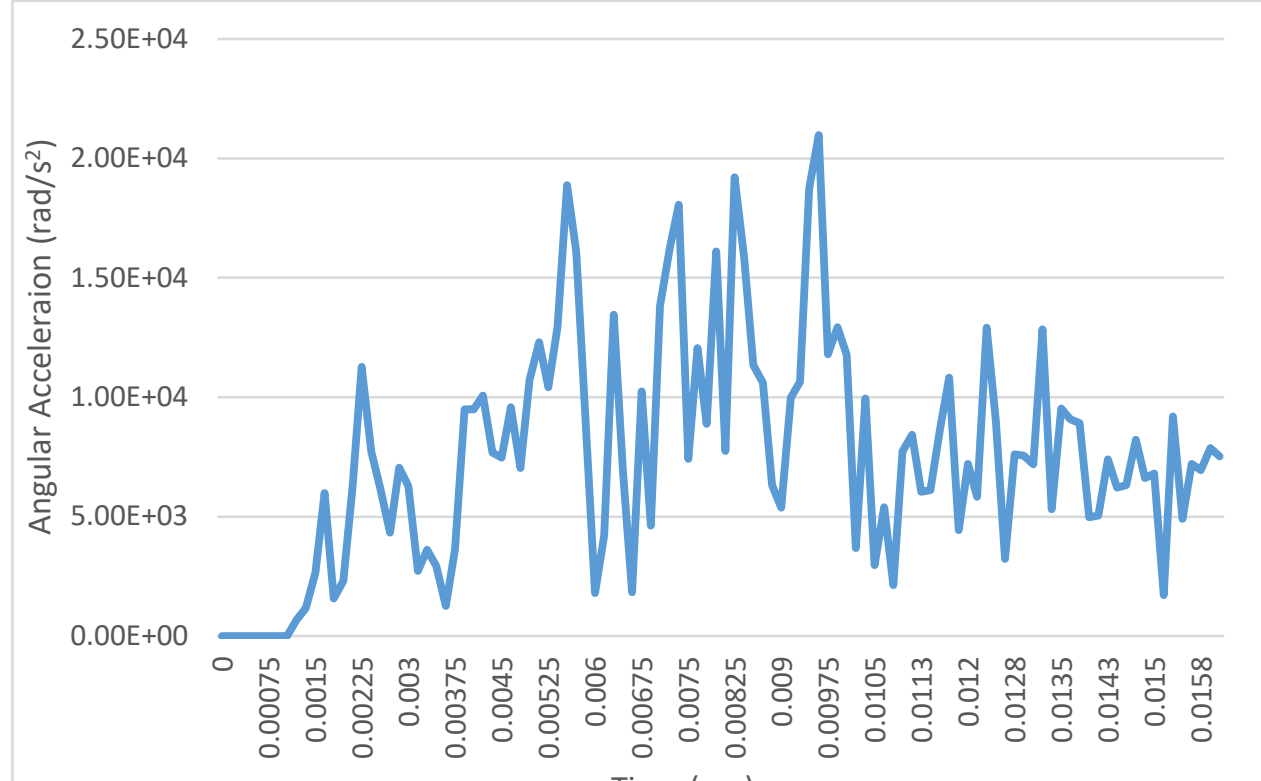

Figure B.5. Angular Acceleration time history of Human Head model for 4ft. Drop Height

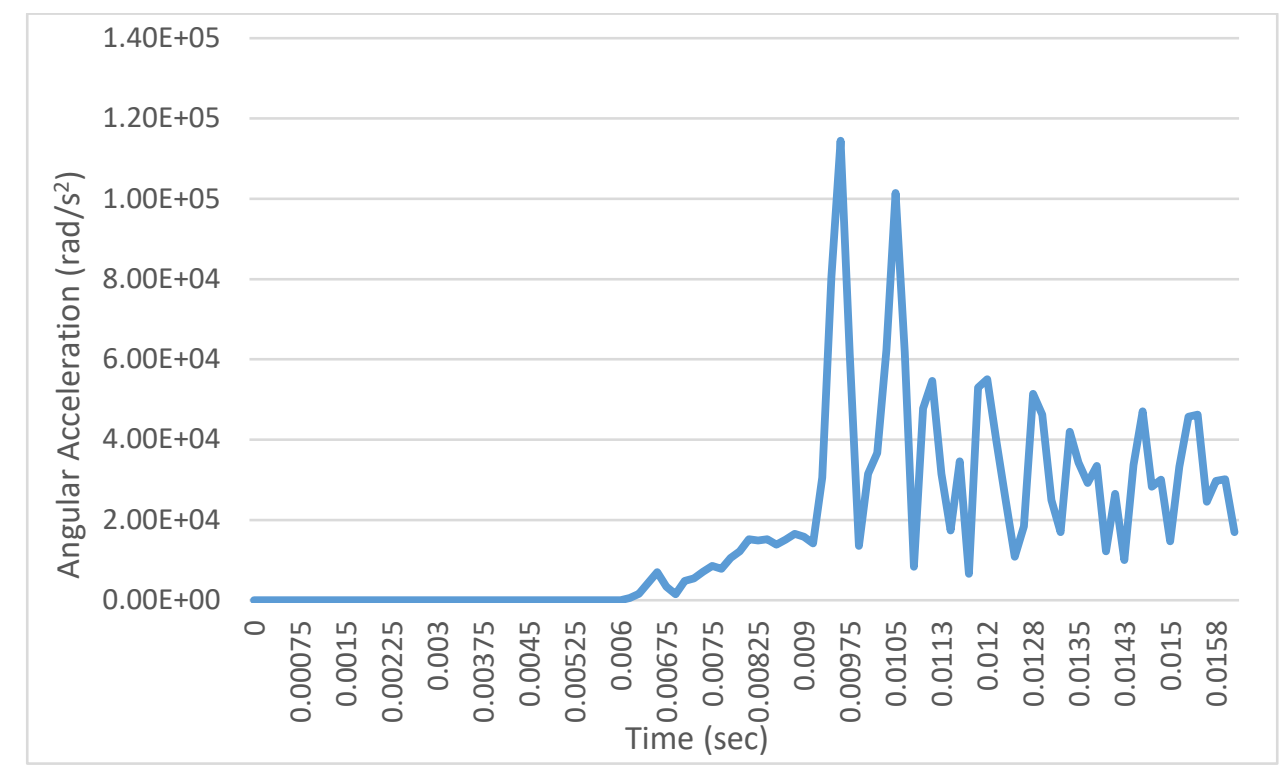

Figure B.6. Angular Acceleration time history of NOCSAE Headform for 4ft. Drop Height 


\section{B.4. Frontal I mpact - 5ft. Drop Height:}

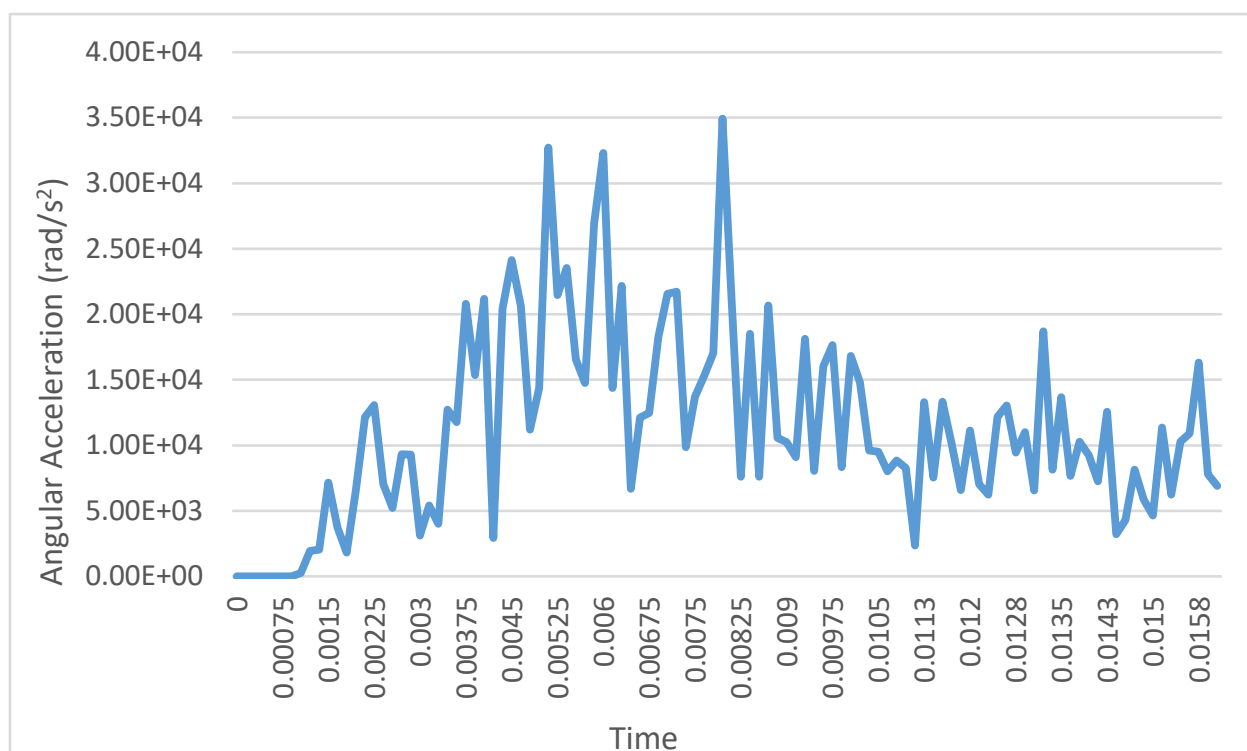

Figure B.7. Angular Acceleration time history of Human Head model for 5ft. Drop Height

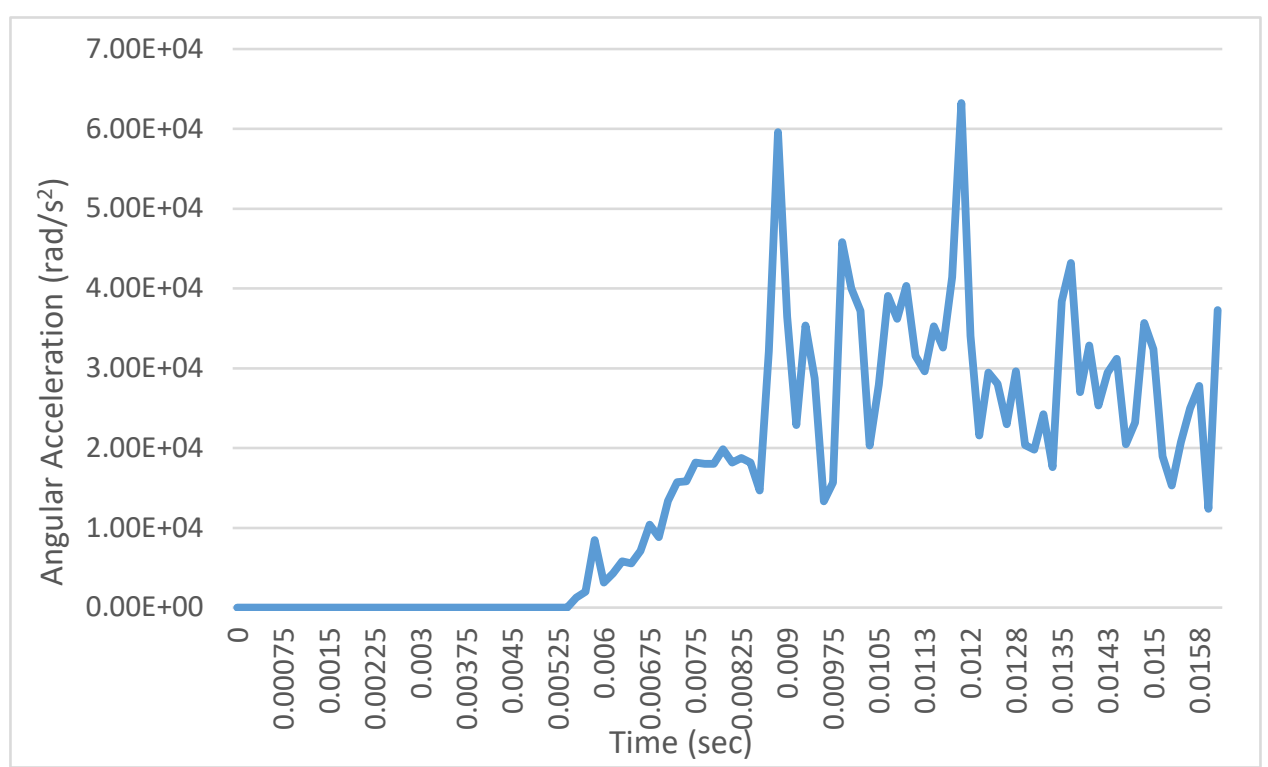

Figure B.8. Angular Acceleration time history of NOCSAE Headform for 5ft. Drop Height 


\section{B.5. Lateral I mpact- 2ft. Drop Height:}

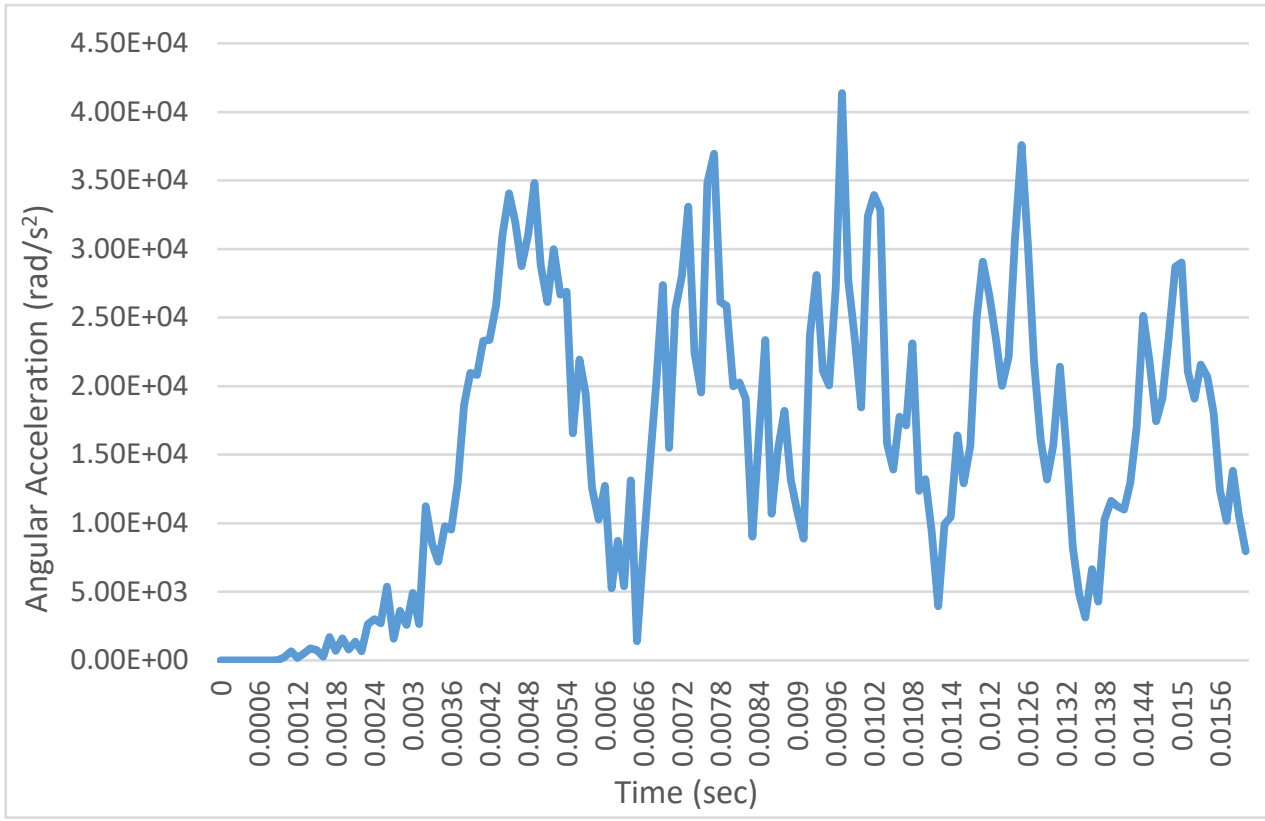

Figure B.9. Angular Acceleration time history of Human Head model for 2ft. Drop Height

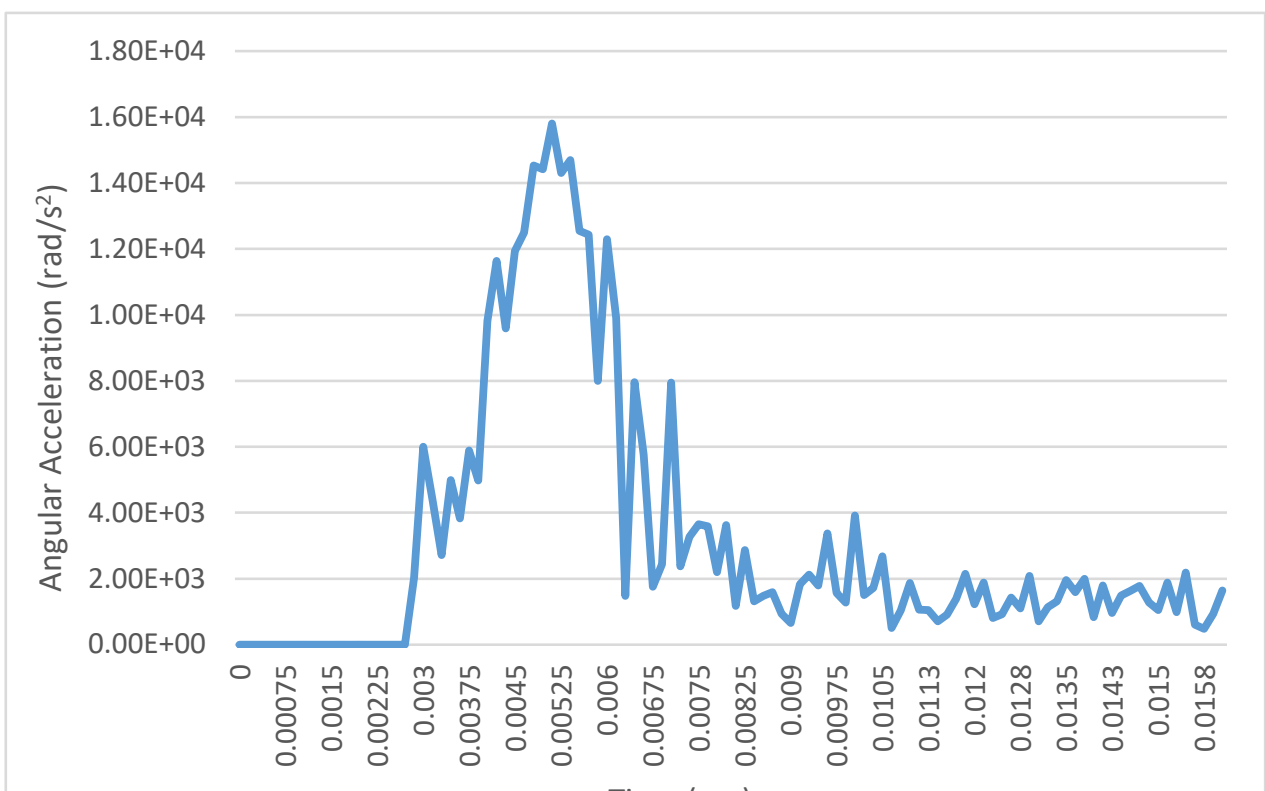

Time (sec)

Figure B.10. Angular Acceleration time history of NOCSAE Headform for 2ft. Drop Height 


\section{B.6. Lateral I mpact- 3ft. Drop Height:}

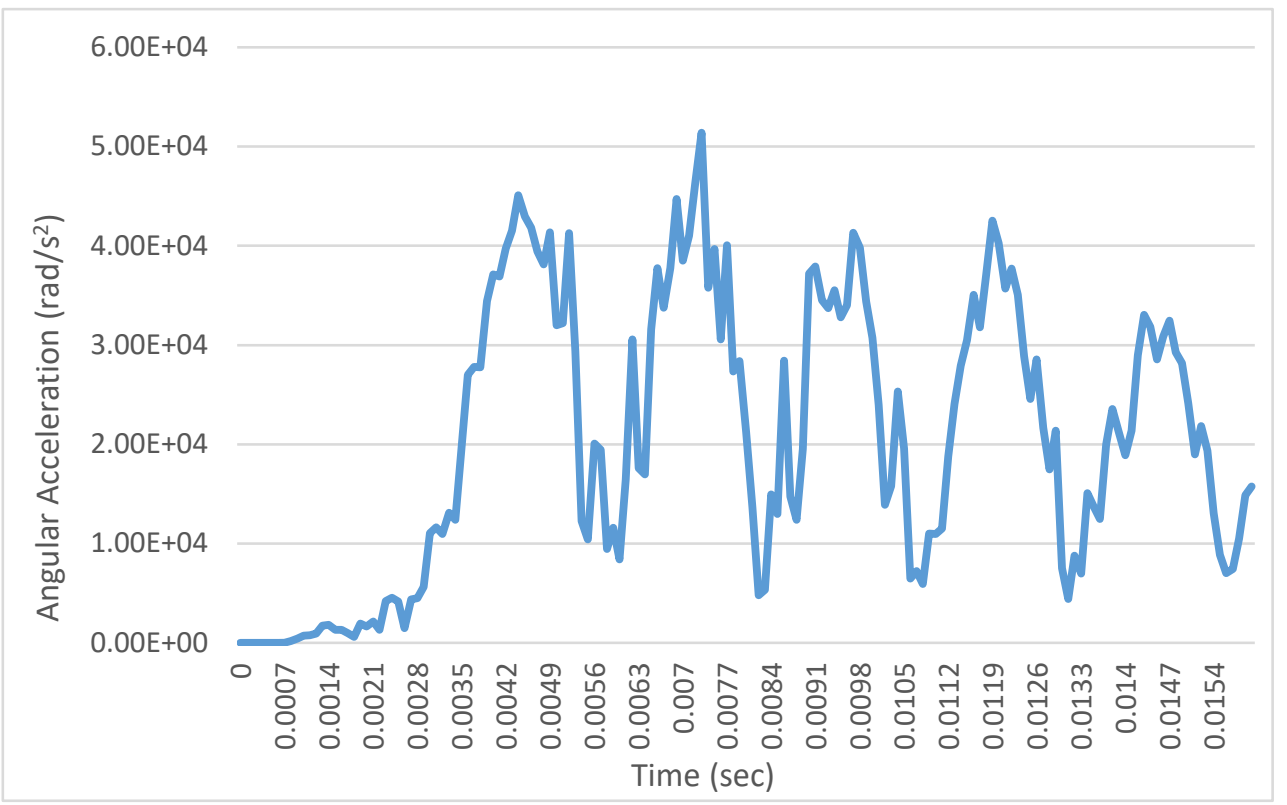

Figure B.11. Angular Acceleration time history of Human Head model for 3ft. Drop Height

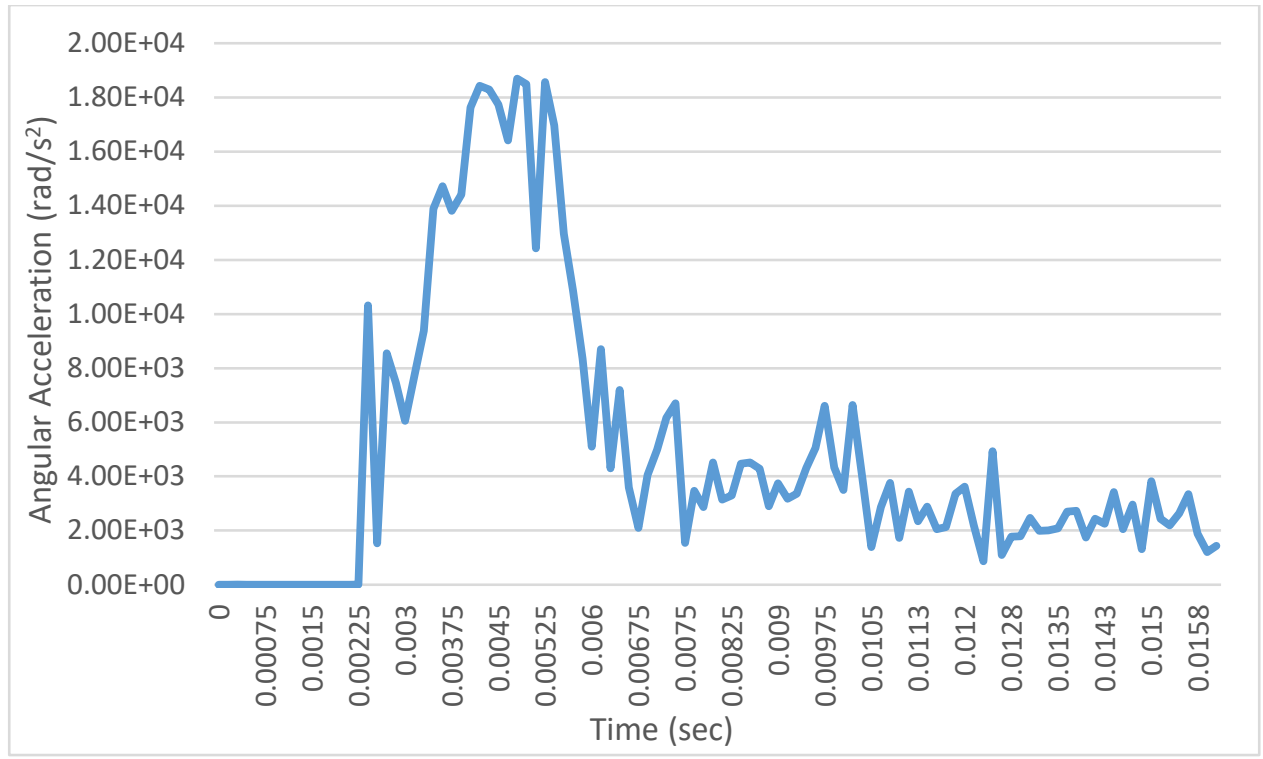

Figure B.12. Angular Acceleration time history of NOCSAE Headform for 3ft. Drop Height 


\section{B.7. Lateral I mpact- 4ft. Drop Height:}

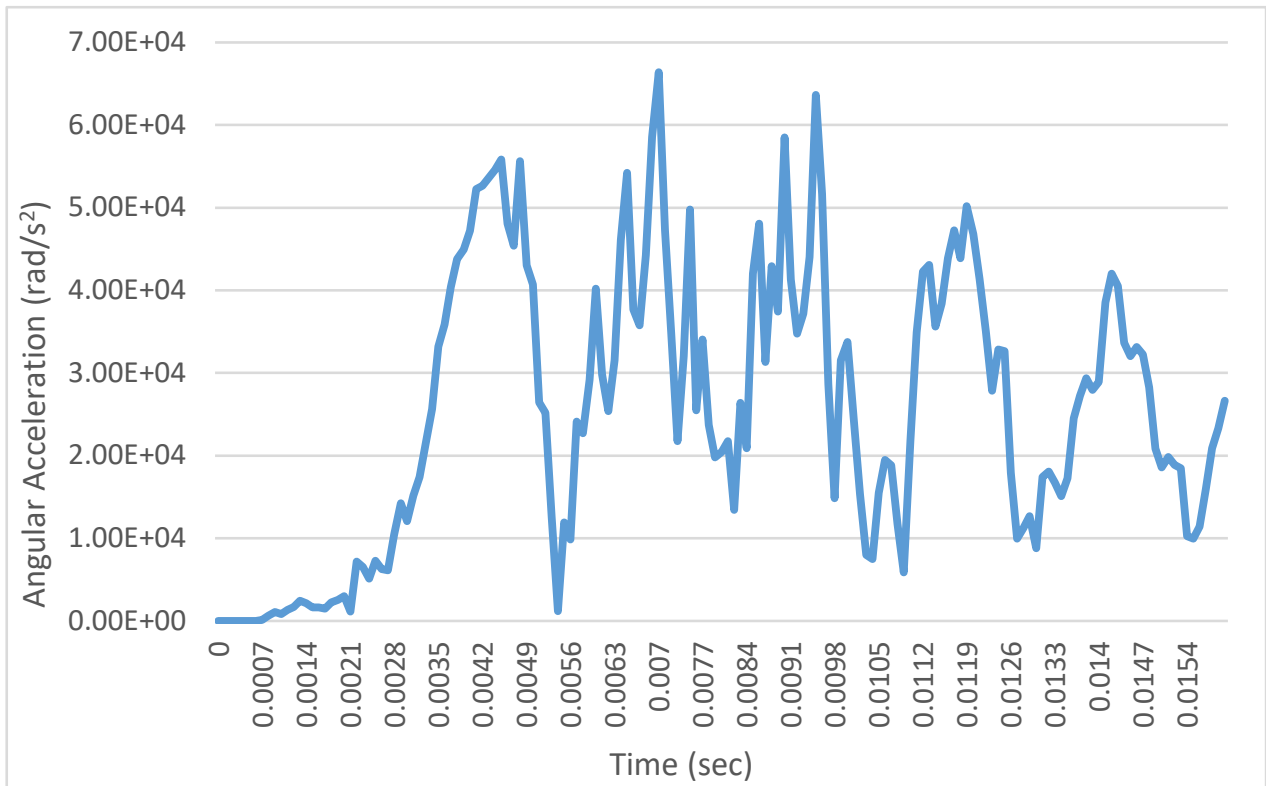

Figure B.13. Angular Acceleration time history of Human Head model for $\mathbf{4 f t}$. Drop Height

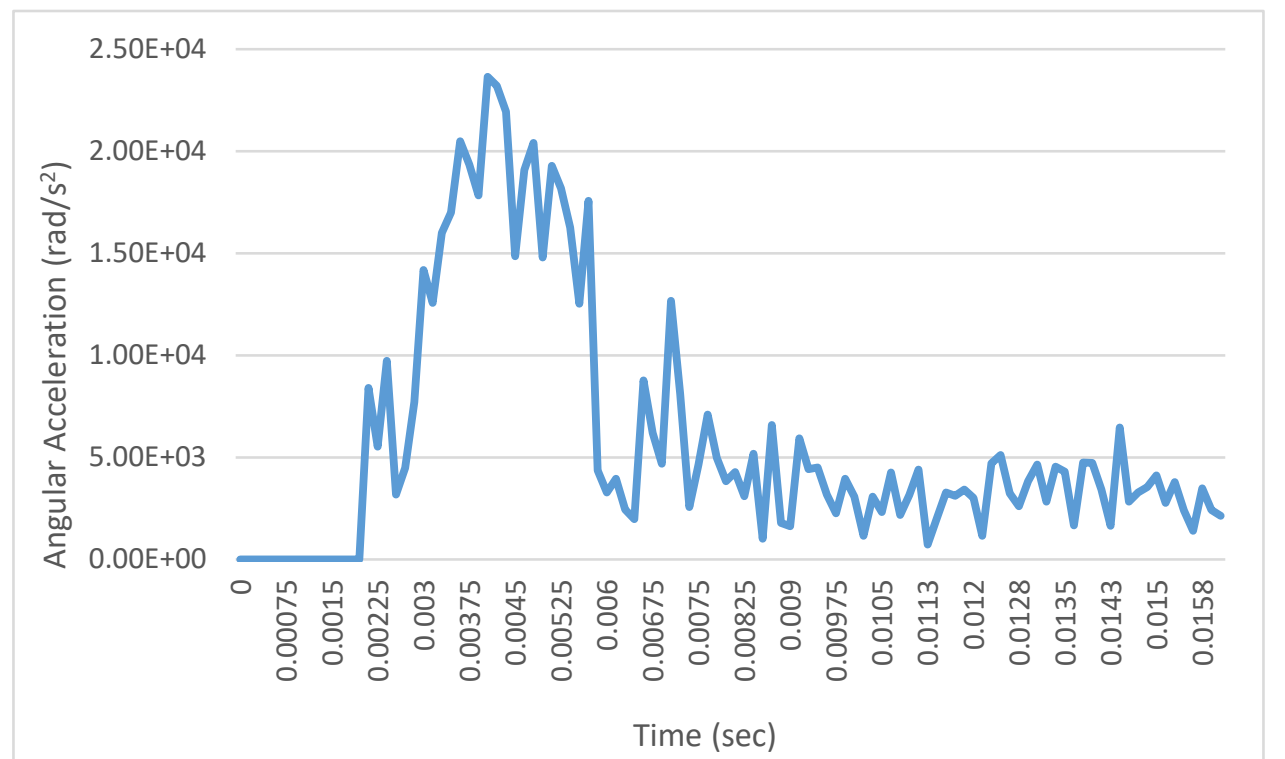

Figure B.14. Angular Acceleration time history of NOCSAE Headform for 4ft. Drop Height 


\section{B.8. Lateral I mpact- 5ft. Drop Height:}

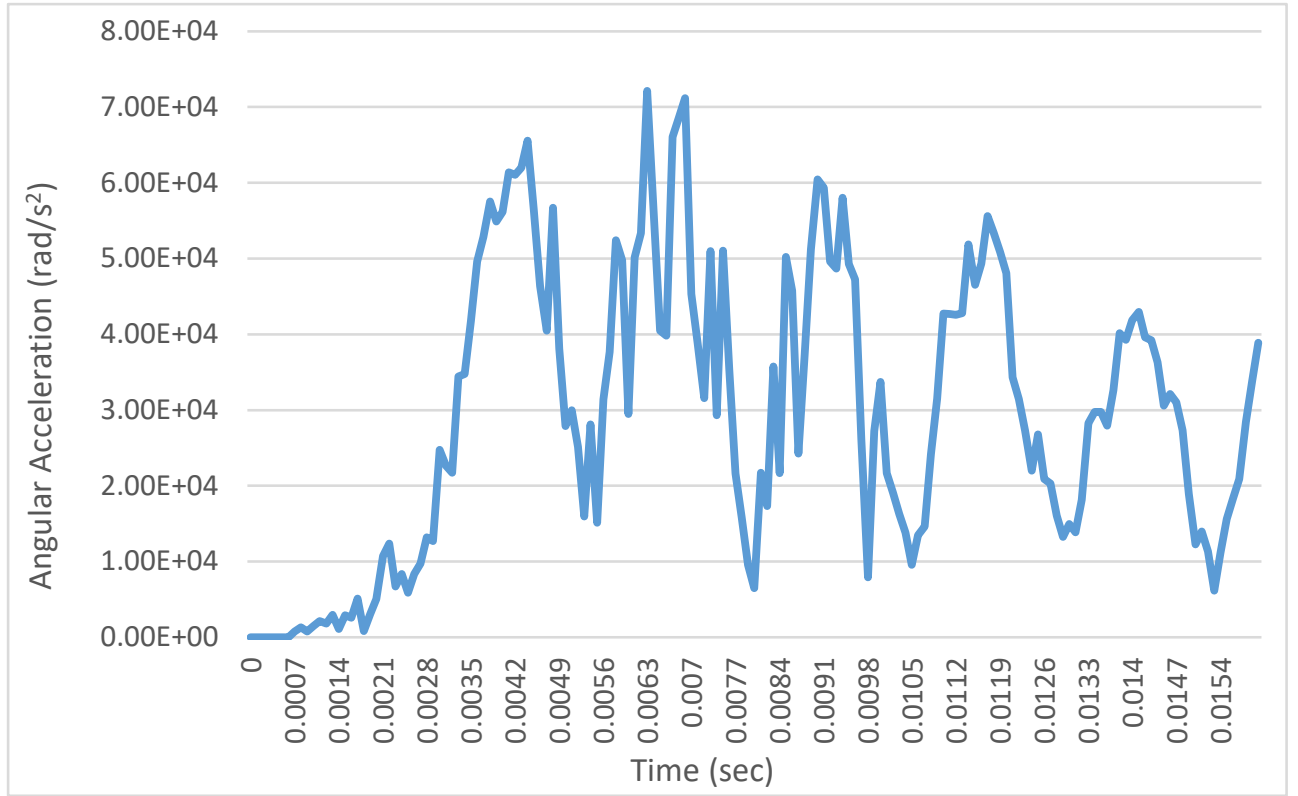

Figure B.15. Angular Acceleration time history of Human Head model for $5 \mathrm{ft}$. Drop Height

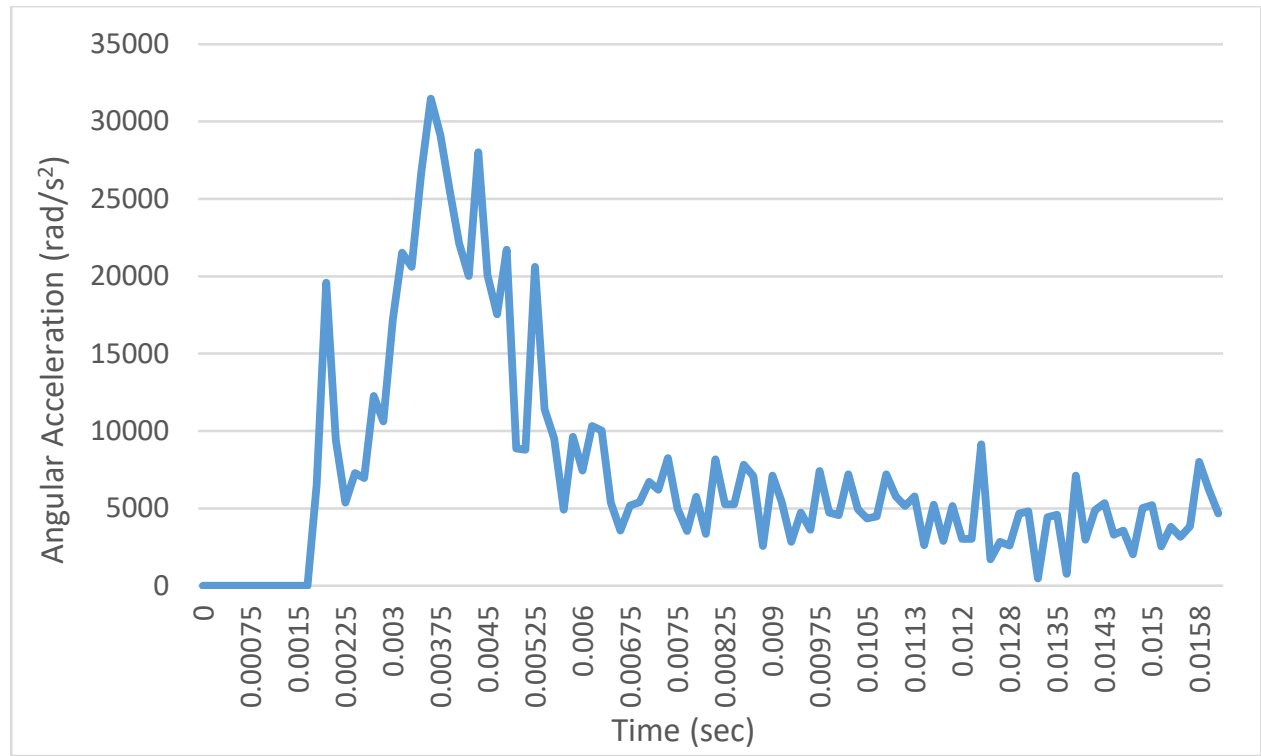

Figure B.16. Angular Acceleration time history of NOCSAE Headform for 5ft. Drop Height 


\section{B.9. Posterior I mpact- 2ft. Drop Height:}

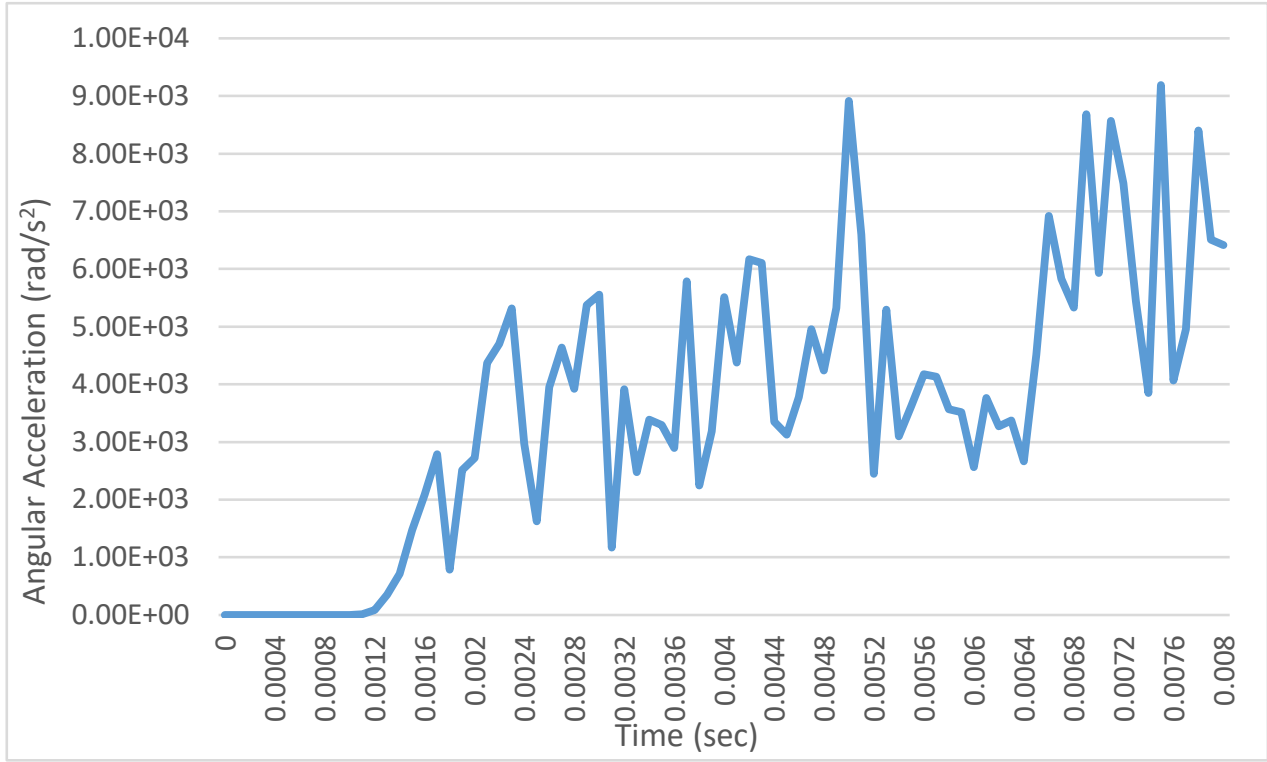

Figure B.17. Angular Acceleration time history of Human Head model for $2 \mathrm{ft}$. Drop Height

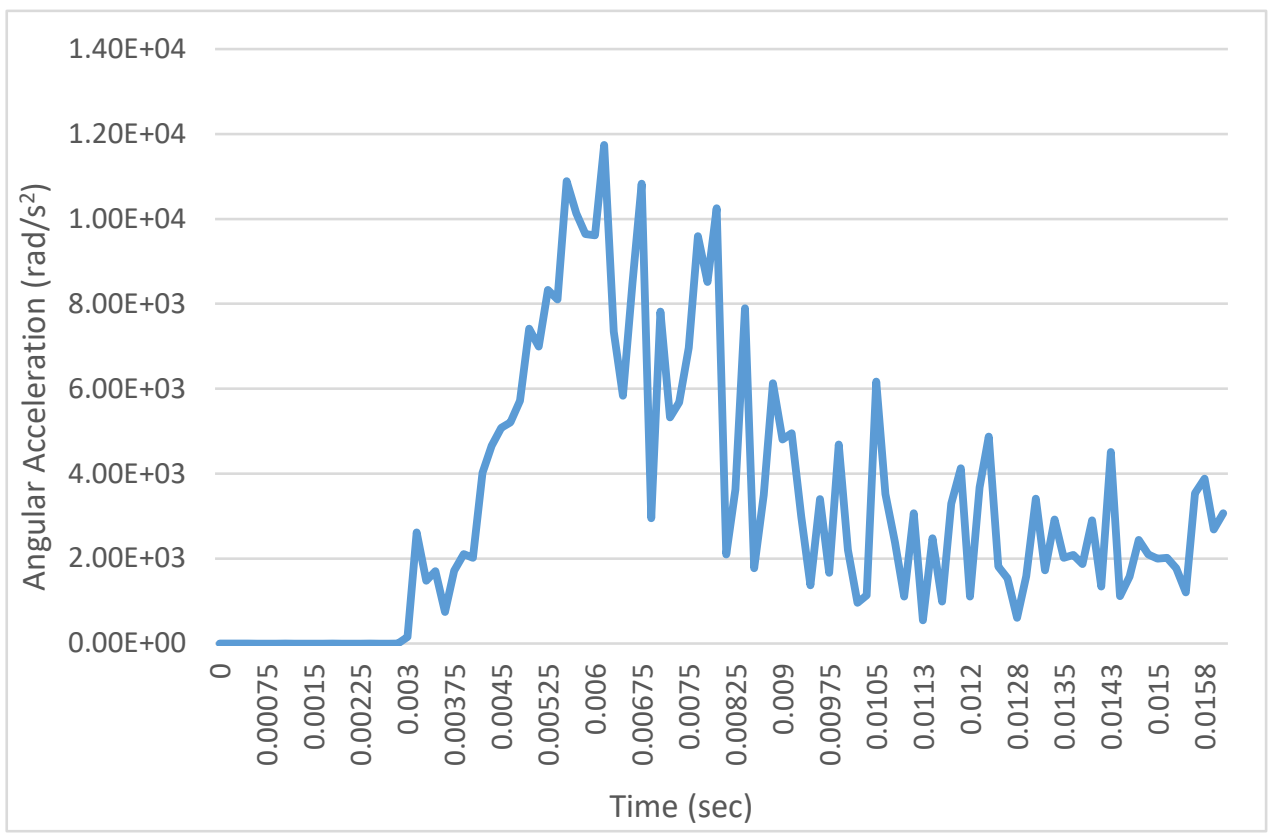

Figure B.18. Angular Acceleration time history of NOCSAE Headform for 2ft. Drop Height 


\section{B.10. Posterior I mpact- 3ft. Drop Height:}

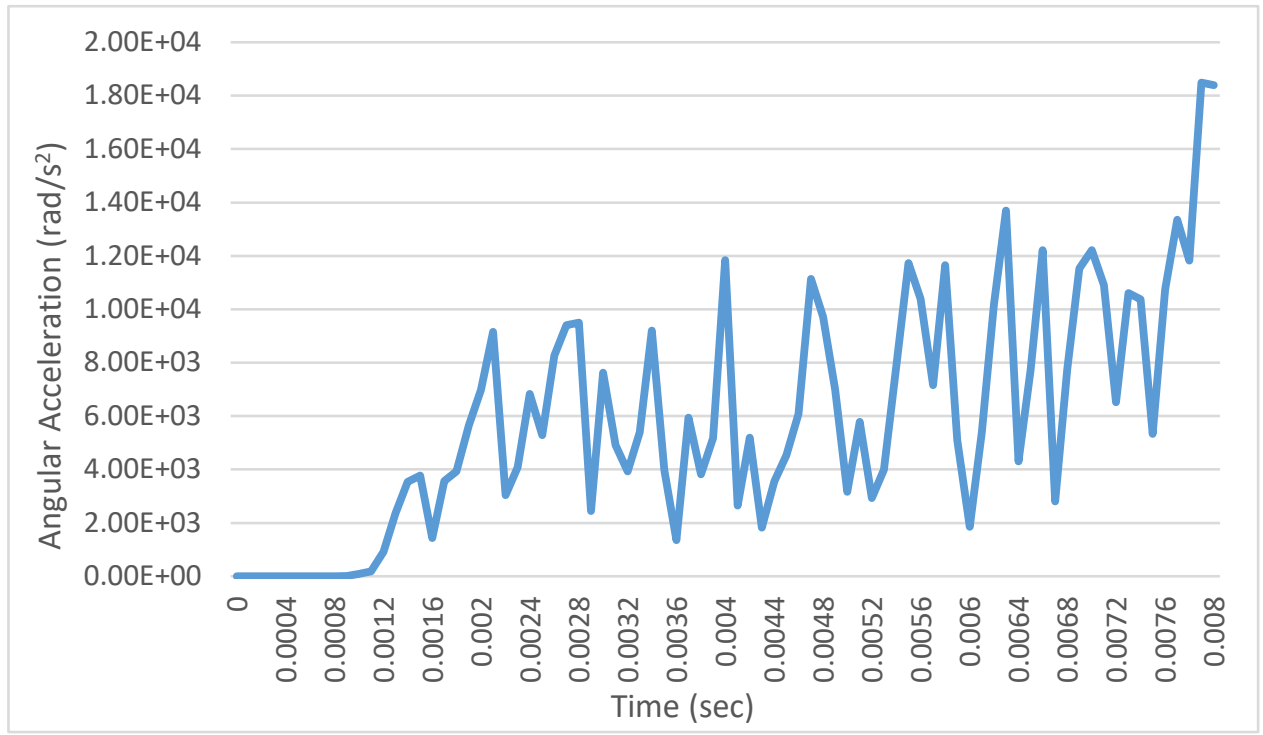

Figure B.19. Angular Acceleration time history of Human Head model for $3 \mathrm{ft}$. Drop Height

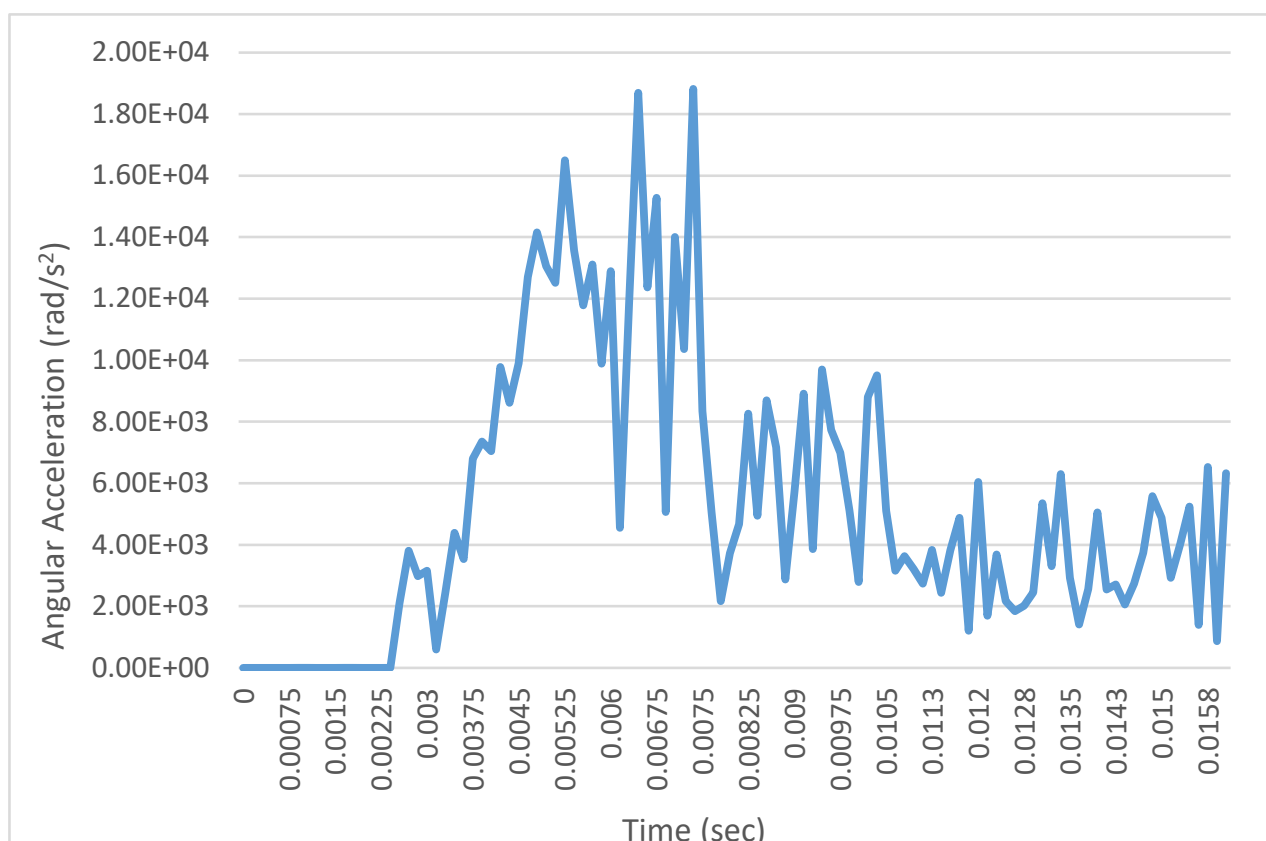

Figure B.20. Angular Acceleration time history of NOCSAE Headform for 3ft. Drop Height 


\section{B.11. Posterior I mpact- 4ft. Drop Height:}

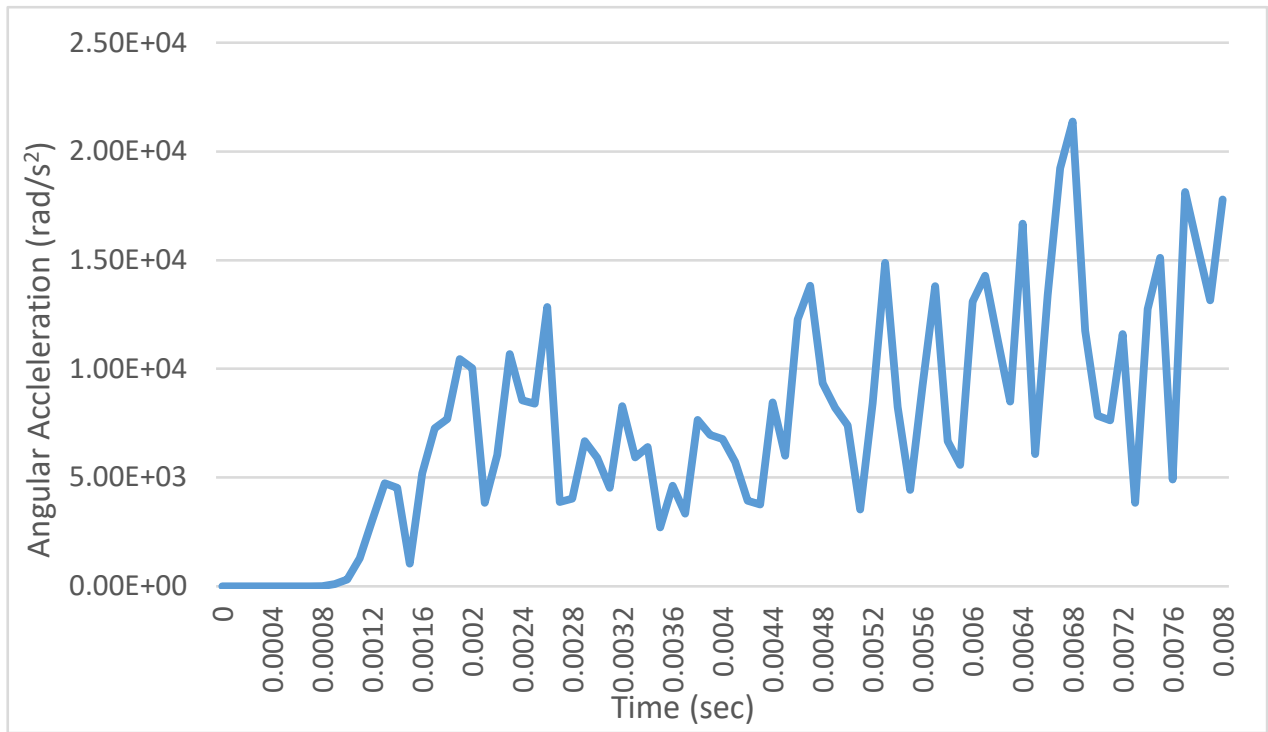

Figure B.21. Angular Acceleration time history of Human Head model for $4 \mathrm{ft}$. Drop Height

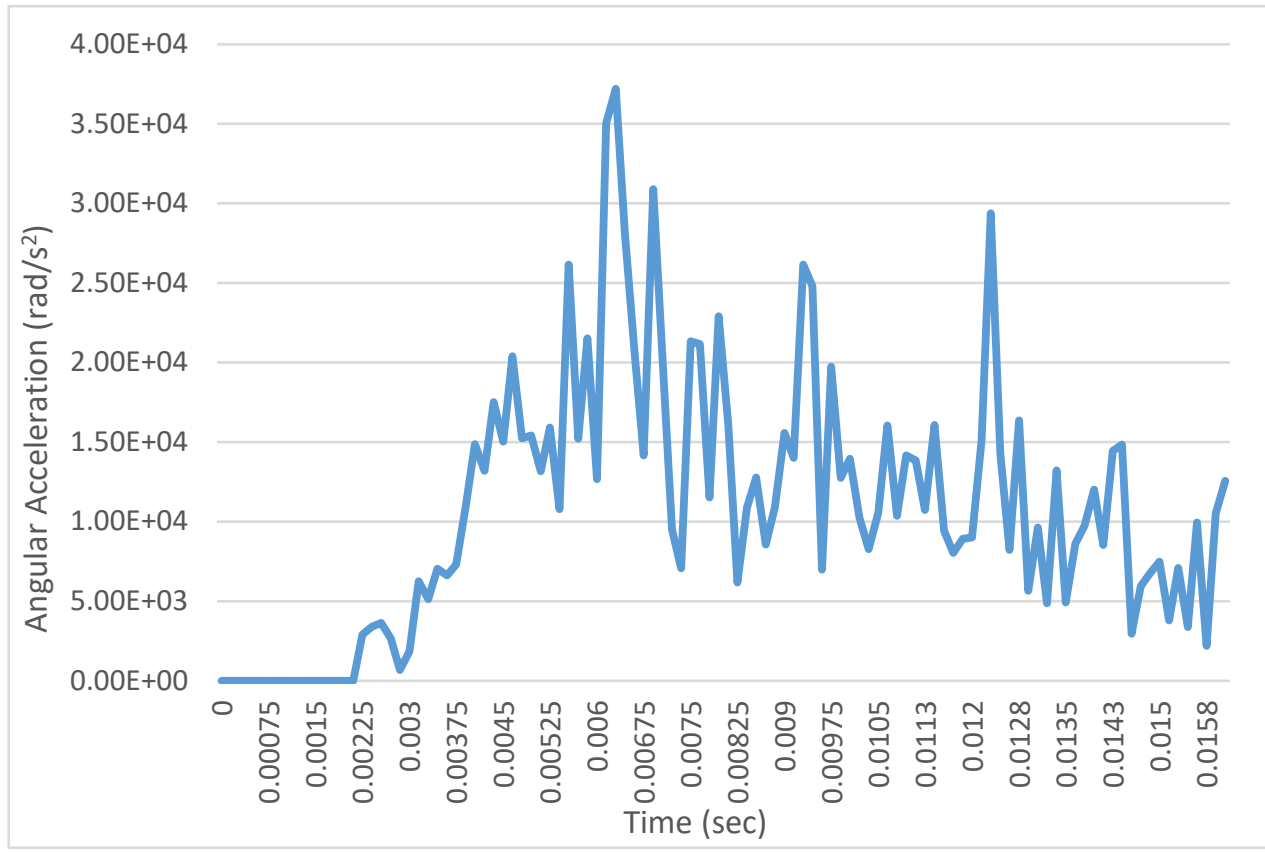

Figure B.22. Angular Acceleration time history of NOCSAE Headform for 4ft. Drop Height 


\section{B.12. Posterior I mpact- 5ft. Drop Height:}

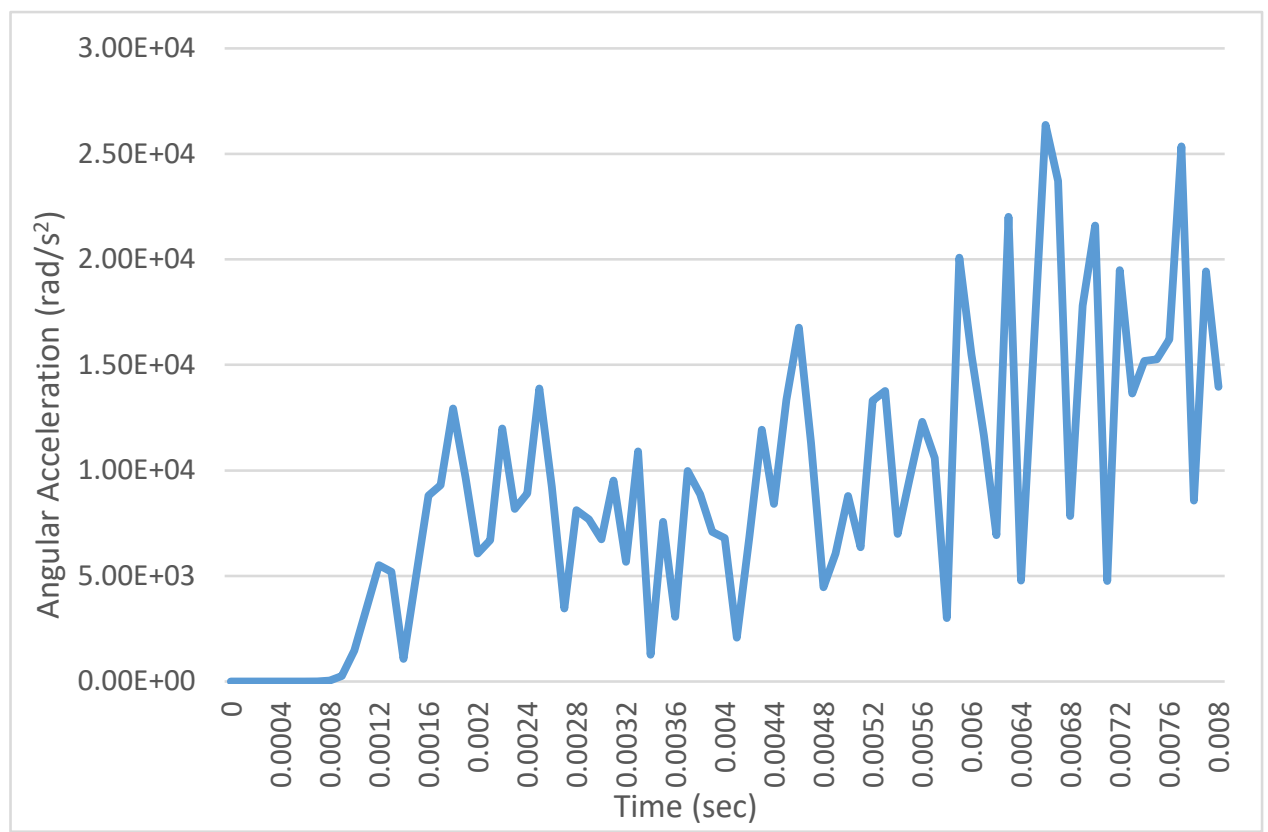

Figure B.23. Angular Acceleration time history of Human Head model for $5 \mathrm{ft}$. Drop Height

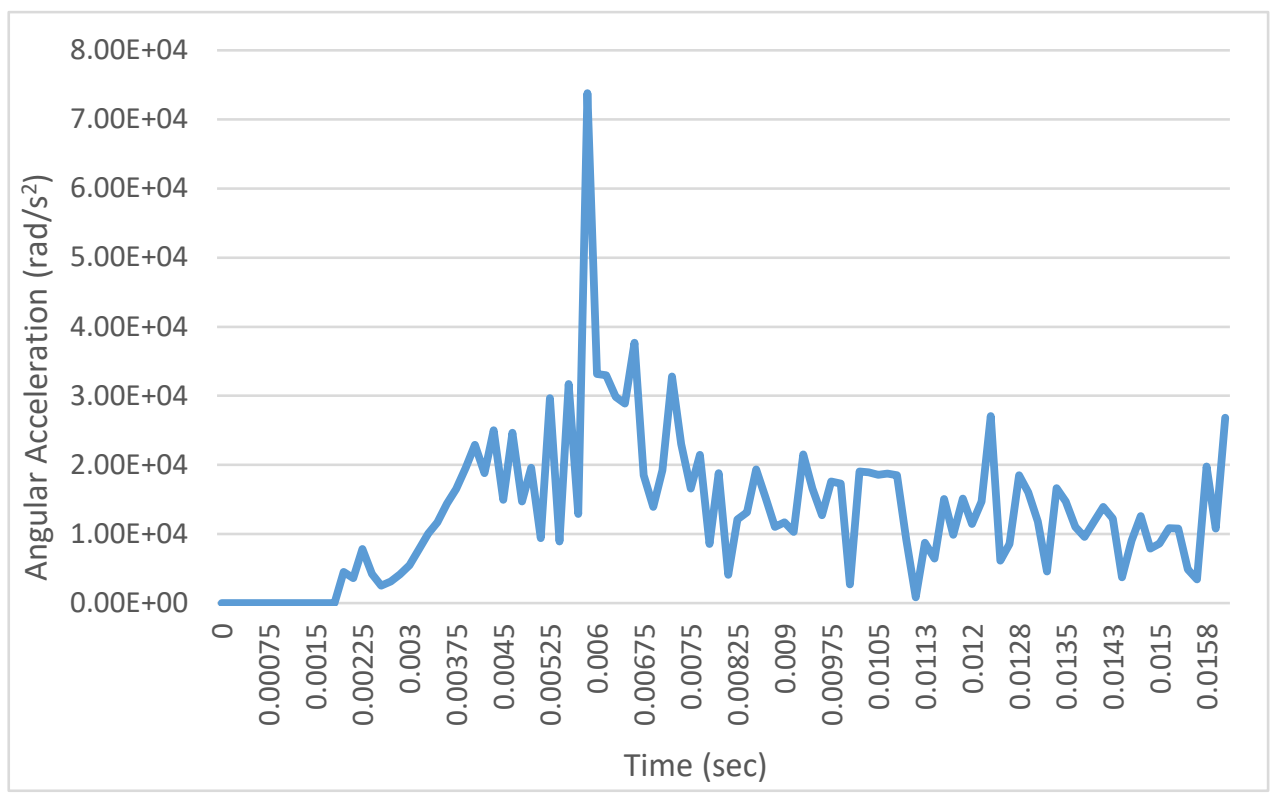

Figure B.24. Angular Acceleration time history of NOCSAE Headform for 5ft. Drop Height 


\section{B.13. Superior I mpact- 2ft. Drop Height:}

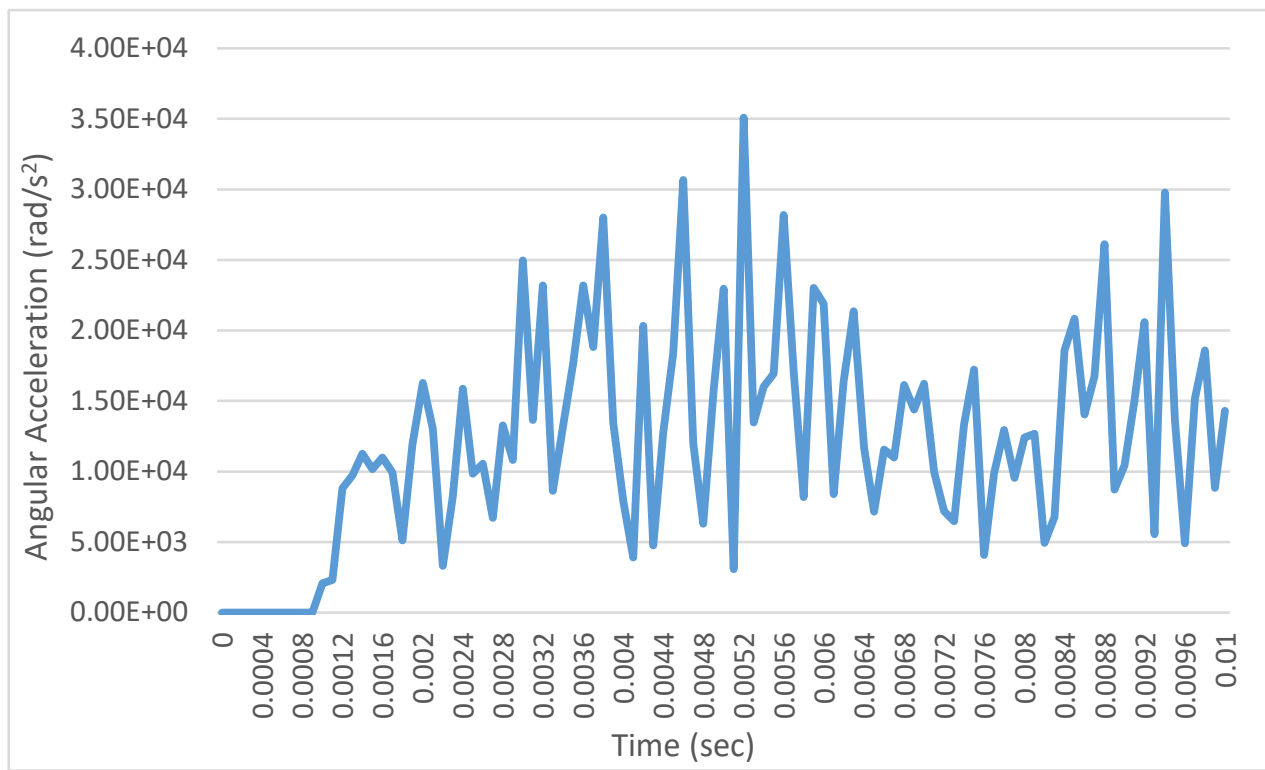

Figure B.25. Angular Acceleration time history of Human Head model for $2 \mathrm{ft}$. Drop Height

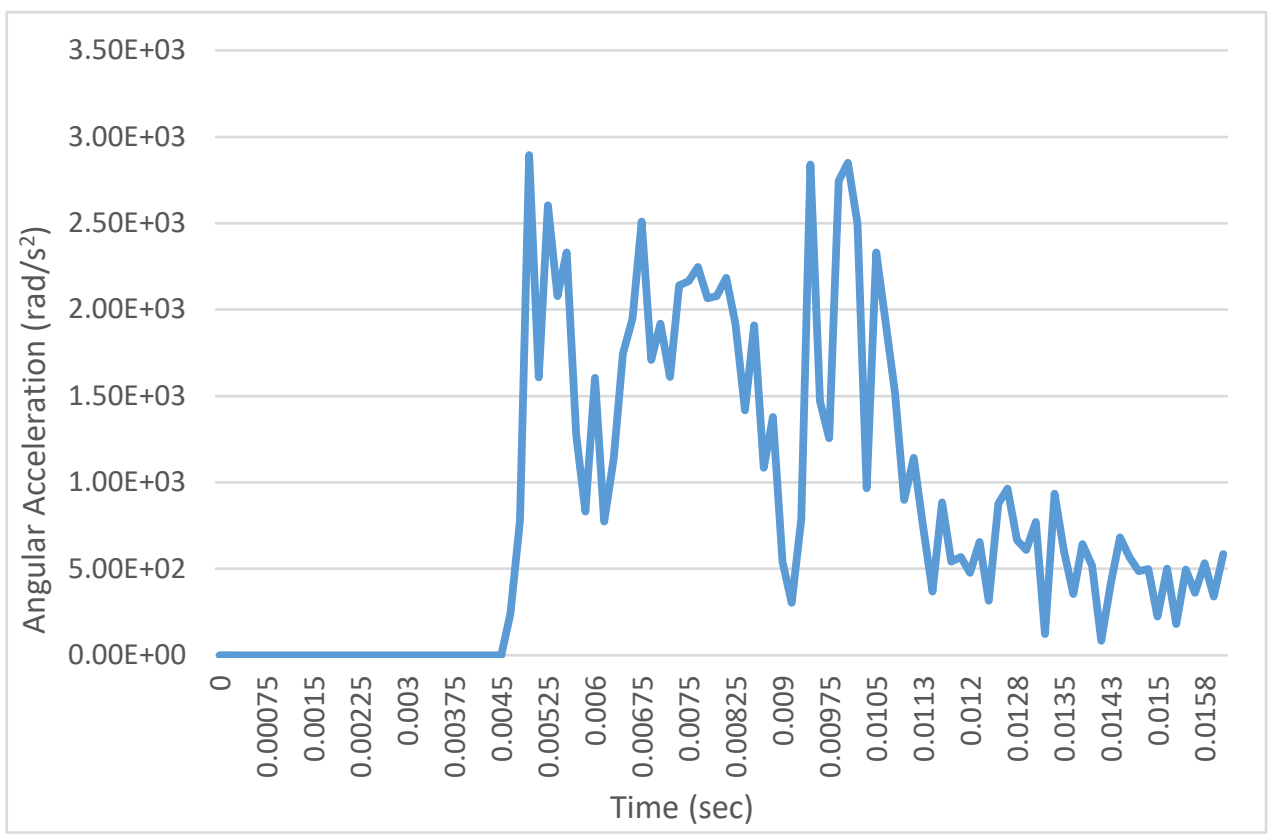

Figure B.26. Angular Acceleration time history of NOCSAE Headform for $2 \mathrm{ft}$. Drop Height 


\section{B.14. Superior I mpact- 3ft. Drop Height:}

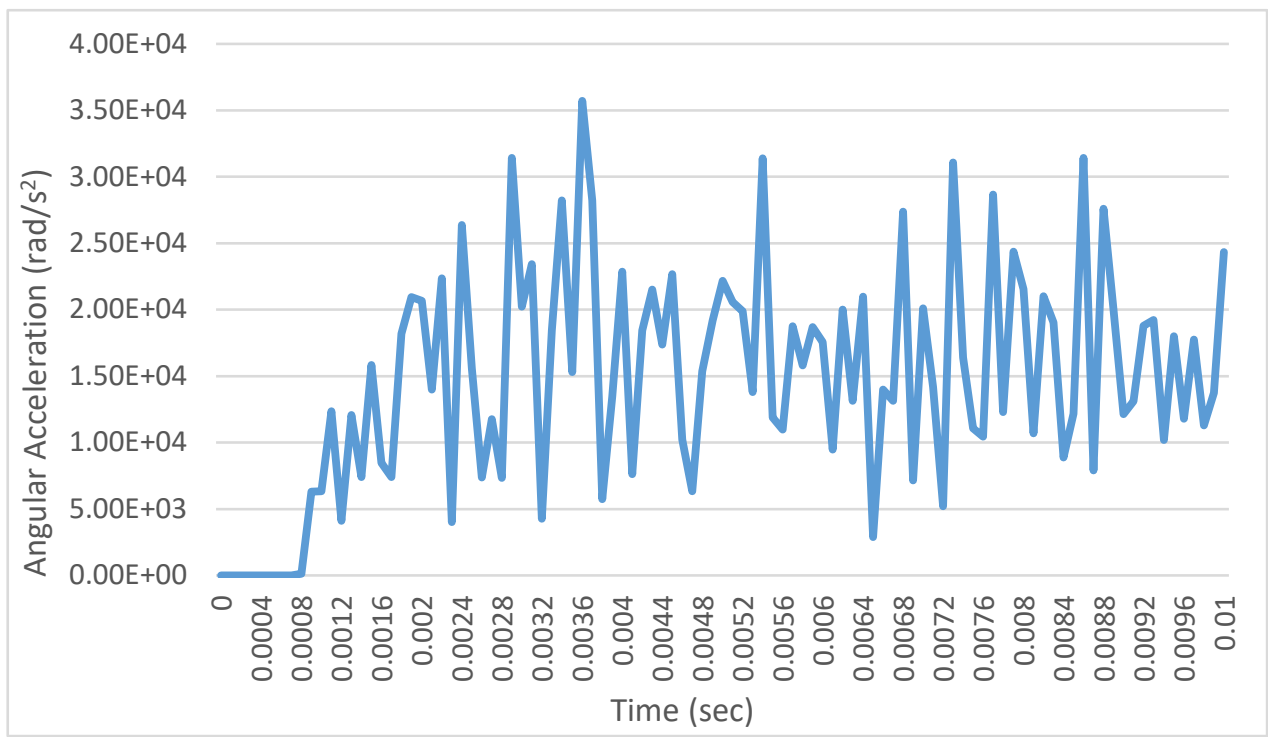

Figure B.27. Angular Acceleration time history of Human Head model for $3 \mathrm{ft}$. Drop Height

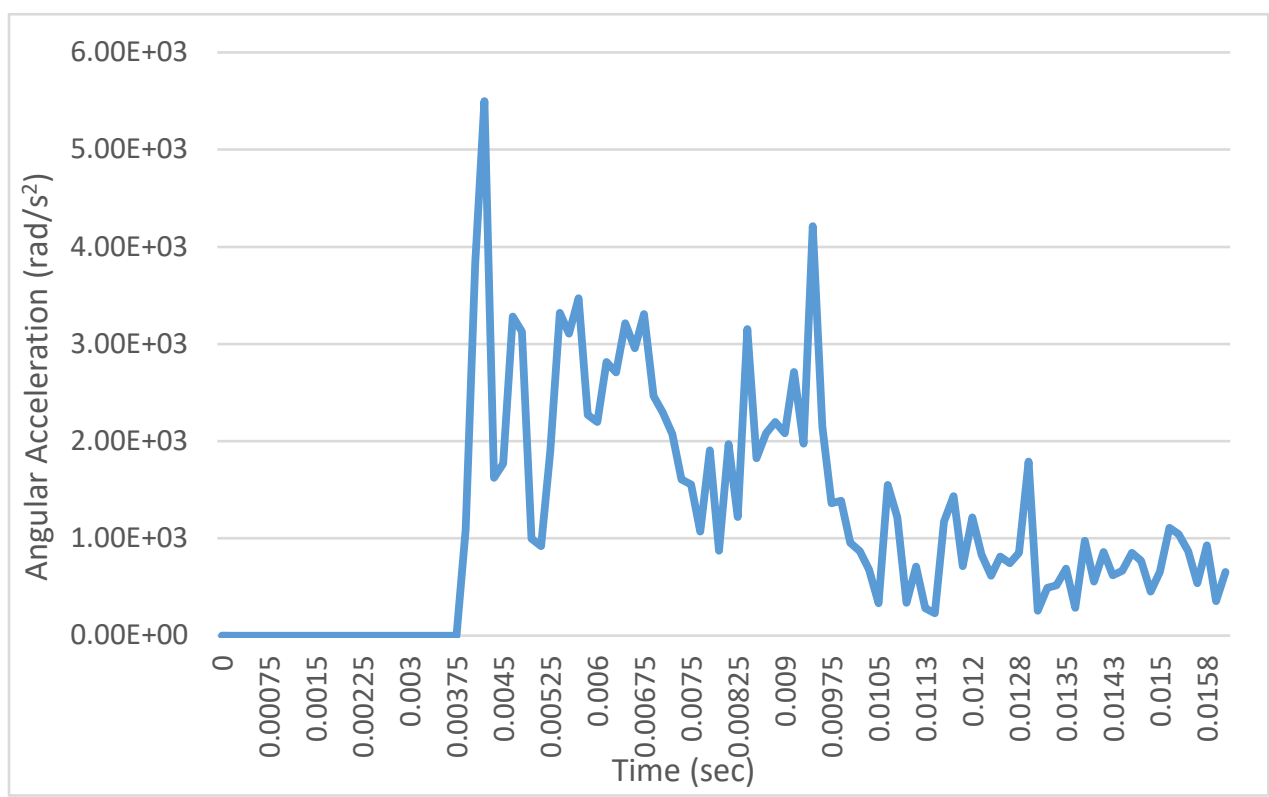

Figure B.28. Angular Acceleration time history of NOCSAE Headform for 3ft. Drop Height 


\section{B.15. Superior I mpact- 4ft. Drop Height:}

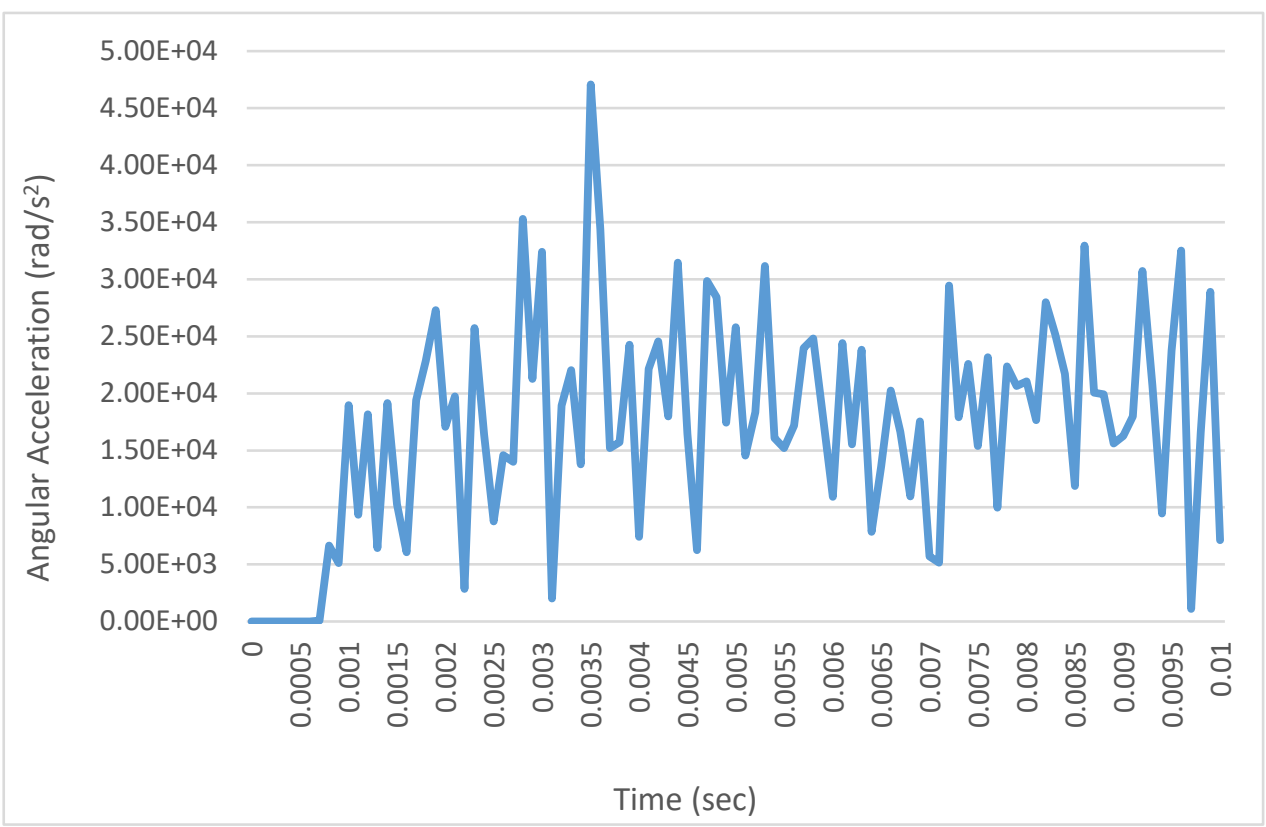

Figure B.29. Angular Acceleration time history of Human Head model for $\mathbf{4 f t}$. Drop Height

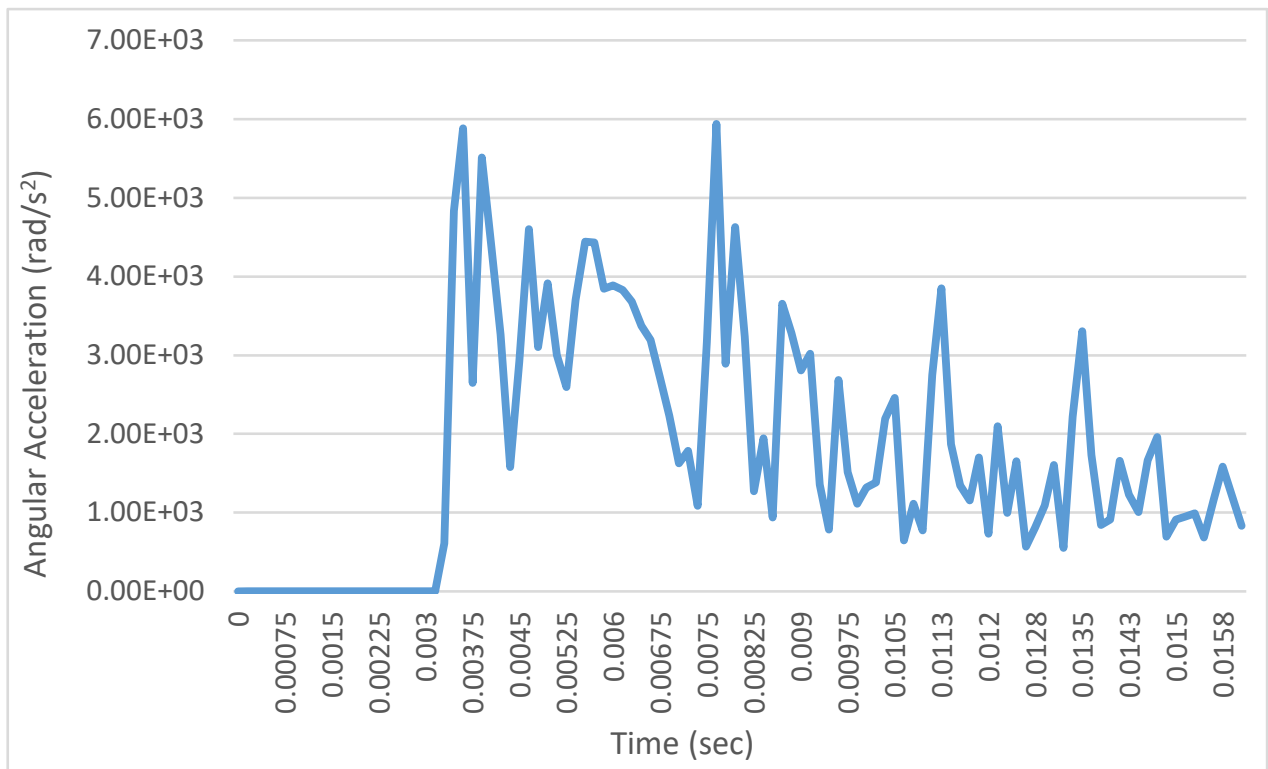

Figure B.30. Angular Acceleration time history of NOCSAE Headform for 4ft. Drop Height 


\section{B.16. Superior I mpact- 5ft. Drop Height:}

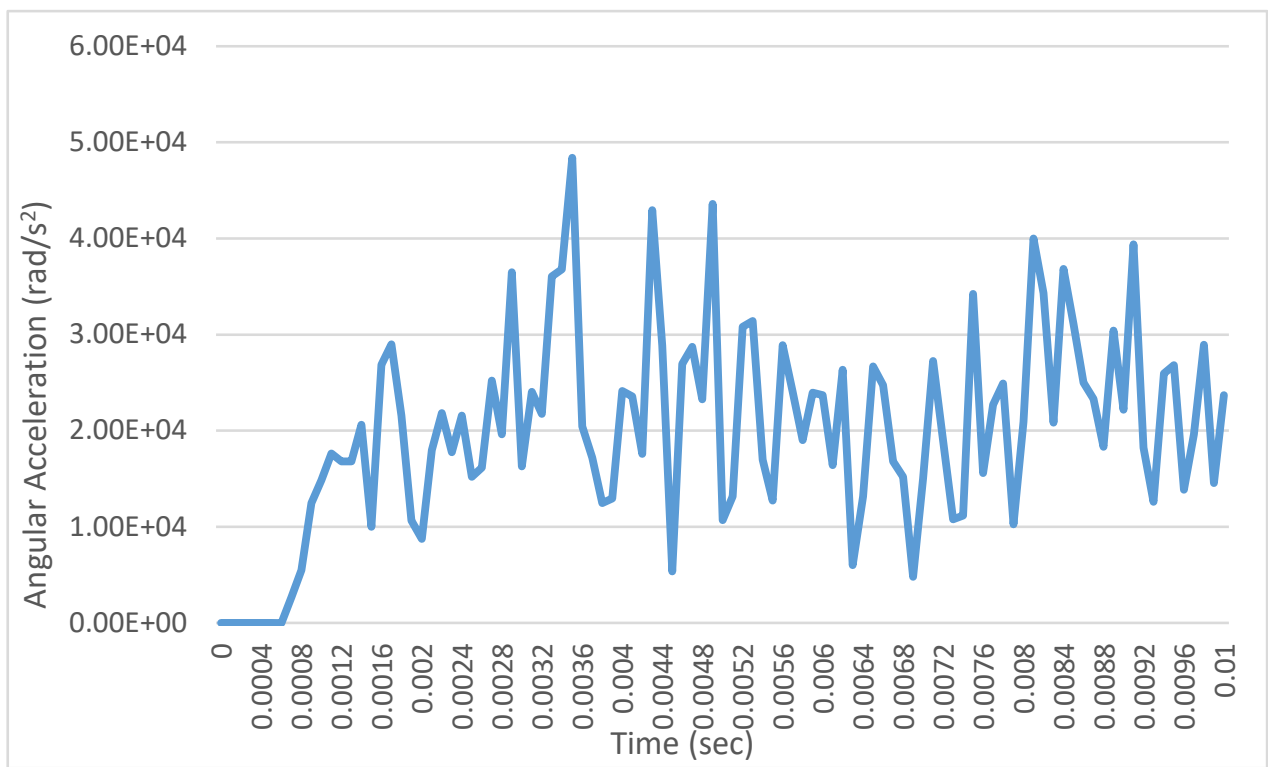

Figure B.31. Angular Acceleration time history of Human Head model for $5 \mathrm{ft}$. Drop Height

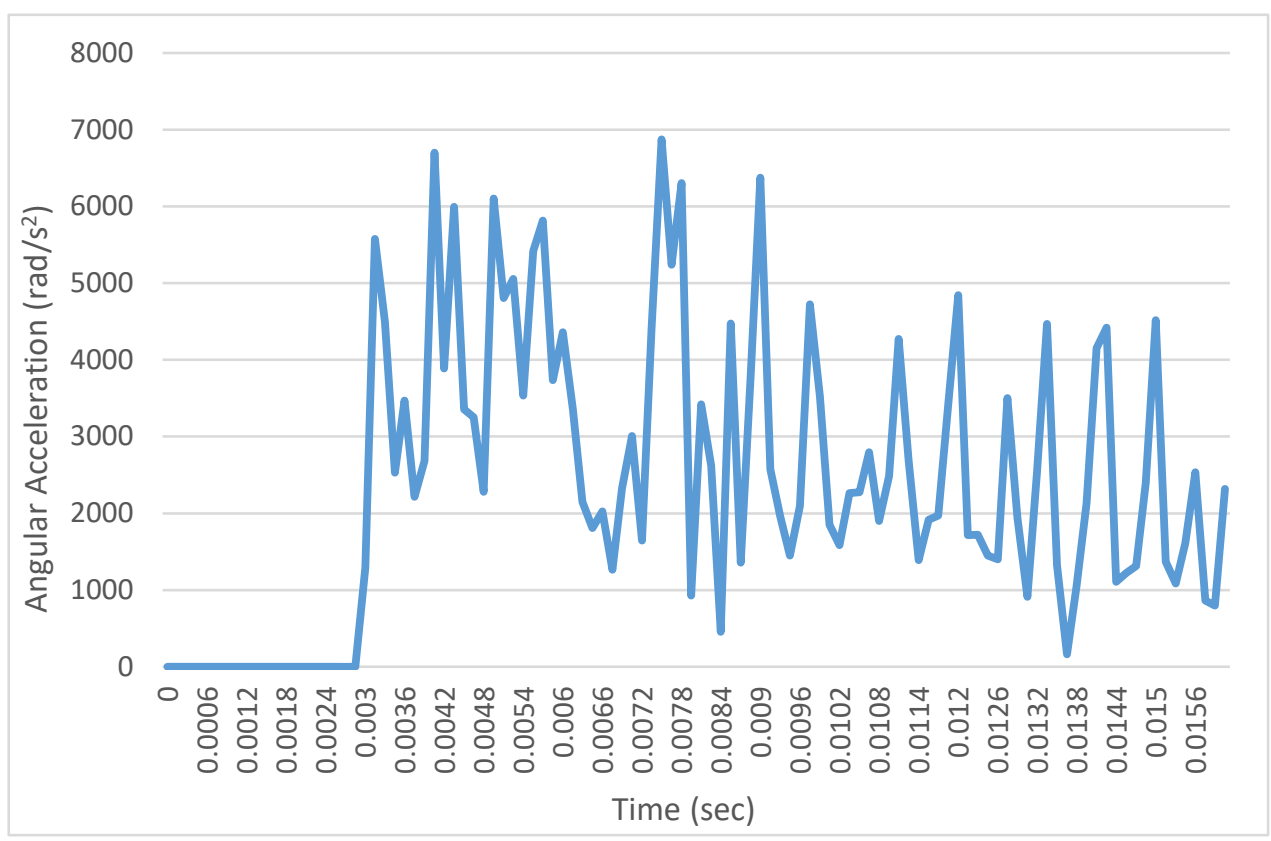

Figure B.32. Angular Acceleration time history of NOCSAE Headform for 5ft. Drop Height 


\section{REFERENCES}

1. American Academy of Orthopaedic Surgeons, "A silent epidemic: Minor traumatic brain injury."

2. Radiological Society of North America, "Single concussion may cause lasting brain damage."

3. F. W. R. S, "Internal Head Injury Assessment," in 15th Stapp Car Crash Conference, The Society of Automotive Engineers, 1971.

4. O. Anna, K. Clara, P. Andrew, R. Philippe, H. Blaine, M. Shawn, B. Susan, S. Aynsley and C. Michael, "An Examination of Headform Dynamic Response for Concussive and Traumatic Brain Injury, " in 1st International Conference on Helmet Performance and Design, London, UK, 2013.

5. D. M. Labyak, "Interpretation of Head Injuries Due to Oblique Impact by Finite Element Modeling," Michigan Technological University, Houghton, 2003.

6. T. Darling, "Finite Element Modelling of Human Brain Response to Football Helmet Impacts", Arizona State University, 2014.

7. http://www. humaneticsatd.com/crash-test-dummies/frontalimpact/hybrid-iii-50m

8. Hyperworks 13.0, Altair Inc.

9. C. S. Abhang, "Measuring Head Impact Contact Pressure in Collegiate Football Games to correlate Head Kinematics to Brain Kinetics elucidating Brain Injury Dynamics.", Michigan Technological University, Houghton, 2010

10.M. Kendall, E. S. Walsh and T. B. Hoshizaki, " Comparison between Hybrid III and Hodgson-WSU headforms by linear and angular dynamic impact response" Proceedings of the Institution of Mechanical Engineers, Part P: J ournal of Sports Engineering and Technology, 2012 